1989

\title{
Task-Oriented Display Design: Concept and Example
}

Terence S. Abbott

College of William \& Mary - Arts \& Sciences

Follow this and additional works at: https://scholarworks.wm.edu/etd

Part of the Computer Sciences Commons

\section{Recommended Citation}

Abbott, Terence S., "Task-Oriented Display Design: Concept and Example" (1989). Dissertations, Theses, and Masters Projects. Paper 1539626821.

https://dx.doi.org/doi:10.21220/s2-nf3y-f315

This Thesis is brought to you for free and open access by the Theses, Dissertations, \& Master Projects at W\&M ScholarWorks. It has been accepted for inclusion in Dissertations, Theses, and Masters Projects by an authorized administrator of W\&M ScholarWorks. For more information, please contact scholarworks@wm.edu. 


\title{
TASK-ORIENTED DISPLAY DESIGN \\ Concept and Example
}

\author{
A Thesis \\ Presented To \\ The Faculty of the Department of Computer Science \\ The College of William and Mary
}

\author{
In Partial Fulfillment \\ of the Requirements for the Degree of \\ Master of Science
}

by

Terence s. Abbott

1989 


\section{APPROVAL SHEET}

This thesis is submitted in partial fulfillment of the requirements for the degree of

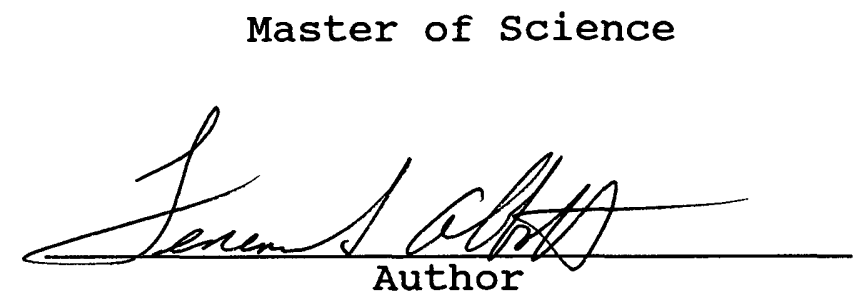

Approved, March 1989
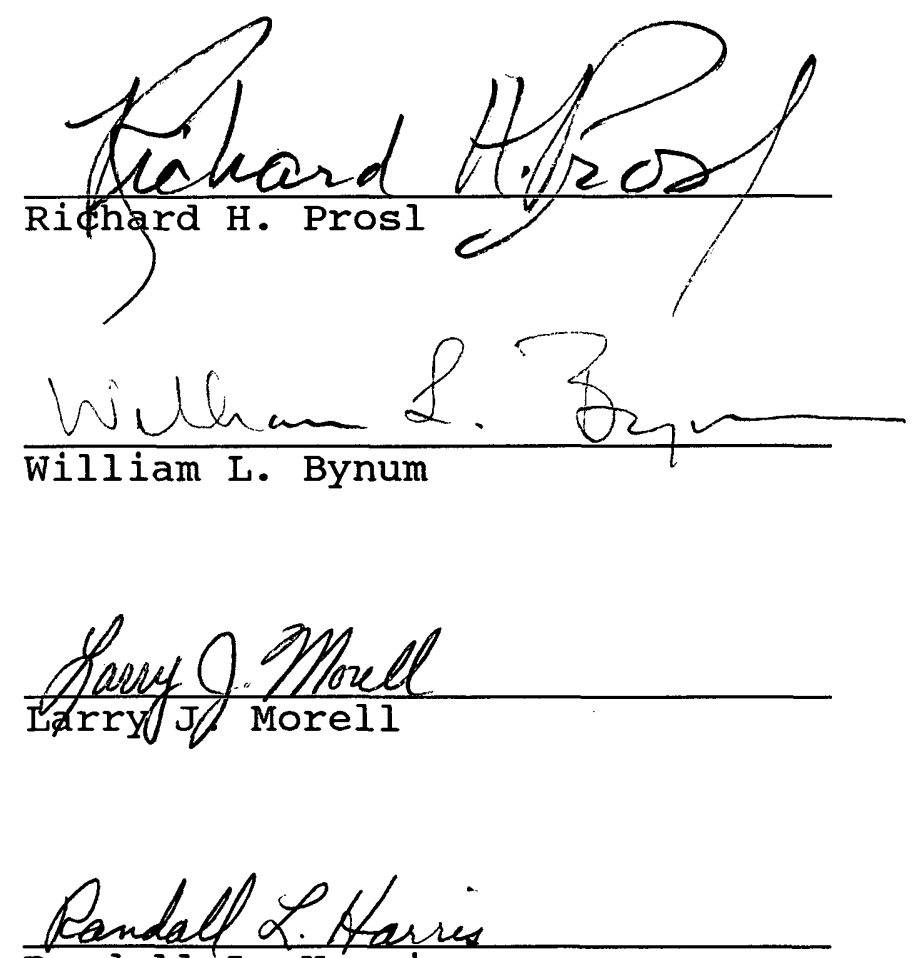
Randall L. Harris

National Aeronautics and Space Administration Langley Research Center 
TABLE OF CONTENTS

Page

LIST OF TABLES • • • • • • • • • • • • • • • • . iv

LIST OF FIGURES • • • • • • • • • • • • • • • • • . V v

ABSTRACT . . . . . . . . . . . . . . . . . . vii

INTRODUCTION • • • • • • • • • • • • • • . . . 2

CHAPTER I. THE DESIGN PROCESS. . • . • . . . . . . 7

CHAPTER II. TRADITIONAL DESIGN ANALYSIS . . . . . 13

CHAPTER III. TRADITIONAL DISPLAY DEFINITION • • • • 45

CHAPTER IV. ALTERNATIVE DESIGN CONCEPT . . . . . . 61

CHAPTER V. TEST CONDITIONS AND DISPLAY EVALUATION • 85

CHAPTER VI. CONCLUSIONS . . . . . . . . . . 115

APPENDICES

A. Abbreviations and definitions . . . . . . 117

B. Information characteristics . . . . . . . 119

c. Modified task set . . . . . . . . . . 138

D. Modified information characteristics . . . . 145

E. Implementation considerations . . . . . . 159

F. Pilot briefing . . . . . . . . . . . 162

G. Quiz of critical engine parameters . . . . . 174

H. Pilot questionnaires . . . . . . . . . . 177

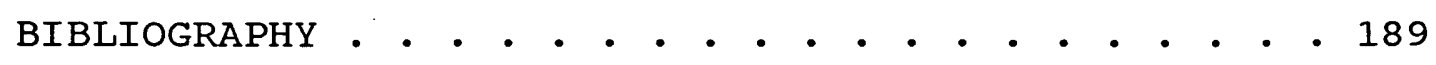

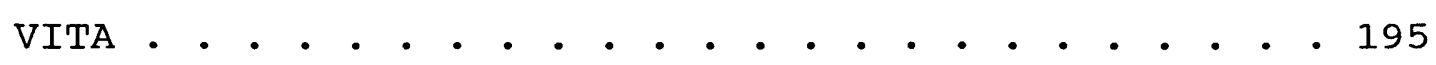




\section{LIST OF TABLES}

Page

1. Normal, caution, and warning regions for the JT8D-7 engine . . . . . . . . . . . 11

2. Procedure for the control of engine power . . 17

3. Procedure for monitoring the engine system/components . . . . . . . . . . . . 21

4. Subtask list for the example problem . . . . 36

5. Information parameters for the subtasks of table 4 . . . . . . . . . . . . . . . 40

6. Representative set of information characteristics . . . . . . . . . . . . . 42

7. Modified set of information characteristics . . 67

8. Scenarios for familiarization and the subjective evaluations . . . . . . . . . . 92

9. Scenarios for the quantitative evaluation . . 97

10. Scenario sequence for the quantitative evaluation . . . . . . . . . . . . . . 98 
LIST OF FIGURES

Page

1. The display design process . . . . . . . . 9

2. Required functions from the procedures of table 2 and $3 . . \cdot$. . . . . . . . . . . . 24

3. Relationship between the two primary functions . 26

4. Tasks for the function establish takeoff power . . . . . . . . . . . . . . 29

5. Tasks for the function adjust inflight power - . 31

6. Tasks for the function check for out-of-tolerance conditions . . . . . . . . . 32

7. Tasks for the function check for degraded conditions . . . . . . . . . . . . . . . . . . . 34

8. Display element for EPR . • . . . . . . . 49

9. Display element for $\mathrm{N}_{1}$. . . . . . . . . 54

10. Display element for oil pressure . . . . . . 55

11. Traditional display, left side . . . . . . 57

12. Traditional display, right side . . . . . . 59

13. The task-oriented display design process . . . 63

14. An example of a column deviation graph . . . . 73

15. An example of the monitoring display element . . 76

16. An example of the control display element . . 78

17. Task-oriented display, left side . . . . . . 80

18. Task-oriented display, right side . . . . . . 82

19. Simulator cockpit . . . . . . . . . . . 87

20. Responses to question 1 of questionnaires
$\mathrm{A}$ and B . . . . . . . . . . . . . . . . . 100

21. Responses to question 2 of questionnaires
$\mathrm{A}$ and B . . . . . . . . . . . 101 
22. Responses to question 3 of questionnaires $\mathrm{A}$ and $\mathrm{B}$. . . . . . . . . . . . . 102

23. Responses to question 4 of questionnaires $\mathrm{A}$ and $\mathrm{B}$. . . . . . . . . . . . . 103

24. Responses to question 5 of questionnaires $\mathrm{A}$ and $\mathrm{B}$. . . . . . . . . . . . . 104

25. Responses to question 6 of questionnaires A and B .................. 105

26. Responses to question 1 of questionnaire C . . 107

27. Responses to question 2 of questionnaire C . . 108

28. Responses to question 3 of questionnaire C . . 109

29. Responses to question 4 of questionnaire C . . 110

30. Responses to question 5 of questionnaire C . . 111

31. Responses to question 6 of questionnaire C . . 112 


\title{
ABSTRACT
}

The general topic for this thesis was in the area of display design alternatives for improved man-machine performance. Usually, displays and instruments, electronic or otherwise, present only the raw data that are collected by the system. Potential benefits may result from processing these data into parameters that are more closely related to the task the user is to perform. The intent of this study was to define and assess a display design concept oriented toward providing this task-oriented information. The underlying premise to this concept was that the computational capabilities of modern, graphics-based display systems should be considered in the display design process. The major focus of this concept, then, deals with the processing of data into parameters that are more relevant to the task of the human operator. Closely coupled to this concept of relevant information is the form or manner in which this information is actually presented. Conventional forms of presentation are normally a direct representation of the underlying data. By providing information in a form that is more easily assimilated and understood, a reduction in human error and cognitive workload may be obtained.

A description of this proposed concept with a design example is provided. The application for the example was an engine display for a generic, twin-engine civil transport aircraft. This application was chosen because it provides an opportunity to examine this alternative display concept in both a control and systems monitoring environment. The product of this concept was evaluated against a functionally similar, traditional display. The results of this evaluation showed that a task-oriented approach to design is a viable concept with regard to reducing user error and cognitive workload. The goal of this design process, providing taskoriented information to the user, both in content and form, appears to be a feasible mechanism for increasing the overall performance of a man-machine system.

\author{
TERENCE S. ABBOTT
}

DEPARTMENT OF COMPUTER SCIENCE

THE COLLEGE OF WILLIAM AND MARY IN VIRGINIA 
TASK-ORIENTED DISPLAY DESIGN Concept and Example 


\section{INTRODUCTION}

The systems interface requirements between man and machine may be categorized by the direction of information transfer; either man to machine or machine to man. In the transfer of information from machine to man, a major mechanism for providing this information transfer is through visual displays. For this interaction of man and machine, displays are generally designed to assist the man in accomplishing one of two operator tasks, either controlling the machine or monitoring the state or actions of the machine. The display requirements for the control task deal with situations where the man must be provided sufficient information to continuously or momentarily direct the activities of the machine. The display requirements for a monitoring task deal with situations where the man is more of a systems supervisor, requiring status information on the system being managed.

In an automotive environment, an example of the display interface for control is a speedometer, which provides feedback to the driver for control of the speed of the vehicle. A monitoring requirement may be represented by a water temperature gage. In this latter instance, the information conveyed by this instrument is used only to determine if the system is operating properly. With two significantly different task requirements imposed on the 
man, the driver in this example, it would be natural to assume that two different methods of information presentation would be used to fulfill these requirements. The point that is significant to this study is that this is not normally the case. Additionally, current presentations using electronic media are typically carryovers of their electromechanical counterparts, both in content and form. What is seen is electronic media providing the man with basically raw sensor data in a traditional form.

The underlying concept to this thesis is that the computational capabilities of modern, graphics-based display systems should be considered in the display design process. By providing information in a form that is more directly aligned with the user's task, a reduction of the cognitive workload associated with the use of displayed information may be possible. This may require that the raw data that are typically displayed be processed into a more appropriate representation and presented in a manner that permits easier assimilation. If one were to assume that this is an obvious concept, then one needs only to survey the use of computer generated display formats in industry to find that this assumption is incorrect or if correct, then not applied. The apparent merit of providing information at a more relevant level and supported by a display form that is more readily assimilated is the foundation of this design concept. 
The traditional approach to display design is considered to have two distinct parts; defining the information content (an analysis phase) and describing the information form (a synthesis phase) (Frey et al. 1984; Banks, Hunter, \& Noviski 1985; DOD-HDBK-763 1987). The definition of the information content usually includes a definition of the system objectives, a function analysis, a task analysis, and the identification of the information requirements. In this process, the system goals generally describe the intent or objectives of the system. The function analysis then details what needs to be done to fulfill the system objectives. Next, a task analysis and decomposition is performed to define how to provide for the functions. Finally, all of the information that the user will need to perform the tasks are identified in an information requirements list.

The second part of the traditional design process is the description of the information form. This description begins by using the information requirements list as the primary specification for the selection of picture elements (e.g., a graph, table, or chart which conveys information to the user to: support a task). After the picture elements have been defined, they are combined together to form a picture. The defined picture must now be modified to conform to the identified implementation constraints. Compromises are frequently necessary for either the selection of a picture element or the organization of the picture as a whole. This 
process of selection and modification is repeated until all constraint conflicts are resolved. The final product of this iterative design process is a display specification.

The approach taken in this thesis was to modify the traditional design process at two points. First, the design process was modified at the point where the information required by the user to perform a specific task is defined. At this point in the traditional design, the user's task was usually decomposed to a level where a data source could be identified. The modification proposed in this thesis is to decompose the user's task only to a level where relevant information can be identified. This relevant information, if not directly provided by the raw data from the system, should be provided by synthesis from the underlying data of the system. By providing information at a more appropriate level of detail, a reduction of the user's cognitive workload associated with the use of this information should be possible.

A second, complementary part of this proposed concept deals with providing information in a form that is more appropriate to the user's task. Often, picture elements chosen to support a particular task are less than optimum, from a user's standpoint, for that task. Frequently, this less-than-optimum choice is predicated on the characteristics of the available raw data. If a better 
picture element can be found, one that better supports the user's task, then data should be processed or synthesized to support this implementation. The goal of this design process, then, is to provide task-oriented information to the user, both in content and form, to support the user's needs at a level more relevant to the user's task.

The specific area of interest for this thesis was secondary flight display formats, with aircraft engine instruments as the actual application. This application area was chosen because it provides both a control task and a systems monitoring task. It is believed that the general concepts being advocated and the results of this thesis will be applicable through a broad range of application areas. 
CHAPTER I

THE DESIGN PROCESS

In recent years, some of the most effective guidelines to the display design process have come from the Department of Defense (MIL-STD-1472C 1981; DOD-HDBK-763 1987) and the nuclear power community (Banks et al. 1983; Frey et al. 1984; Banks, Hunter, \& Noviski 1985; Gilmore 1985), the latter probably as a result of the Three Mile Island incident. As described in these documents (as well as DeGreene (1970); Gould \& Lewis (1983); and Grudin, Ehrlich \& Shriner (1987)), the display design process should be accomplished using a top-down, iterative approach with at least two distinct phases: analysis and synthesis. The analysis phase is used to define the use of the display system from the user's standpoint. As a minimum, this phase includes the definition of the requirements of the system to meet some overall objective and the information needed to fulfill those requirements. The product of the analysis phase is a list of the information and its characteristics required by the intended user of the display system. This list is then used as the primary specification for the synthesis phase. The synthesis phase is used to define the optimum display format, the picture. This picture is then transformed into an achievable display specification. The transformation process includes the identification of implementation constraints and the iteration of these 
constraints back into the design. The relationship of these phases is illustrated in figure 1.

The primary concepts explored in this thesis deal with a modification of the analysis phase and the relationship of the analysis phase with the synthesis phase. To exemplify these concepts, a partial design will first be performed for a jet aircraft engine display using the current design approach. A second design will then be performed for the same display requirement using the concepts proposed in this thesis. For this example, the objectives will be constrained to aircraft takeoff situations and typical inflight situations. Additionally, the design will be constrained to normal control and monitoring tasks, to include fault detection. Failure diagnosis and the related procedures were not included in this design analysis.

The aircraft system used for this example, a Pratt and Whitney JT8D-7 turbofan engine, typically provides the following sensor data:

1. Exhaust pressure ratio, EPR, which is the ratio in pressure sensed at the exhaust portion of the engine relative to the intake portion of the engine.

2. Low-pressure compressor rotational speed, $\mathrm{N}_{1}$. 
FIGURE 1

THE DISPLAY DESIGN PROCESS

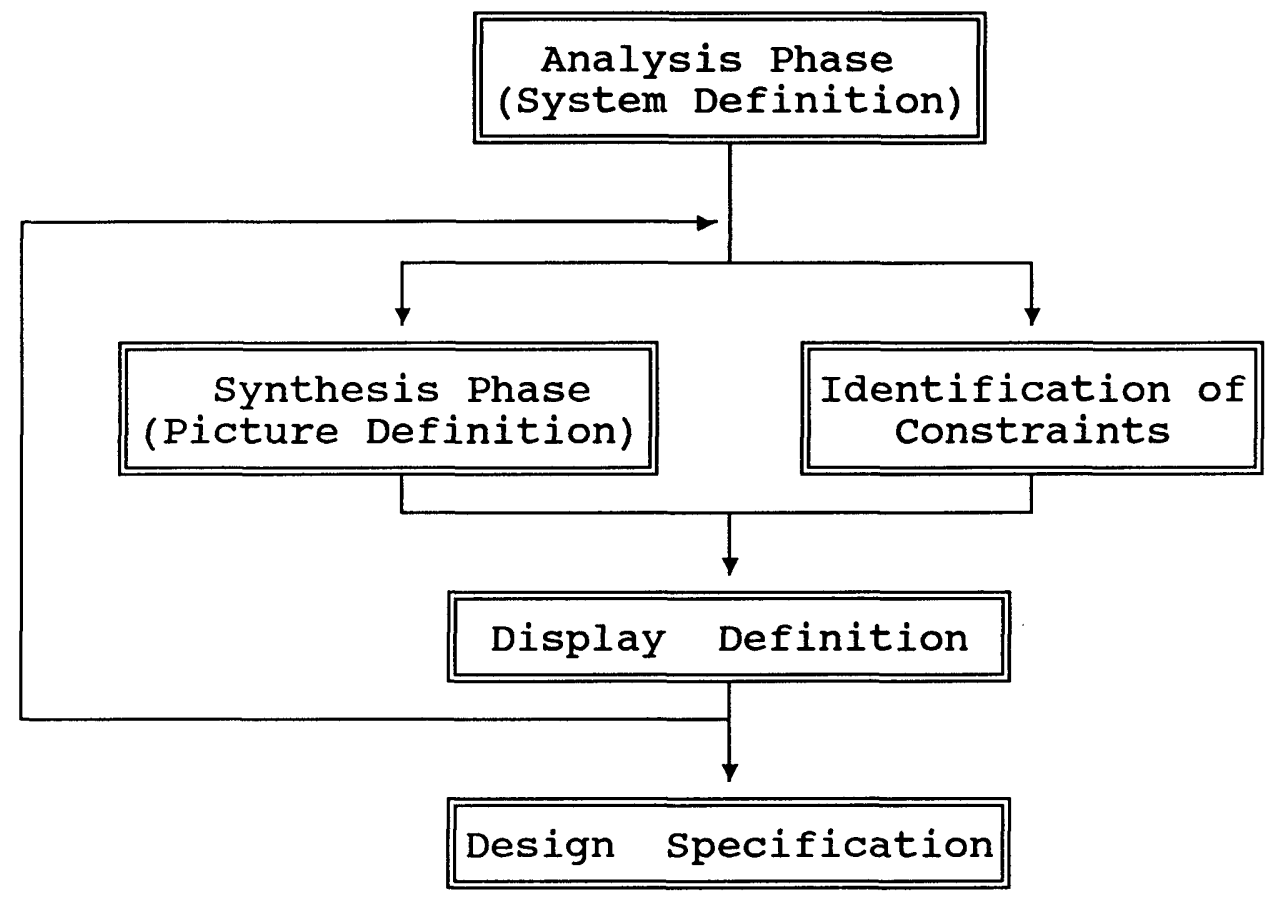


3. High-pressure compressor rotational speed, $\mathrm{N}_{2}$.

4. Exhaust gas temperature, EGT.

5. Fuel flow.

6. Oil pressure.

7. Oil temperature.

8. Oil quantity.

The primary sensor for representing engine power is EPR. Additionally, $\mathrm{N}_{1}, \mathrm{~N}_{2}, \mathrm{EGT}$, and fuel flow are also directly related to engine power. As such, these parameters may be highly dynamic in nature. The oil system is relatively insensitive to engine power or changes in power.

Most of the systems and components described by these sensors have special operating regions associated with them: caution regions, requiring special attention by the operator, and warning regions, where continued operation is likely to cause component damage. These regions must, obviously, be considered in the design requirements for the display design. For this engine, these regions are given in table 1 . 
TABLE 1

NORMAL, CAUTION, AND WARNING REGIONS FOR THE JT8D-7 ENGINE

\begin{tabular}{|c|c|c|}
\hline EPR regions: & $\begin{array}{l}\text { Normal } \\
\text { Caution }\end{array}$ & $\begin{array}{l}\text { - below caution region } \\
\text { - (maximum continuous } \\
\text { EPR) variable, based } \\
\text { on ambient conditions. } \\
\text { - (maximum takeoff EPR) } \\
\text { variable, based on } \\
\text { ambient conditions. }\end{array}$ \\
\hline $\mathrm{N}_{1}$ regions: & $\begin{array}{l}\text { Normal } \\
\text { Caution } \\
\text { Warning }\end{array}$ & $\begin{array}{l}\text { - } 0 \text { to } 94 \% \\
\text { - } 94 \text { to } 100.1 \% \\
\text { - above } 100.1 \%\end{array}$ \\
\hline $\mathrm{N}_{2}$ regions: & $\begin{array}{l}\text { Normal } \\
\text { Caution } \\
\text { Warning }\end{array}$ & $\begin{array}{l}\text { - } 0 \text { to } 94 \% \\
\text { - } 94 \text { to } 100 \% \\
\text { - above } 100 \%\end{array}$ \\
\hline EGT regions: & $\begin{array}{l}\text { Normal } \\
\text { Caution } \\
\text { Warning }\end{array}$ & $\begin{array}{l}\text { - below } 535^{\circ} \mathrm{C} \\
\text { - } 535^{\circ} \text { to } 570^{\circ} \mathrm{C} \\
\text { - above } 570^{\circ} \mathrm{C}\end{array}$ \\
\hline Oil pressure regions: & $\begin{array}{l}\text { Warning } \\
\text { Caution } \\
\text { Normal } \\
\text { Warning }\end{array}$ & $\begin{array}{l}\text { - below } 35 \mathrm{psi} \\
\text { - } 35 \text { to } 40 \mathrm{psi} \\
\text { - } 40 \text { to } 55 \mathrm{psi} \\
\text { - above } 55 \mathrm{psi}\end{array}$ \\
\hline oil temperature regions: & $\begin{array}{l}\text { Warning } \\
\text { Normal } \\
\text { Caution } \\
\text { Warning }\end{array}$ & $\begin{array}{l}\text { - below } 40^{\circ} \mathrm{C} \\
\text { - } 40^{\circ} \text { to } 120^{\circ} \mathrm{C} \\
\text { - } 120^{\circ} \text { to } 157^{\circ} \mathrm{C} \\
\text { - above } 157^{\circ} \mathrm{C}\end{array}$ \\
\hline oil quantity regions: & $\begin{array}{l}\text { Warning } \\
\text { Normal }\end{array}$ & $\begin{array}{l}\text { - below } 1.0 \mathrm{gal} \\
\text { - above } 1.0 \mathrm{gal}\end{array}$ \\
\hline
\end{tabular}


As part of the design description, the following chapters will present, in the context of this example, the traditional display analysis process, a limited synthesis phase, and a display implementation that fulfills this analysis. The alternative design concept will then be presented with a complementary display implementation. At this point, an experimental comparison of the products of both designs will be described. 
CHAPTER II

TRADITIONAL DESIGN ANALYSIS

The traditional design methodology used in this study is patterned after two display guidelines from the nuclear power industry (Frey et al. 1984; Banks, Hunter, \& Noviski 1985). Using the approach described in these references, the analysis phase is partitioned, again in a top-down manner, into four parts: the definition of the system objectives, a function analysis, a task analysis, and the identification and description of the information requirements. The system objectives are used to describe what the system is to do, who will use the system, where it will be used, and when it will be used. The system objectives for the current work are defined as follows:

What is the system to do? This display system should provide real-time information to allow the user to monitor the systems/components of the engine for proper operation and to establish and maintain engine power. Additionally, for a takeoff situation, precise engine control is required. The design is for a two-engine installation, where the installed engines are Pratt and Whitney JT8D-7 turbofan engines.

Who will use the system? The users will be aircraft-rated pilots who will interact with and control the engines of the aircraft using this display as the primary source of engine 
information. The users will also use this display system to monitor engine systems/components for normal, abnormal, and out-of-tolerance conditions. The control and monitoring tasks will be performed in accordance with the aircraft flight crew operating manual. The users are trained and are operationally familiar with this equipment.

Where will the system be used? The display system will be located on the center of the instrument panel of the aircraft and will be able to be viewed by both pilots simultaneously.

When will the system be used? The system will be used primarily to monitor engine conditions during flight. Additionally, the system will be used to precisely set engine power during takeoff situations. In neither case will the use of this system be the users' principal task.

A simplified summary of the system objectives is: provide real-time information to a pilot through an instrument-panel mounted display system for controlling and monitoring the operation of two Pratt and Whitney JT8D-7 turbofan engines.

The second portion of the analysis phase is the functional analysis. The functional analysis is simply the decomposition of the system objectives into a set of functions required to meet the goals of these objectives. 
That is, a function is a fairly specific and detailed description on what needs to be done to fulfill some part of the system objectives. A complete and thorough decomposition assures that all the system objectives will be met. After all functions have been defined, an allocation is performed to determine who, man or machine, should perform each function. This allocation is generally based on lists (e.g., Fitts list (DOD-HDBK-763 1987)) that delineate between the areas that the man or machine are more adept at performing. For the design of a display system, we are primarily concerned with the human part of the functional allocation, functions that the man is allocated to perform. Additionally, care should be taken in the selection process such that the human is allocated functions that will yield a logically sequenced or arranged set of operator tasks.

One major mechanism for defining the functions is through the use of functional flow diagrams (DOD-HDBK-763 1987). Using this technique, system requirements are iteratively decomposed from system or mission objectives into increasingly detailed functions. A functional flow diagram is generated for each level of detail in the decomposition. The decomposition continues until a level that identifies specific operator tasks is reached. Functional flows are constructed at each level by arranging the functions into a systematic, sequential arrangement by the proposed order of use. The direction of interaction or normal sequence of use 
of each function is then depicted by connecting, directional arrows on the diagram. Functional flow diagrams provide a traceable and relative easy technique for defining the functional requirements in the design process.

An alternative mechanism for defining the functions allocated to the human is by using proposed or existing operator procedures (Frey et al. 1984), where a function will generally coincide with a procedure. If these procedures do not exist, then similar procedures may serve as models or candidate procedures may be generated. This particular technique is especially suited for retrofit situations or situations under which existing procedures will be used. This procedural technique will be used for the example in this study. The functions for this example will be generated from the procedures of table 2 and 3 . These procedures were produced by expanding the procedures from the operator's handbook (Boeing Company 1973).

Using the procedural approach, the functional analysis yields two primary functions, one from each of the two procedures. It should be evident from the procedures that the primary functions are a control function and a monitoring function. Additionally, both the control and monitoring functions may each be further divided into two subfunctions (see figure 2). It is interesting to note that the separation between these functions is not quite as 
TABLE 2

PROCEDURE FOR THE CONTROL OF ENGINE POWER

Step User Action or Expected Response

Action for Invalid Response

1 If this is a takeoff condition, then go to step 7 .

2 Verify system operation:

a. Check system/component operation (see engine monitoring procedure). a. If any parameter is outof-tolerance or abnormal, then initiate appropriate procedure. Go to step 11.

3 If no power adjustment is required, then terminate this procedure.

4 Adjust power:

a. Increase or decrease power as necessary to maintain/ establish the required aircraft speed. For an increase of power, do not exceed the

a. If power fluctuates or results in opposite response, then initiate appropriate procedure. Go to step 11 . maximum continuous power available.

b. For an increase of power, immediately

b. See step $5 a$. cross-check $\mathrm{N}_{1}, \mathrm{~N}_{2}$, and EGT for high, out-oftolerance conditions (may be combined with step 5a). 
TABLE 2 (continued)

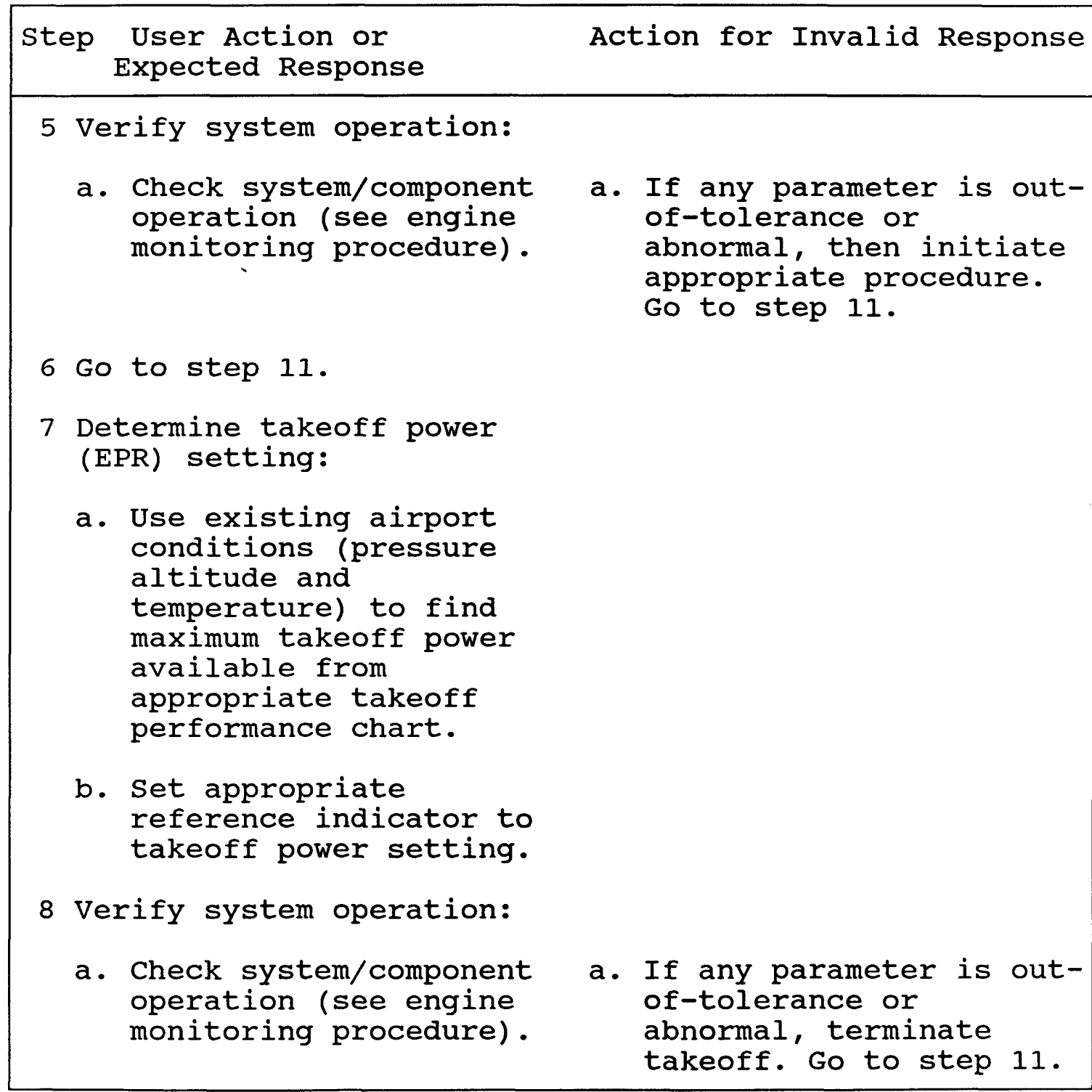


TABLE 2 (continued)

\begin{tabular}{|c|c|c|}
\hline \multicolumn{2}{|c|}{$\begin{array}{c}\text { Step User Action or } \\
\text { Expected Response }\end{array}$} & Action for Invalid Response \\
\hline 9 & $\begin{array}{l}\text { Establish takeoff power: } \\
\text { a. Set power to or slightly } \\
\text { less than the maximum } \\
\text { takeoff power setting. }\end{array}$ & $\begin{array}{l}\text { a. If abnormal response, go } \\
\text { to step } 8 \text {. }\end{array}$ \\
\hline & $\begin{array}{l}\text { b. Immediately cross-check } \\
\mathrm{N}_{1}, \mathrm{~N}_{2} \text {, and EGT for high } \\
\text { out-of-tolerance } \\
\text { conditions (may be } \\
\text { combined with step 9c). }\end{array}$ & b. See step $9 \mathrm{c}$. \\
\hline & $\begin{array}{l}\text { c. Check system/component } \\
\text { operation (see engine } \\
\text { monitoring procedure). }\end{array}$ & $\begin{array}{l}\text { c. If any parameter is } \\
\text { out-of-tolerance or } \\
\text { abnormal, terminate } \\
\text { takeoff. Go to step } 11 .\end{array}$ \\
\hline & $\begin{array}{l}\text { d. Prior to } 60 \mathrm{kts} \text {, } \\
\text { establish takeoff power. }\end{array}$ & $\begin{array}{l}\text { d. If power decreases or } \\
\text { significantly fluctuates } \\
\text { terminate takeoff. Go to } \\
\text { step } 11 .\end{array}$ \\
\hline & $\begin{array}{l}\text { e. Immediately cross-check } \\
\mathrm{N}_{1}, \mathrm{~N}_{2} \text {, and EGT for high } \\
\text { out-of-tolerance } \\
\text { conditions (may be } \\
\text { combined with step } 9 \mathrm{f} \text { ). }\end{array}$ & e. See step $9 f$. \\
\hline & $\begin{array}{l}\text { f. Check system/component } \\
\text { operation (see engine } \\
\text { monitoring procedure). }\end{array}$ & $\begin{array}{l}\text { f. If any parameter is } \\
\text { out-of-tolerance or } \\
\text { abnormal, terminate } \\
\text { takeoff. Go to step } 11 \text {. }\end{array}$ \\
\hline 10 & $\begin{array}{l}\text { Verify system performance } \\
\text { at } v_{1} \text { : }\end{array}$ & \\
\hline & a. Confirm takeoff power. & $\begin{array}{l}\text { a. If power has } \\
\text { significantly decreased } \\
\text { or is fluctuating, } \\
\text { terminate takeoff. Go to } \\
\text { step } 11 .\end{array}$ \\
\hline
\end{tabular}


TABLE 2 (continued)

Step User Action or Expected Response

b. Check system/component operation (see engine monitoring procedure).
Action for Invalid Response

b. If any parameter is out-of-tolerance or abnormal, terminate takeoff. Go to step 11 .

11 Terminate this procedure. 
TABLE 3

PROCEDURE FOR MONITORING THE ENGINE SYSTEM/COMPONENTS

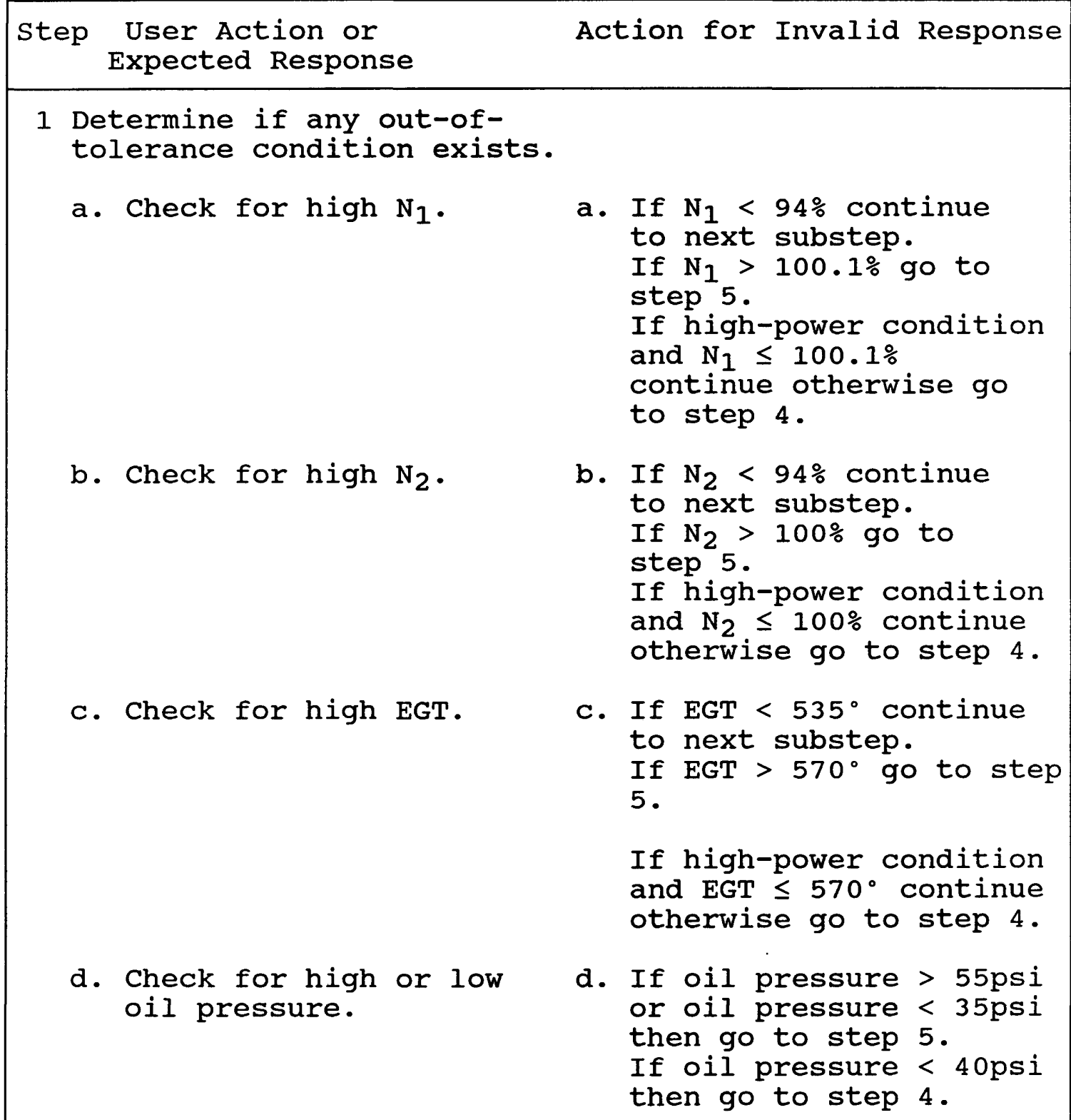


TABLE 3 (continued)

\begin{tabular}{|c|c|c|}
\hline \multicolumn{2}{|c|}{$\begin{array}{l}\text { Step User Action or } \\
\text { Expected Response }\end{array}$} & Action for Invalid Response \\
\hline & $\begin{array}{l}\text { e. Check for high or low } \\
\text { oil temperature. }\end{array}$ & $\begin{array}{l}\text { e. If oil temperature }>157 \\
\text { or oil temperature }<40^{\circ} \\
\text { then go to step } 5 . \\
\text { If oil temperature }> \\
120^{\circ} \text { then go to step } 4 .\end{array}$ \\
\hline & $\begin{array}{l}\text { f. Check for low oil } \\
\text { quantity. }\end{array}$ & $\begin{array}{l}\text { f. If oil quantity }<1 \text { gal } \\
\text { then go to step } 5 .\end{array}$ \\
\hline 2 & $\begin{array}{l}\text { Determine if any degraded } \\
\text { condition exists. }\end{array}$ & \\
\hline & $\begin{array}{l}\text { a. Check for an unusual } \\
\text { rate of change of any } \\
\text { parameter. }\end{array}$ & a. Go to step 6 . \\
\hline & $\begin{array}{l}\text { Determine if EPR is } \\
\text { appropriate for the } \\
\text { conditions. }\end{array}$ & b. Go to step 6 . \\
\hline & $\begin{array}{l}\text { Determine if } \mathrm{N}_{1} \text { is } \\
\text { appropriate for the } \\
\text { conditions. }\end{array}$ & c. Go to step 6 . \\
\hline & $\begin{array}{l}\text { d. Determine if } \mathrm{N}_{2} \text { is } \\
\text { appropriate for the } \\
\text { conditions. }\end{array}$ & d. Go to step 6 . \\
\hline & $\begin{array}{l}\text { e. Determine if EGT is } \\
\text { appropriate for the } \\
\text { conditions. }\end{array}$ & e. Go to step 6 . \\
\hline & $\begin{array}{l}\text { f. Determine if fuel flow } \\
\text { is appropriate for the } \\
\text { conditions. }\end{array}$ & f. Go to step 6 . \\
\hline
\end{tabular}


TABLE 3 (continued)

Step User Action or Expected Response

Action for Invalid Response

3 No abnormal or out-oftolerance conditions exists, terminate this procedure.

4 Terminate this procedure with an out-of-tolerance, caution condition.

5 Terminate this procedure with an out-of-tolerance, warning condition.

6 Terminate this procedure with an abnormal condition. 
FIGURE 2

REQUIRED FUNCTIONS FROM THE PROCEDURES OF TABLE 2 AND 3

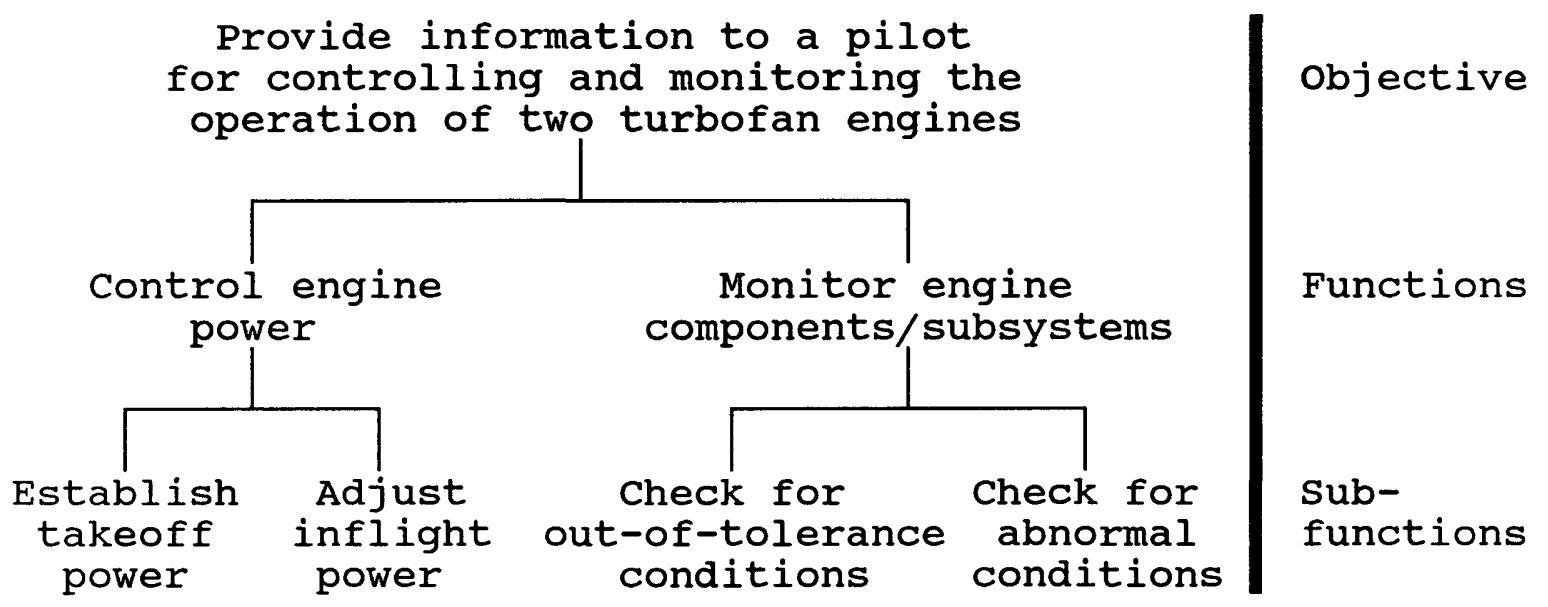


distinct as implied by figure 2. This is due largely to the cross-check requirement, a monitoring task, within the control task. This relationship is shown in figure 3. As can be seen in figure 3 , the control function can be divided into a control function for takeoff and control function for inflight (for this example, inflight is defined as all conditions except takeoff). The monitoring function can be divided into a function for determining out-of-tolerance conditions and a function for determining abnormal conditions. The control subfunctions themselves are mutually exclusive while the monitoring subfunctions are not.

The third portion of the analysis phase is the decomposition of the functions into tasks. A task is a description or definition of how to provide all or some portion of a function. For a function allocated to the human, the task is a specific action that needs to be performed by the human to provide this function. The task analysis should generally determine the required knowledge, skills, and information that the human needs to accomplish a task. The assumed knowledge and skills of the user are usually fixed at some minimum level for the design analysis. Additionally, since it is unusual for a task to be totally independent from all other tasks and the information required to perform them, consideration should be given to the relationship among the tasks. This relationship will have an influence on how the information should be 
FIGURE 3

\section{RELATIONSHIP BETWEEN THE TWO PRIMARY FUNCTIONS}

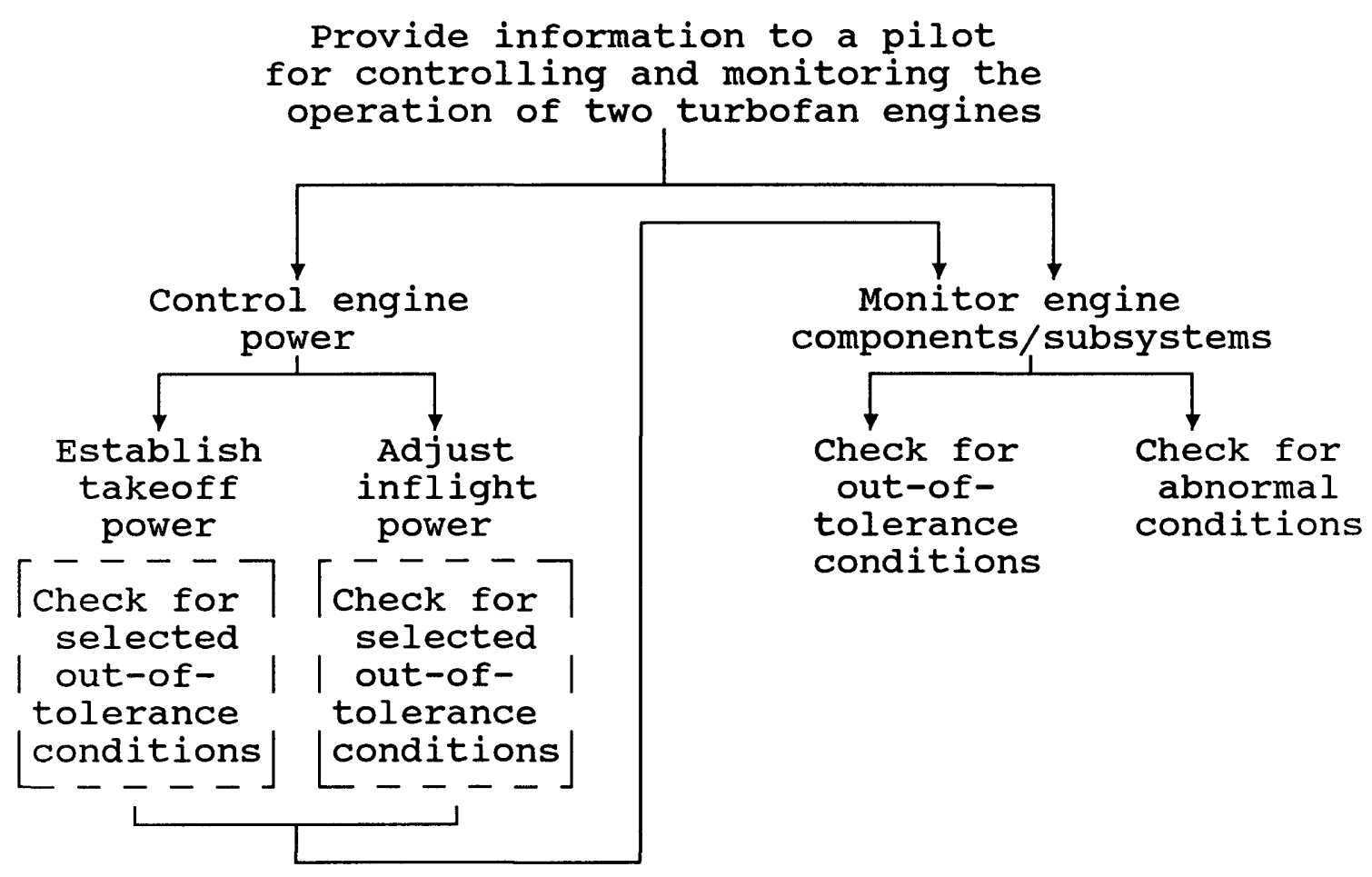


presented, both in form and placement, to best allow the operator to integrate the provided information. From a display design standpoint, the aim of the task analysis is toward identifying the information required by the human to perform the tasks. The product of the task analysis is a complete list of all tasks that are needed to fulfill the functional requirements.

To produce the task list, the designer may again use the procedural approach where, in this case, a task will generally coincide with a step in the procedure. As in the functional analysis, a decomposition may be required for task identified at this level. The task analysis and decomposition should be repeated until all tasks can be determined by one of the following:

1. The need to read some particular instrumentation. That is, the "decomposition should be repeated as many times as necessary to arrive at a statement which yields the information needed at the level it is provided from the plant instrumentation" (Frey et al. 1984, p. 9-9)

2. The need to use some particular job aid, such as a checklist procedure.

3. The need to know some particular fact, either from 
training or experience.

Using this technique, it can be seen that the four subfunctions of this example yield 16 unique steps or tasks (figures 4 to 7 ). These 16 tasks are further decomposed until one of the three criterion, from above, is met. This decomposition produces 35 subtasks, shown in table 4 .

The final portion of the analysis phase is the definition of the information requirements. This step requires the identification and description of all information that the operator will need to perform the tasks. By the addition of the information source to the task list, as was done in figures 4 through 7 , the majority of the identification process should be reasonably straightforward. However, the identification of the information requirements must also include "anything that the operator needs to know about the current state of the plant and any factual knowledge that he might forget or be unsure of. Any required information not available from the display system must come from some other source such as training, experience, procedures, or existing display devices" (Frey et al. 1984, p. 4-12). Operational expertise of the designer is important at this point in identifying any unresolved information requirement. This need is attributable to the fact that tasks generated from procedures often do not explicitly mention the many possible unsolicited sources of information that must be provided to 
FIGURE 4

TASKS FOR THE FUNCTION ESTABLISH TAKEOFF POWER

TASK

Find maximum power (EPR) available
SUBTASK [SOURCE]

obtain takeoff EPR setting from the Takeoff EPR Chart for the airport pressure altitude and temperature [chart]

Set EPR reference $\left[\begin{array}{l}\text { Set the EPR } \\ \text { reference } \\ \text { indicator } \\ \text { (pointer) to the } \\ \text { takeoff EPR } \\ \text { setting }( \pm 0.01)\end{array}\right.$

Check system/ component operation
See the Monitoring Function for this set of tasks
SUBTASK [SOURCE]

See instructions

on the Takeoff EPR

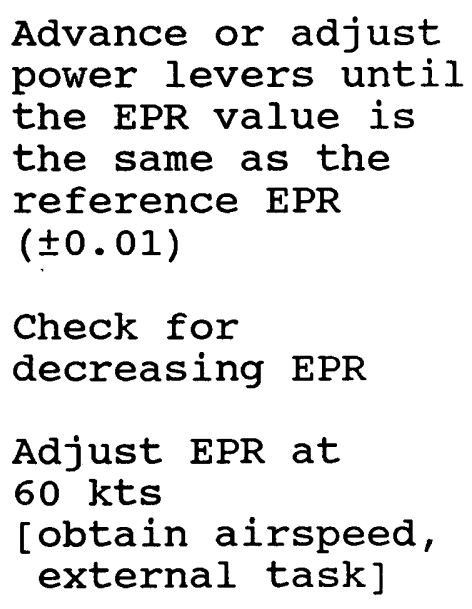


FIGURE 4 (continued)

TASK

SUBTASK [SOURCE]

SUBTASK [SOURCE]

Confirm takeoff
power $\quad\left[\begin{array}{l}\text { Compare power } \\ \text { output with the } \\ \text { reference } \\ \text { [EPR sensor] }\end{array}\right.$

Compare the EPR value with the EPR reference

Check for

decreasing EPR

Check EPR at $V_{1}$

[obtain airspeed, external task] 
FIGURE 5

TASKS FOR THE FUNCTION ADJUST INFLIGHT POWER

TASK

Check system/ component operation
SUBTASK [SOURCE]

See the Monitoring Function for this set of tasks
Adjust power as necessary to establish/

maintain speed

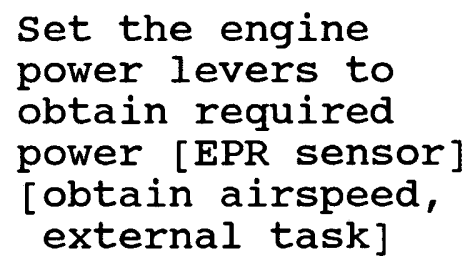

SUBTASK [SOURCE]

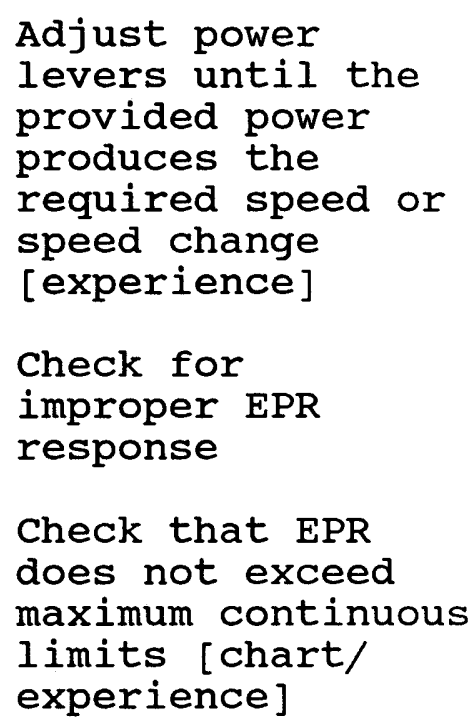

Adjust power levers until the provided power produces the required speed or speed change [experience]

Check for improper EPR response

Check that EPR does not exceed maximum continuous limits [chart/ experience] 
FIGURE 6

TASKS FOR THE FUNCTION CHECK FOR OUT-OF-TOLERANCE CONDITIONS

TASK

SUBTASK [SOURCE] SUBTASK [SOURCE]

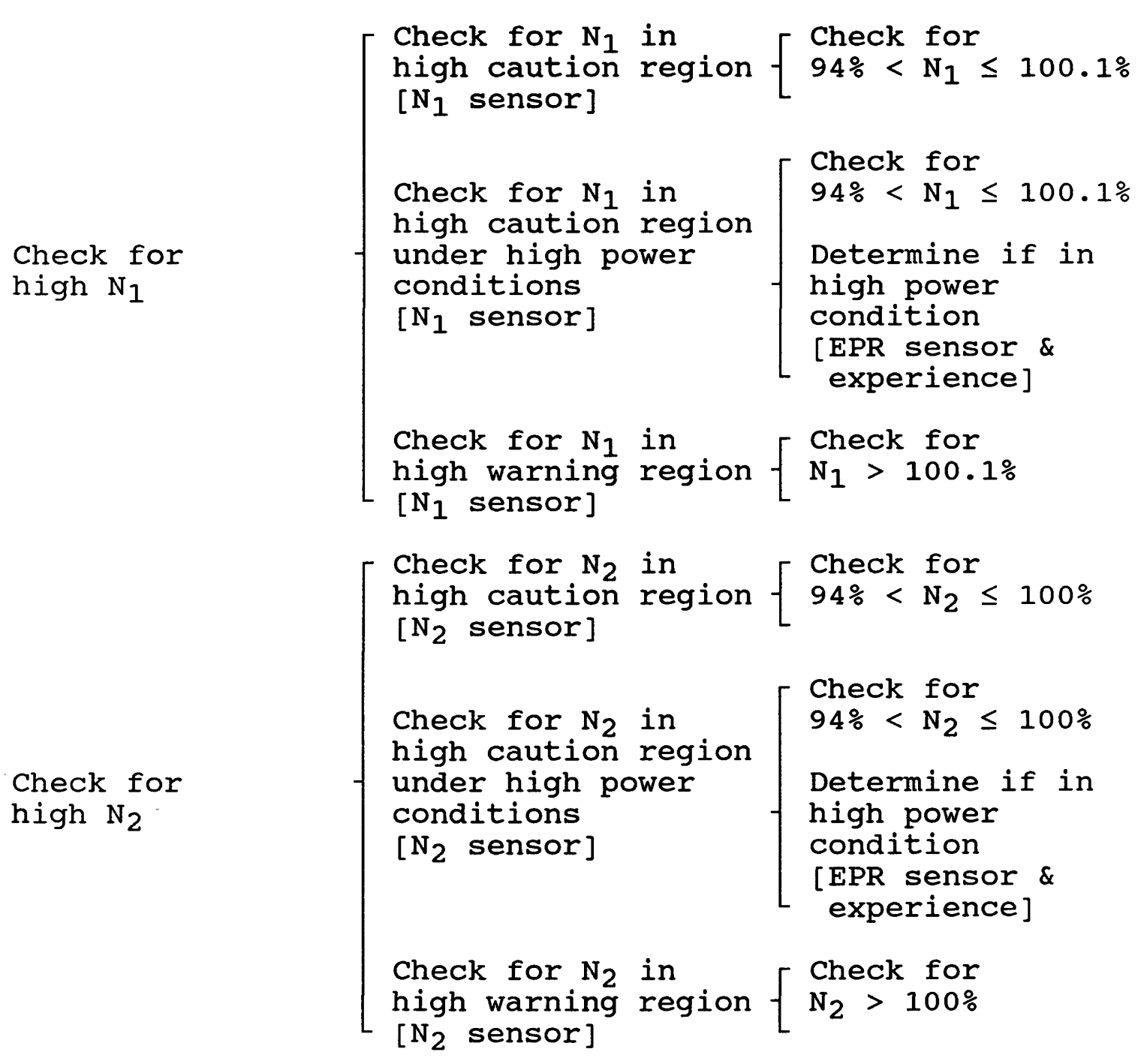




\section{FIGURE 6 (continued)}

TASK

Check for high EGT

Check for high or low oil pressure (OP)

Check for high or low oil temperature (OT)

\section{SUBTASK [SOURCE]}

Check for EGT in [EGT sensor]

Check for EGT in high caution region under high power conditions high caution region [EGT sensor]

SUBTASK [SOURCE]

Check for $535^{\circ}<\mathrm{EGT} \leq 570^{\circ}$

Check for $535^{\circ}<\mathrm{EGT} \leq 570^{\circ}$

Determine if in high power condition [EPR sensor \& experience]

Check for EGT in
high warning region $-\left[\begin{array}{l}\text { Check for } \\ \text { EGT }>570^{\circ}\end{array}\right.$

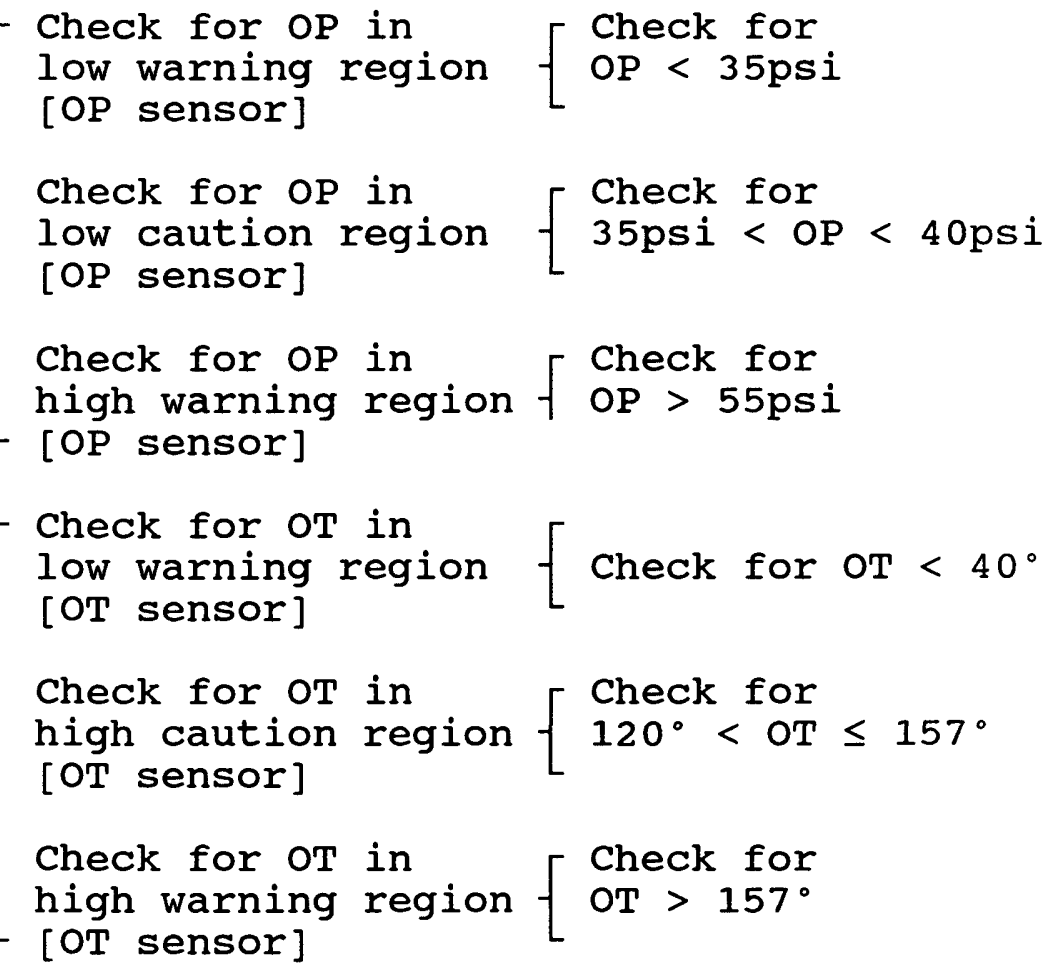

Check for low oil quantity 
FIGURE 7

TASKS FOR THE FUNCTION CHECK FOR DEGRADED CONDITIONS

TASK

SUBTASK [SOURCE]

SUBTASK [SOURCE]

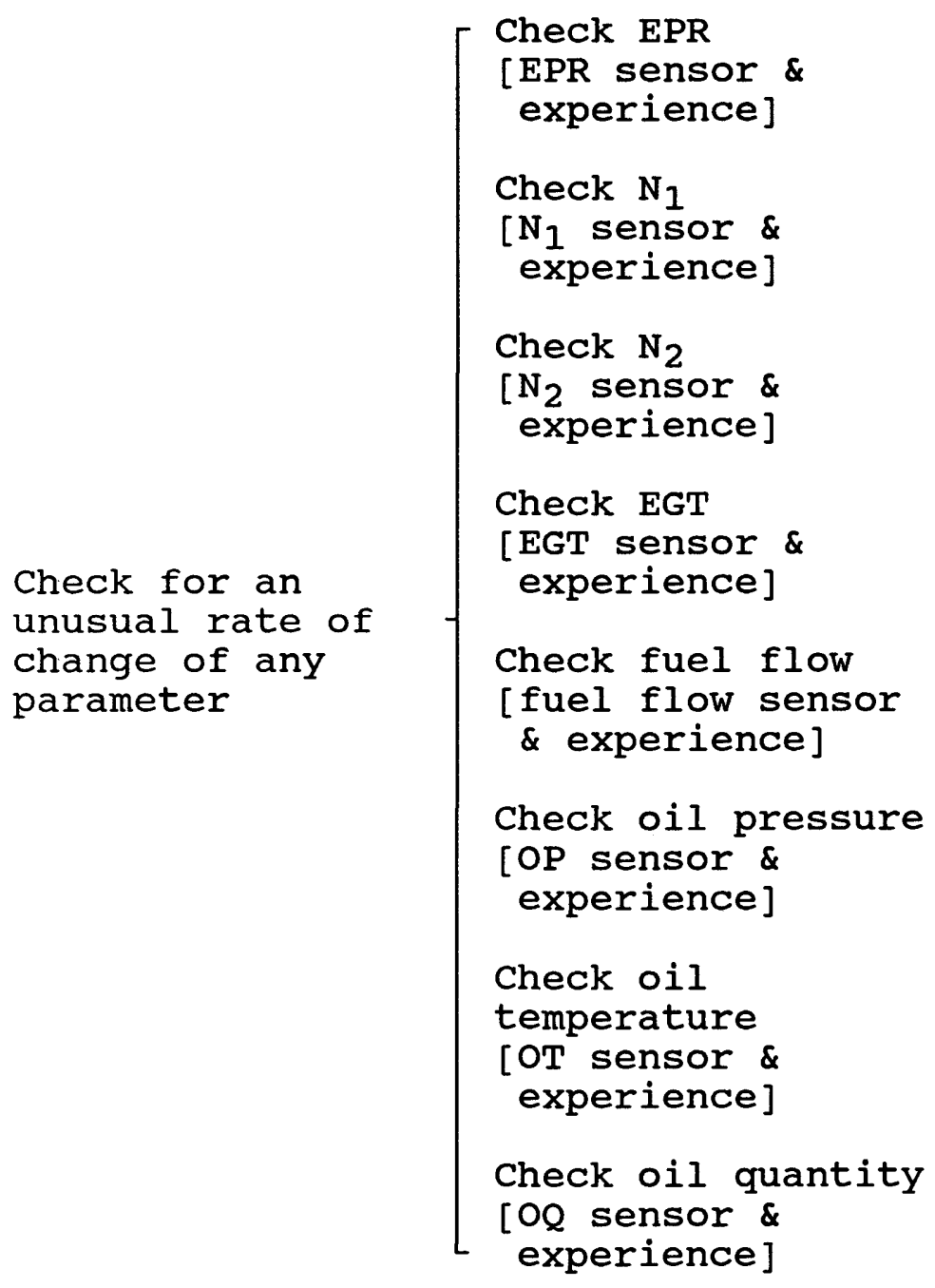


FIGURE 7 (continüed)

TASK

Determine if EPR value is appropriate

Determine if $\mathrm{N}_{1}$ value is appropriate

Determine if $\mathrm{N}_{2}$ value is appropriate

Determine if EGT value is appropriate

Determine if fuel flow value is appropriate

\section{SUBTASK [SOURCE]}

SUBTASK [SOURCE]

\section{Compare EPR value} against nominal value

[EPR sensor \& experience]

Compare $\mathrm{N}_{1}$ value against nominal value

$\left[\mathrm{N}_{1}\right.$ sensor \& experience]

Compare $\mathrm{N}_{2}$ value against nominal value

$\left[\mathrm{N}_{2}\right.$ sensor \& experience]

Compare EGT value against nominal value [EGT sensor \& experience]

Compare fuel flow value against nominal value [fuel flow sensor \& experience] 
TABLE 4

SUBTASK LIST FOR THE EXAMPLE PROBLEM

\begin{tabular}{|c|c|c|}
\hline & SUBTASK & SOURCE \\
\hline & $\begin{array}{l}\text { Obtain takeoff EPR setting from } \\
\text { the Takeoff EPR Chart for the } \\
\text { airport pressure altitude and } \\
\text { temperature }\end{array}$ & chart \\
\hline & $\begin{array}{l}\text { Set the EPR reference indicator } \\
\text { (pointer) to the takeoff EPR } \\
\text { setting }( \pm 0.01)\end{array}$ & operator action \\
\hline 3 . & $\begin{array}{l}\text { Advance or adjust power levers } \\
\text { until the EPR value is the same } \\
\text { as the reference EPR }( \pm 0.01)\end{array}$ & $\begin{array}{l}\text { EPR sensor \& } \\
\text { EPR reference }\end{array}$ \\
\hline & $\begin{array}{l}\text { Adjust power levers until the } \\
\text { provided power produces the } \\
\text { required speed or speed change }\end{array}$ & $\begin{array}{l}\text { EPR sensor, } \\
\text { airspeed, } \\
\text { \& experience }\end{array}$ \\
\hline 5 . & $\begin{array}{l}\text { Check that EPR does not exceed } \\
\text { maximum continuous limits }\end{array}$ & $\begin{array}{l}\text { EPR sensor \& } \\
\text { chart }\end{array}$ \\
\hline & $\begin{array}{l}\text { Adjust/check EPR at 60kts } \\
\text { and } V_{1}\end{array}$ & $\begin{array}{l}\text { EPR sensor \& } \\
\text { airspeed }\end{array}$ \\
\hline 7 . & Check for decreasing EPR & EPR sensor \\
\hline 8 . & Check for improper EPR response & EPR sensor \\
\hline & $\begin{array}{l}\text { Check EPR for unusual rate of } \\
\text { change }\end{array}$ & $\begin{array}{l}\text { EPR sensor \& } \\
\text { experience }\end{array}$ \\
\hline 10 & $\begin{array}{l}\text { Compare EPR value against } \\
\text { operator's estimate }\end{array}$ & $\begin{array}{l}\text { EPR sensor \& } \\
\text { experience }\end{array}$ \\
\hline 11 & $\begin{array}{l}\text { Determine if in high power } \\
\text { condition }\end{array}$ & $\begin{array}{l}\text { EPR sensor \& } \\
\text { experience }\end{array}$ \\
\hline 12. & Check for $94 \%<\mathrm{N}_{1} \leq 100.1 \%$ & $\mathrm{~N}_{1}$ sensor \\
\hline
\end{tabular}


TABLE 4 (continued)

\begin{tabular}{|c|c|c|}
\hline & SUBTASK & SOURCE \\
\hline 13. & Check for $\mathrm{N}_{1}>100.1 \%$ & $\mathrm{~N}_{1}$ sensor \\
\hline 14. & $\begin{array}{l}\text { Check } N_{1} \text { for unusual rate of } \\
\text { change }\end{array}$ & $\begin{array}{l}\mathrm{N}_{1} \text { sensor \& } \\
\text { experience }\end{array}$ \\
\hline 15 . & $\begin{array}{l}\text { Compare } \mathrm{N}_{1} \text { value against } \\
\text { operator's estimate }\end{array}$ & $\begin{array}{l}\mathrm{N}_{1} \text { sensor \& } \\
\text { experience }\end{array}$ \\
\hline 16. & Check for $94 \%<\mathrm{N}_{2} \leq 100 \%$ & $\mathrm{~N}_{2}$ sensor \\
\hline 17. & Check for $\mathrm{N}_{2}>100 \%$ & $\mathrm{~N}_{2}$ sensor \\
\hline 18 . & $\begin{array}{l}\text { Check } \mathrm{N}_{2} \text { for unusual rate of } \\
\text { change }\end{array}$ & $\begin{array}{l}\mathrm{N}_{2} \text { sensor \& } \\
\text { experience }\end{array}$ \\
\hline 19. & $\begin{array}{l}\text { Compare } \mathrm{N}_{2} \text { value against } \\
\text { operator's estimate }\end{array}$ & $\begin{array}{l}\mathrm{N}_{2} \text { sensor \& } \\
\text { experience }\end{array}$ \\
\hline 20 . & Check for $535^{\circ}<\mathrm{EGT} \leq 570^{\circ}$ & EGT sensor \\
\hline 21. & Check for EGT > $570^{\circ}$ & EGT sensor \\
\hline 22 . & $\begin{array}{l}\text { Check EGT for unusual rate of } \\
\text { change }\end{array}$ & $\begin{array}{l}\text { EGT sensor \& } \\
\text { experience }\end{array}$ \\
\hline 23 . & $\begin{array}{l}\text { Compare EGT value against } \\
\text { operator's estimate }\end{array}$ & $\begin{array}{l}\text { EGT sensor \& } \\
\text { experience }\end{array}$ \\
\hline 24 . & Check for oil pressure < 35psi & $\begin{array}{l}\text { oil pressure } \\
\text { sensor }\end{array}$ \\
\hline 25 & $\begin{array}{l}\text { Check for } \\
35 \text { psi }<\text { oil pressure < } 40 \text { psi }\end{array}$ & $\begin{array}{l}\text { oil pressure } \\
\text { sensor }\end{array}$ \\
\hline 26. & Check for oil pressure $>55 \mathrm{psi}$ & $\begin{array}{l}\text { oil pressure } \\
\text { sensor }\end{array}$ \\
\hline 27 . & $\begin{array}{l}\text { Check oil pressure for unusual } \\
\text { rate of change }\end{array}$ & $\begin{array}{l}\text { oil pressure } \\
\text { sensor \& } \\
\text { experience }\end{array}$ \\
\hline
\end{tabular}


TABLE 4 (continued)

\begin{tabular}{|c|c|c|}
\hline & SUBTASK & SOURCE \\
\hline 28 & Check for oil temperature $<40^{\circ}$ & $\begin{array}{l}\text { oil temperature } \\
\text { sensor }\end{array}$ \\
\hline 29. & $\begin{array}{l}\text { Check for } \\
120^{\circ}<\text { oil temperature } \leq 157^{\circ}\end{array}$ & $\begin{array}{l}\text { oil temperature } \\
\text { sensor }\end{array}$ \\
\hline 30. & Check for oil temperature $>157^{\circ}$ & $\begin{array}{l}\text { oil temperature } \\
\text { sensor }\end{array}$ \\
\hline 31. & $\begin{array}{l}\text { Check oil temperature for } \\
\text { unusual rate of change }\end{array}$ & $\begin{array}{l}\text { oil temperature } \\
\text { sensor \& } \\
\text { experience }\end{array}$ \\
\hline 32 . & Check for oil quantity $<1$ gal & $\begin{array}{l}\text { oil quantity } \\
\text { sensor }\end{array}$ \\
\hline 33. & $\begin{array}{l}\text { Check oil quantity for unusual } \\
\text { rate of change }\end{array}$ & $\begin{array}{l}\text { oil quantity } \\
\text { sensor \& } \\
\text { experience }\end{array}$ \\
\hline 34 & $\begin{array}{l}\text { Check fuel flow for unusual } \\
\text { rate of change }\end{array}$ & $\begin{array}{l}\text { fuel flow sensor } \\
\text { \& experience }\end{array}$ \\
\hline 35 . & $\begin{array}{l}\text { Compare fuel flow value against } \\
\text { operator's estimate }\end{array}$ & $\begin{array}{l}\text { fuel flow sensor } \\
\& \text { experience }\end{array}$ \\
\hline
\end{tabular}


perform the tasks (Banks, Hunter, and Noviski 1985). The information parameters identified for this example are given in table 5 .

After the information parameters have been identified, they must be described. The description of the information requirements should characterize the information so that they may be directly applied to the picture specification. That is, the properties (e.g., the required range of usage, the number of variables, the number of dimensions, the level of accuracy or precision, the intended use of the information) for each information item must be described during this process. Several techniques have been defined for this characterization process (Danchak 1981; Frey et al. 1984; Banks, Hunter, \& Noviski 1985) with the final product being the same; a comprehensive list of information attributes that describe the information required to perform each task. This information characterization is then used to select the most appropriate picture element to convey this information.

For the example of this study, a representative set of information characteristics is presented in table 6 and the entire set is provided in appendix B. It should be noted that the designer's (or a member of the design team's) expertise in the application area is critical to the design process. At this stage, the knowledge of the application 
TABLE 5

INFORMATION PARAMETERS FOR THE SUBTASKS OF TABLE 4

\begin{tabular}{|c|c|c|c|c|}
\hline PARAMETER & UNIT & $\begin{array}{l}\text { TOTAL } \\
\text { RANGE }\end{array}$ & $\begin{array}{c}\text { CAUTION/WARNING } \\
\text { RANGES }\end{array}$ & $\begin{array}{l}\text { NOMINAL } \\
\text { VALUE }\end{array}$ \\
\hline $\begin{array}{l}\text { Takeoff EPR } \\
\text { setting }\end{array}$ & A psi & $0.8-2.5$ & & $f(p, t)$ \\
\hline EPR & $\Delta p s i$ & $0.8-2.5$ & $\begin{array}{ll}f(p, t) & (1) \\
f(p, t) & (2)\end{array}$ & $f(T, m, p, t)$ \\
\hline $\mathrm{N}_{1}$ & $\%$ rpm & $0-115$ & $\begin{array}{l}94-100.1(5) \\
\mathrm{N}_{1}>100.1(6)\end{array}$ & $f(T, m, p, t)$ \\
\hline $\mathrm{N}_{2}$ & $\% \mathrm{rpm}$ & $0-115$ & $\begin{array}{l}94-100(5) \\
\mathrm{N}_{2}>100(6)\end{array}$ & $f(T, m, p, t)$ \\
\hline EGT & ${ }^{\circ} \mathrm{C}$ & $290-600$ & $\begin{array}{l}535-570(5) \\
\text { EGT >570 (6) }\end{array}$ & $f(T, m, p, t)$ \\
\hline $\begin{array}{l}\text { Fuel } \\
\text { flow }\end{array}$ & $1 \mathrm{~b} / \mathrm{hr}$ & $0-12000$ & & $f(T, m, p, t)$ \\
\hline $\begin{array}{l}\text { Oil } \\
\text { pressure } \\
\text { (OP) }\end{array}$ & psi & $0-100$ & $\begin{array}{l}O P<35(3) \\
35-40(4) \\
O P>55(6)\end{array}$ & 45 \\
\hline $\begin{array}{l}\text { Oil } \\
\text { temperature } \\
\text { (OT) }\end{array}$ & ${ }^{\circ} \mathrm{C}$ & $0-180$ & $\begin{array}{l}\text { OT }<40(3) \\
120-157(5) \\
O T>180(6)\end{array}$ & 80 \\
\hline $\begin{array}{l}\text { oil } \\
\text { quantity }\end{array}$ & gal & $0-5$ & quantity $<1$ (3) & 1.2 \\
\hline $\begin{array}{l}\text { Airspeed/ } \\
\operatorname{mach}(7)\end{array}$ & kts & $\begin{array}{l}0-600 \\
0.5-1\end{array}$ & & \\
\hline Altitude (7) & feet & $0-100000$ & & \\
\hline $\begin{array}{l}\text { Air ( } 7) \\
\text { temperature }\end{array}$ & ${ }^{\circ} \mathrm{C}$ & $-40-40$ & & \\
\hline
\end{tabular}


TABLE 5 (continued)

$\begin{aligned} & \text { KEY - (1): } \text { maximum continuous EPR } \\ &(2): \text { maximum takeoff EPR } \\ &(3): \text { low warning range } \\ &(4): \text { low caution range } \\ &(5): \text { high caution range } \\ &(6): \text { provided by an external instrument } \\ &(7): \begin{array}{l}\text { primarily a function of air pressure, } \\ f(p, t):\end{array} \\ & f(T, m, p, t)=\begin{array}{l}\text { primarily a function of throttle } \\ \text { position, mach, air pressure, and } \\ \text { air temperature }\end{array}\end{aligned}$


TABLE 6

REPRESENTATIVE SET OF INFORMATION CHARACTERISTICS

\begin{tabular}{|c|c|c|c|}
\hline \multicolumn{4}{|l|}{ TASK: set takeoff power } \\
\hline SUBTASK & $\begin{array}{l}\text { Set EPR to } \\
\text { reference }\end{array}$ & $\begin{array}{c}\text { Check for } \\
\text { EPR } \\
\text { decrease }\end{array}$ & $\begin{array}{c}\text { Adjust EPR } \\
\text { at } 60 \mathrm{kts} \\
\text { to } \\
\text { reference }\end{array}$ \\
\hline PARAMETER & $\begin{array}{c}\text { EPR } \\
\text { EPR ref * }\end{array}$ & EPR & $\begin{array}{l}\text { EPR } \\
\text { EPR ref * } \\
\text { airspeed** }\end{array}$ \\
\hline Number of dimensions & 1 & 1 & 1 \\
\hline Number of variables & 2 & 1 & 2 \\
\hline Number of samples & 1 & $2-3$ & 1 \\
\hline Alert/Inform & inform & inform & inform \\
\hline $\begin{array}{l}\text { Response to control } \\
\text { actions }\end{array}$ & yes & no & no \\
\hline Measured/Derived & $\begin{array}{r}\text { measured } \\
\text { derived }\end{array}$ & measured & $\begin{array}{r}\text { measured } \\
\text { derived }\end{array}$ \\
\hline $\begin{array}{l}\text { Qualitative/ } \\
\text { Quantitative }\end{array}$ & $\begin{array}{l}\text { both } \\
\text { quan }\end{array}$ & quan & $\begin{array}{l}\text { both } \\
\text { quan }\end{array}$ \\
\hline Range (Units) & $\begin{array}{l}0.8-2.5 \\
\quad(\Delta \text { psi) } \\
1.7-2.5 \\
(4 \text { psi) }\end{array}$ & $\begin{array}{c}0.8-2.5 \\
(\Delta \text { psi) }\end{array}$ & $\begin{array}{c}0.8-2.5 \\
(4 \text { psi) } \\
1.7-2.5 \\
(4 \text { psi) }\end{array}$ \\
\hline Required accuracy & $\begin{array}{l}0.01 \\
0.01\end{array}$ & 0.03 & $\begin{array}{l}0.01 \\
0.01\end{array}$ \\
\hline
\end{tabular}

* computed by the user.

the reference is lower than the maximum limit.

** external source. 
TABLE 6 (continued)

FUNCTION: ESTABLISH TAKEOFF POWER

TASK: Set takeoff power

\begin{tabular}{|l|c|c|c|}
\hline SUBTASK & $\begin{array}{c}\text { Set EPR to } \\
\text { reference }\end{array}$ & $\begin{array}{c}\text { Check for } \\
\text { EPR } \\
\text { decrease }\end{array}$ & $\begin{array}{c}\text { Adjust EPR } \\
\text { at } 60 \text { kts } \\
\text { to } \\
\text { reference * }\end{array}$ \\
\hline PARAMETER & $\begin{array}{c}\text { EPR } \\
\text { EPR ref * }\end{array}$ & EPR & $\begin{array}{c}\text { EPR } \\
\text { EPR ref * } \\
\text { airspeed** }\end{array}$ \\
\hline Relative/Absolute & $\begin{array}{l}\text { relative } \\
\text { relative }\end{array}$ & absolute & $\begin{array}{l}\text { relative } \\
\text { relative }\end{array}$ \\
\hline Relative importance & medium & low & high \\
\hline
\end{tabular}

* computed by the user.

the reference is lower than the maximum limit. ** external source. 
area is essential in characterizing the information into a form that is appropriate to the user's task.

At this point, the analysis phase for the traditional design process has been completed. In doing so, the system objectives have been defined. Following the objectives definition, the functional decomposition, detailing what needs to be done to fulfill the system objectives, was performed. The task analysis, defining how (what action needs to be done) to provide the functions, was then completed. Finally, the information requirements were then listed, identifying and characterizing all of the information that the operator will need to perform the tasks. This list of information requirements may now be directly applied to the next phase of the design process, the synthesis phase. 
CHAPTER III

TRADITIONAL DISPLAY DEFINITION

The analysis phase of the design process has produced the information requirements list, identifying and characterizing all of the information that is needed by the user or operator to perform the necessary tasks. This list is now used as the primary specification for the synthesis phase. In this phase of the design process, the optimum display format, the picture, is defined. This picture is then transformed into an achievable display specification based on implementation constraints identified during this process.

The development of the picture begins with the choice of appropriate picture elements for the information requirements defined during the analysis phase. This picture element choice will be based on the information characteristics and the intended use of the information. While numerous guidelines are available to assist in this selection process (Engel \& Granda 1975; Danchak 1981; MILSTD-1472C 1981; NUREG-0835 1981; Banks et al. 1983; Frey et al. 1984; Banks, Hunter, \& Noviski 1985; Gilmore 1985; DODHDBK-763 1987), some expertise is usually required in this selection. It is not unusual that none of the picture element types will perfectly match the needs specified in the information requirements. An example of this process may 
be provided by selecting picture elements for the three information requirements of table 6 . For the subtasks set EPR to reference and adjust EPR at $60 \mathrm{kts}$ to reference, both conventional analog and trend plot picture types would be acceptable. For the subtask check for EPR decrease, both band chart and trend plot picture types would be acceptable.

After the initial picture elements have been defined, they are grouped together to form the initial picture. This grouping may be based on functional relationships, frequency of use, criticality of information, existing convention, or sequence of use (Smith \& Aucella 1983; Gilmore 1985). Additionally, consideration should be given to consistency and display density. It should be noted that this is probably one of the more subjective parts of the design process.

Following the construction of the initial picture, a mockup or prototype of the picture format should be created. This prototype is then evaluated with respect to the information requirements and human design considerations. Any deficiencies in the picture should be corrected at this time.

The next significant portion of this phase of the design is the identification of the implementation constraints. These constraints should include the following: revision of 
existing operating procedures or practices; limited availability of display hardware; physical display size; compatibility and relationships with existing displays; signal or sensor availability; and physical compatibility with existing equipment. For the example of this study, the most important constraints are the number of display devices and the physical size of the available displays. For this example, we are limited to two displays, each of which are approximately 8 inches diagonal.

At this point in the design, contention usually exists between these constraints and the information requirements. The defined picture must now be modified to conform to the identified constraints. Compromises are frequently necessary for either the selection of a picture element or the organization of the picture as a whole. For this example, it is noted that neither of the picture element types selected for the subtask check for EPR decrease is suitable for this application. Both of the selected picture elements, band chart and trend plot, required excessive display area to implement. Additionally, assuming that EPR information will be provided for the subtasks set EPR to reference and adjust EPR at $60 \mathrm{kts}$ to reference using a conventional analog display element, then this element may also be used for the subtask check for EPR decrease. A major aspect in this compromise was that the subtask check for EPR decrease is an information requirement of low importance. 
This sequence of picture development and evaluation is repeated until all constraint conflicts are resolved. The final product of this iterative process is a display specification ready for prototyping and prototype evaluation.

Instead of continuing the development of an entire display format using the traditional design approach, a modern, state-of-the-art engine display format will be substituted at this point. The format chosen for this substitution was modelled after the Engine Indication and Crew Alerting system (EICAS) in the Boeing $757 / 767$ aircraft (Ropelewski 1982; Boeing Commercial Airplane Company 1983; Broderson 1984). This display was based on contemporary design practices and has proven to be superior to the conventional electromechanical instruments that it replaced (Parke 1988). This display satisfies all the information requirements within the identified constraints.

A brief examination of this display will begin with a description of the display elements. The most significant information requirements for this display involve data relating to EPR. On a cursory inspection of figure 8 , the display element for EPR, it would appear that little more than EPR sensor data were being presented via a conventional analog display element, a circular dial. This display element is, in fact, a combination of several display 


\section{FIGURE 8}

\section{DISPLAY ELEMENT FOR EPR}

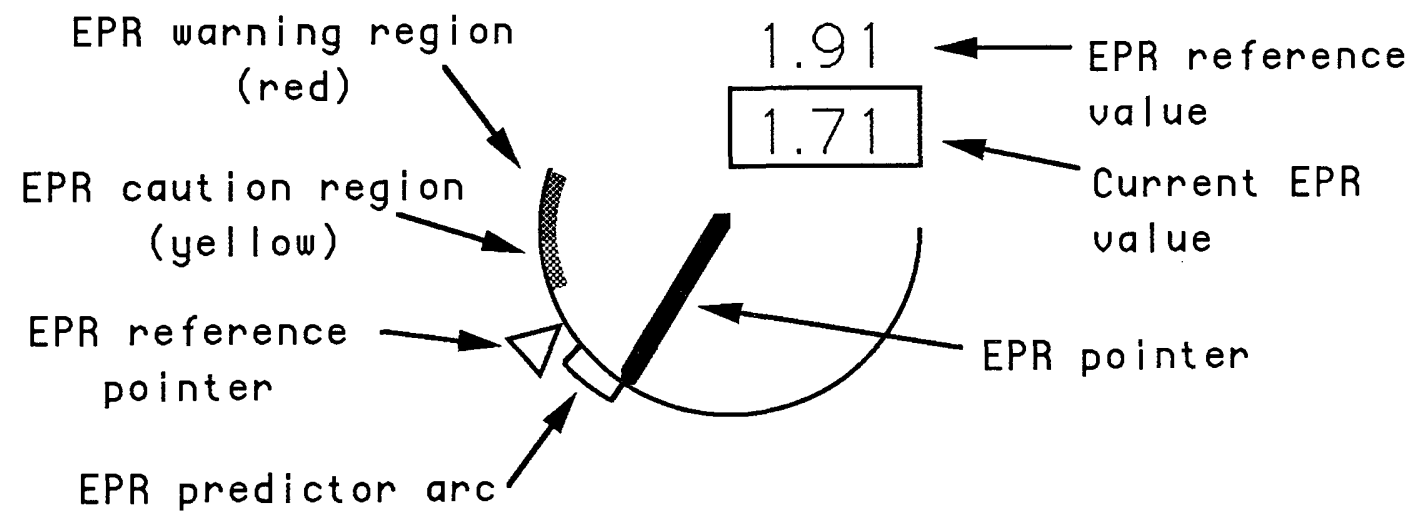


elements and possesses some unusual features.

The first information parameter to note is the EPR reference, which is presented both as a digital value and as a reference pointer on the dial circumference. Similarly, the actual EPR value is presented digitally as well as by the major pointer on the dial. The digital presentation will provide the user with a precise indication of the EPR value while the dial and pointer will provide the user a means of estimating and predicting the EPR value during dynamic conditions. Since a precise EPR value is provided via the digital element, scale markings were not deemed necessary on the EPR dial. This aids in visually decluttering the display.

In addition to the movement of the EPR pointer, an alternative means for estimating EPR is provided by the EPR predictor arc. The arc appears on the display whenever the actual EPR value and the commanded EPR value, as sensed by the fuel control of the engine, are not the same. The arc will span across a region beginning at the current EPR value, at the end of the EPR pointer, and terminate at a position relative to an EPR value that the fuel control is attempting to obtain. (This is not the same value as the EPR reference.) It should again be noted that the EPR is the primary indicator of engine power and that numerous and large changes of the EPR are typical during normal flight 
operations. Additionally, a lag or delay of 5 to 10 seconds in engine response to a pilot control input is not unusual when going from an idle to a high power condition. Therefore, the ability to accurately estimate or predict EPR will reduce the required attention by the user during power changes.

Similar to the EPR predictor, the EPR warning limit is a continuously computed maximum limit based on current ambient conditions. This limit is shown by a red range-marking on the EPR dial. This limit is the takeoff EPR limit or the maximum-continuous EPR limit if the takeoff and maximumcontinuous limits are the same. The range marking spans the region from the warning limit to an EPR value of 2.5 . The EPR caution limit, shown by a yellow range-marking on the EPR dial, is a computed maximum-continuous EPR limit based on current ambient conditions. If the takeoff and maximumcontinuous EPR limits are the same, no caution limit is shown. The range marking spans the region from the caution limit to the warning limit. The computation of both of these limits by the system alleviates the pilot from this duty.

An additional cue is provided to the pilot whenever the EPR is within either the warning or caution region. The digital EPR value is usually presented in a white color. During operation in the caution region, the digital readout will be displayed in yellow; during operation in the warning 
region, the digital readout will be displayed in red.

The display element for EPR, then, provides EPR reference information through a digital display element, providing an exact display of the EPR reference, and a reference pointer, which is used in conjunction with the actual EPR pointer. EPR trend information is provided implicitly by the motion of the actual EPR pointer and explicitly by an EPR predictor symbol. Precise EPR information is provided by a digital display element which may be used with the digital element for EPR reference to determine if the engine power is set correctly. Operating ranges are dynamically provided. Alert cuing is provided by color coding the digital element for actual EPR. The total integration of these features yield a fairly sophisticated and easy to use display of EPR information.

The dial portion of the display elements for $\mathrm{N}_{1}, \mathrm{~N}_{2}, \mathrm{EGT}$, and fuel flow are similar to EPR, with the ranges appropriate for the particular parameter. As with EPR, a digital display element for the actual value of the parameter is provided. Warning and caution range markings, corresponding to the ranges identified in the information requirements, are provided for $\mathrm{N}_{1}, \mathrm{~N}_{2}$, and EGT. Like the EPR display element, the color of the digital element will correspond to the operating region of the parameter. An example illustration, using the $\mathrm{N}_{1}$ parameter, is given in 
figure 9 .

Because of their generally stable characteristics, the oil system parameters are presented in a slightly different manner. Each of these parameters is presented by a combination of a linear scale with a moving pointer and a digital display element. The linear scale was partitioned into the appropriate normal, caution, and warning regions for the parameter. The presentation of this information using linear scale display elements reduced the physical display area compared with that of a circular dial approach. This was a reasonable choice due to the stable nature of these parameters. The digital element was mechanized in a manner similar to the circular dial display elements. An example illustration, using the oil pressure parameter, is given in figure 10

The individual display elements are grouped or arranged primarily by criticality and then by frequency of use. The arrangement is in a top to bottom, left to right order. Additionally, since the general application is for a two engine aircraft, two sets of display elements must be factored into this design. The two major means for grouping this type of application is either as a unit or by function. The unit grouping places all the display elements for each engine by themselves. A functional grouping, which was used for this example, places the display elements together by 
FIGURE 9

DISPLAY ELEMENT FOR $\mathrm{N}_{1}$

$N_{1}$ warning region (red)

$\mathrm{N}_{1}$ caution region (yellow)
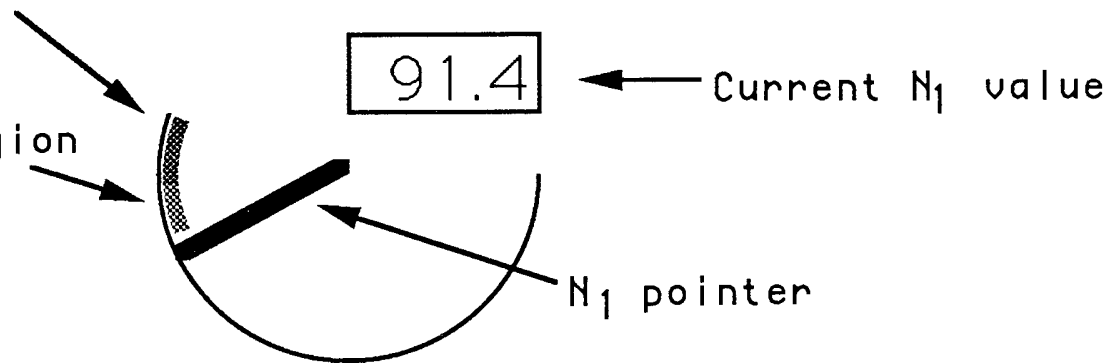
FIGURE 10

\section{DISPLAY ELEMENT FOR OIL PRESSURE}

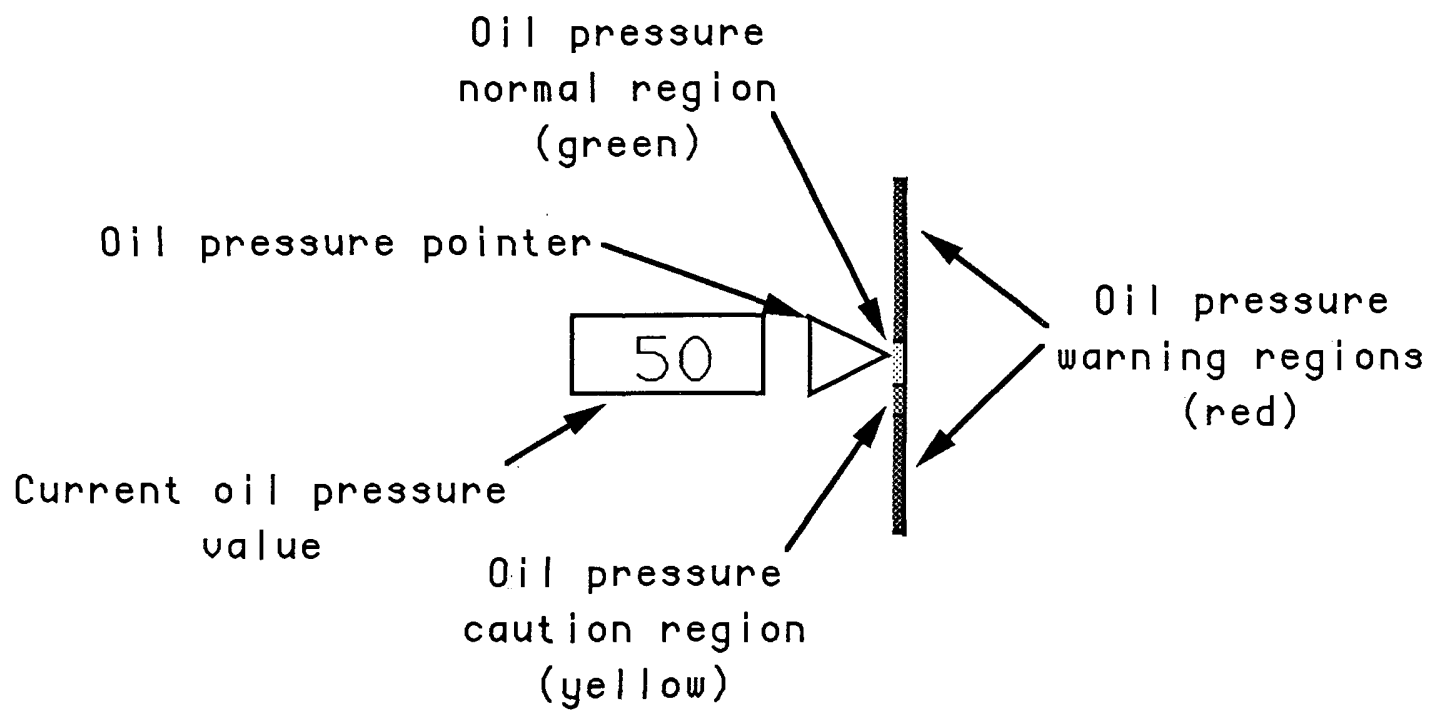


function. For example, the EPR display elements for both engines are grouped together; the EPR element for the left engine is placed physically to the left of the EPR element for the right engine. An advantage of this arrangement is that because both engines are typically set to produce equivalent amounts of power, similar parameters should be operating with relatively similar values with respect to one another. By being able to compare similar parameters, some of the uncertainty that the pilot may experience in determining proper component operation may be reduced.

The final product of this design analysis is shown in figures 11 and 12. The display format is physically presented on two CRT displays in a left to right arrangement. This particular left to right arrangement was a constraint imposed by the cockpit layout that was used in the experimental evaluation phase of this study. The original EICAS arrangement was slightly modified to conform to this layout. The modification involved shifting the entire left display format toward the right side of the CRT. This shifting provided for a reduced visual scan area. The actual EICAS implementation was two CRT displays in a top to bottom arrangement. 
FIGURE 11

TRADITIONAL DISPLAY, LEFT SIDE

The following figure is approximately full size. To be viewed properly, the figure must be rotated $90^{\circ}$ in a clockwise direction. 

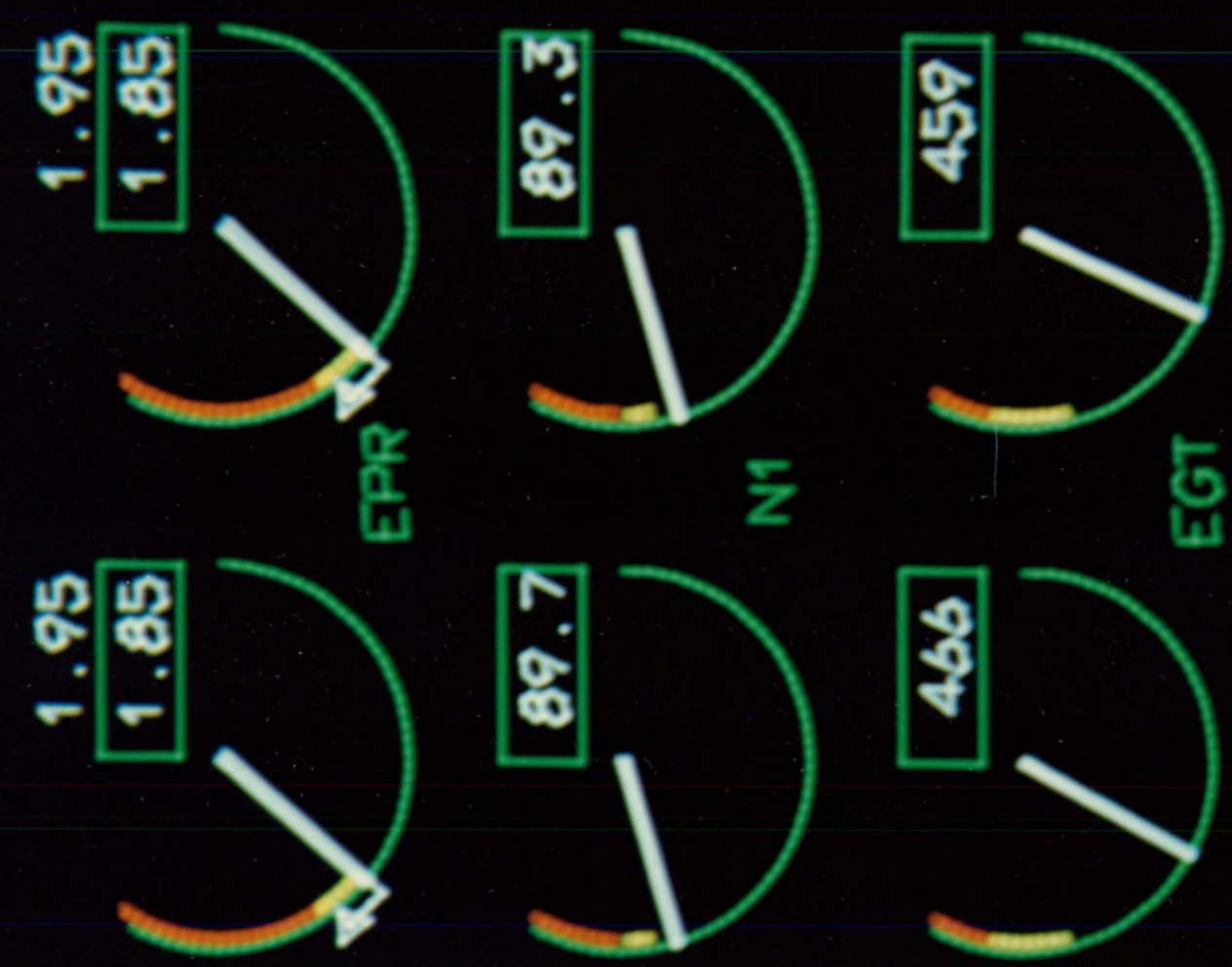
FIGURE 12

\section{TRADITIONAL DISPLAY, RIGHT SIDE}

The following figure is approximately full size. To be viewed properly, the figure must be rotated $90^{\circ}$ in a clockwise direction. 

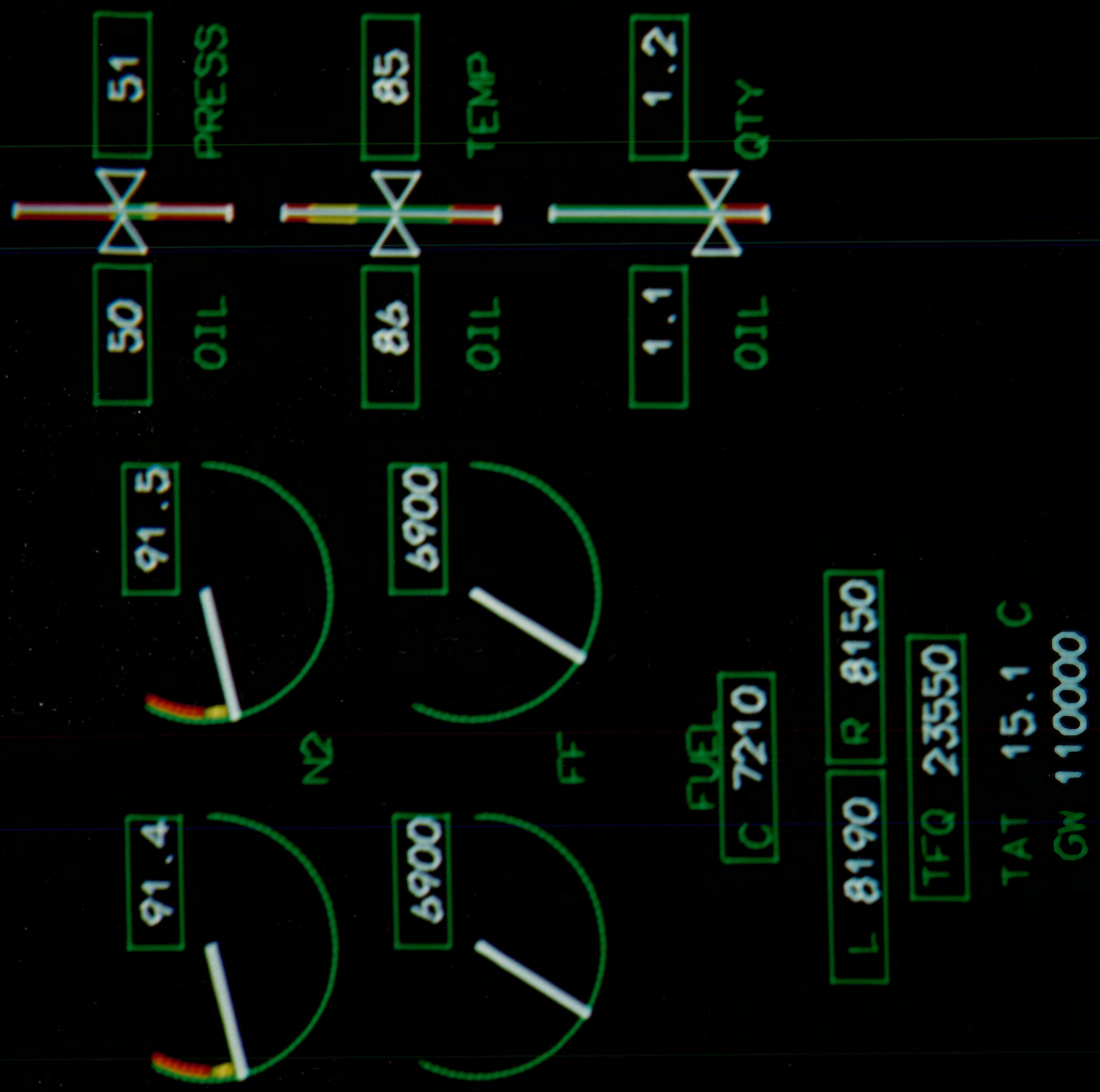
CHAPTER IV

ALTERNATIVE DESIGN CONCEPT

The intent of this thesis was to define and assess a display design concept oriented toward providing information at a level that is more relevant to the user's needs than traditionally designed displays. The underlying premise to this concept is that the computational capabilities of modern, graphics-based display systems should be considered in the display design process. By doing so, information may be provided in a form that is more directly related to the user's task, thereby reducing the cognitive workload associated with the use of displayed information. This provision may require that the raw data supplied by the system sensors to be processed into a more appropriate representation and presented in a manner that permits easier assimilation. That is, by exploiting the capabilities of these display systems, information may be obtained from previously stored data or synthesized from existing data and conveyed through forms that allow easy comprehension. The major focus of this design concept, then, deals with providing information that is appropriate to the task of the user; a task-oriented display design concept.

The primary concept proposed in this thesis begins in the traditional design process at the task analysis phase. In the traditional design, the task analysis and decomposition 
are repeated until all tasks can be determined by one of the following: the need to read some particular instrumentation (sensor); the need to use a checklist; or the need to know some particular fact, either from training or experience. The key point to the proposed concept is that the user's task should only be decomposed to a level where relevant information, information fitted for a particular task, can be identified. This relevant information, if not directly provided by the system, should be provided by synthesis from the underlying data of the system. A complementary part of this concept deals with providing information in a form that is appropriate to the user's task. Often, display elements chosen to support a particular task are less than optimum, from the user's perspective, for that task. Frequently, this less than optimum choice is dictated by the characteristics of the available data. If a better display element choice is possible, then data should again be processed or synthesized to support this implementation. An illustration of the relationship of these phases is given in figure 13 .

From the functional analysis for this example, the two primary functions defined were for the user to control engine power and to monitor engine components/subsystems (figure 2). The first step in this modification to the design process is to understand the actual task that the user needs to perform. For the engine of this example, EPR is the primary information parameter for the control task. 


\section{FIGURE 13}

\section{THE TASK-ORIENTED DISPLAY DESIGN PROCESS}

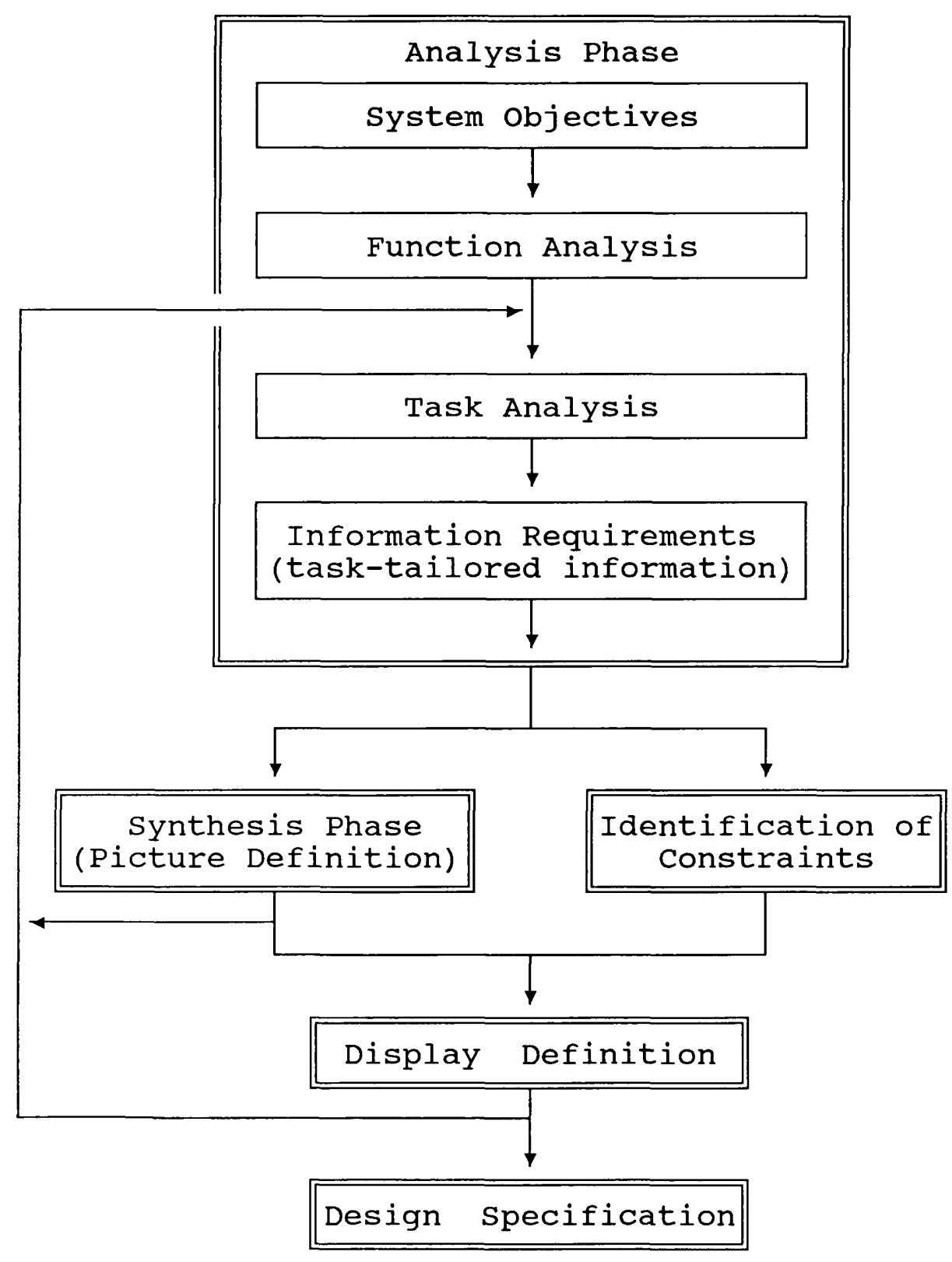


Also, $\mathrm{N}_{1}, \mathrm{~N}_{2}$, and EGT parameters must be used during high power operations to prevent over-limit conditions. The point, however, is that the user should not be controlling EPR, $N_{1}, N_{2}$, or EGT. The task requires the control of engine power (thrust), so the user should be controlling engine thrust (Way et al. 1987). Additionally, the monitoring requirements for $\mathrm{N}_{1}, \mathrm{~N}_{2}$, and EGT over-limit conditions should be integrated into the design for the control display element.

If the function establish takeoff power is examined, three primary display-related tasks are identified from the traditional design process, exclusive of the monitoring task (including the $\mathrm{N}_{1}, \mathrm{~N}_{2}$, and EGT cross-check subtasks which were identified in table 2 and are shown in figure 3). From these three tasks, a total of eight subtasks were identified. The modification of the tasks of this function toward a task-oriented design was founded on the following:

1. Base all power-related information on thrust, much like the EPR-based method in the traditional design.

2. Provide a thrust prediction, independent of the engine. Like the traditional display described previously, the ability to accurately estimate or predict power will reduce the attention required by the user during power changes. However, by providing 
prediction independent of the actual engine, a valid comparison of the actual thrust with an "ideal" thrust may be made during steady-state conditions. This capability should reduce the user's uncertainty regarding the performance of the system with respect to power.

3. Integrate all power related limitations. Warning limitations should be designed such that under normal operations, no other engine parameter $\left(\mathrm{N}_{1}, \mathrm{~N}_{2}\right.$, or $\left.\mathrm{EGT}\right)$ will be within a warning area unless the actual thrust value is in the warning area. An equivalent approach would be taken for the caution limitations.

4. Provide any power related information the user would normally obtain from charts or tables.

Key phrases, found in the original task lists, that may aid in identifying areas where information tailoring may be appropriate are: "based on experience," "computed by the operator," "estimated," and "based on prior knowledge." Areas identified by these phrases typically involve information requirements that could be provided by the system. In doing so, the user would be provided with accurate and timely information for performing a task, thereby reducing operator cognitive workload and uncertainty. 
Using these four guidelines, the first point to note is that the task find maximum power (EPR) available is no longer required. This task is now performed by the system. From these guidelines, new information requirements for the task set takeoff power were produced. These information requirements are shown in table 7 and may be compared with the traditional requirements shown in table 6. From this comparison, it may appear that only a substitution of thrust for EPR has taken place. Even if this were the case, thrust should be a more meaningful parameter to the user than EPR (Way et al. 1987). In actuality, however, the user is now provided with the information necessary to determine engine power limitations, based on all pertinent parameters, and a means for assessing power performance.

A similar approach may be taken with the monitoring function check for abnormal conditions. The modification of the tasks of this function toward a task-oriented design was founded on the following:

1. Provide an estimate of the operating state of each parameter. This idea is similar to the thrust predictor discussed previously. By providing an estimate independent of the actual engine, a valid comparison of the actual parameter with an "ideal" parameter may be made. Like the thrust predictor, this capability should reduce the user's uncertainty 
TABLE 7

MODIFIED SET OF INFORMATION CHARACTERISTICS

\begin{tabular}{|c|c|c|c|}
\hline \multicolumn{4}{|c|}{ FUNCTION: ESTABLISH TAKEOFF POWER } \\
\hline SUBTASK & $\begin{array}{c}\text { Set thrust } \\
\text { predictor } \\
\text { to } \\
\text { reference }\end{array}$ & $\begin{array}{l}\text { Compare } \\
\text { thrust } \\
\text { with } \\
\text { predictor }\end{array}$ & $\begin{array}{l}\text { Adjust } \\
\text { predictor } \\
\text { at } 60 \mathrm{kts} \text { to } \\
\text { reference }\end{array}$ \\
\hline PARAMETER & $\begin{array}{l}\text { predictor } \\
\text { reference * }\end{array}$ & $\begin{array}{l}\text { thrust } \\
\text { predictor }\end{array}$ & $\begin{array}{l}\text { predictor } \\
\text { reference * } \\
\text { airspeed * }\end{array}$ \\
\hline Number of dimensions & 1 & 1 & 1 \\
\hline Number of variables & 2 & 2 & 2 \\
\hline Number of samples & 1 & 1 & 1 \\
\hline Alert/Inform & inform & inform & inform \\
\hline $\begin{array}{l}\text { Response to control } \\
\text { actions }\end{array}$ & yes & no & no \\
\hline Measured/Derived & $\begin{array}{l}\text { derived } \\
\text { derived }\end{array}$ & $\begin{array}{l}\text { derived } \\
\text { derived }\end{array}$ & $\begin{array}{l}\text { derived } \\
\text { derived }\end{array}$ \\
\hline $\begin{array}{l}\text { Qualitative/ } \\
\text { Quantitative }\end{array}$ & $\begin{array}{l}\text { both } \\
\text { quan }\end{array}$ & $\begin{array}{l}\text { both } \\
\text { both }\end{array}$ & $\begin{array}{l}\text { both } \\
\text { quan }\end{array}$ \\
\hline Range (Units) & $\begin{array}{c}-1.5 \mathrm{k}-15 \mathrm{k} \\
(1 \mathrm{bs}) \\
8 \mathrm{k}-15 \mathrm{k} \\
(1 \mathrm{bs})\end{array}$ & $\begin{array}{c}-1.5 \mathrm{k}-15 \mathrm{k} \\
(1 \mathrm{bs}) \\
-1.5 \mathrm{k}-15 \mathrm{k} \\
(1 \mathrm{bs})\end{array}$ & $\begin{array}{c}-1.5 \mathrm{k}-15 \mathrm{k} \\
(1 \mathrm{bs}) \\
8 \mathrm{k}-15 \mathrm{k} \\
(1 \mathrm{bs})\end{array}$ \\
\hline Required accuracy & $\begin{array}{l}300 \\
300\end{array}$ & $\begin{array}{l}400 \\
400\end{array}$ & $\begin{array}{l}300 \\
300\end{array}$ \\
\hline
\end{tabular}

* computed by the system.

** external source. 
TABLE 7 (continued)

\begin{tabular}{|l|l|l|l|}
\hline \multicolumn{2}{|l|}{ FUNCTION: ESTABLISH TAKEOFF POWER } \\
\hline TASK: Set takeoff power & $\begin{array}{c}\text { Set thrust } \\
\text { predictor } \\
\text { to } \\
\text { reference }\end{array}$ & $\begin{array}{c}\text { Compare } \\
\text { thrust } \\
\text { with } \\
\text { predictor }\end{array}$ & $\begin{array}{c}\text { Adjust } \\
\text { predictor } \\
\text { 60kts to } \\
\text { reference }\end{array}$ \\
\hline PARAMETER & $\begin{array}{c}\text { predictor } \\
\text { reference } \star\end{array}$ & $\begin{array}{c}\text { thrust } \\
\text { predictor }\end{array}$ & $\begin{array}{c}\text { predictor } \\
\text { reference } \\
\text { airspeed** }\end{array}$ \\
\hline Relative/Absolute & $\begin{array}{c}\text { relative } \\
\text { relative }\end{array}$ & $\begin{array}{c}\text { relative } \\
\text { relative }\end{array}$ & $\begin{array}{c}\text { relative } \\
\text { relative }\end{array}$ \\
\hline Relative importance & medium & medium & high \\
\hline
\end{tabular}

* computed by the system.

** external source. 
regarding the performance of each parameter in the system .

2. Integrate all related limitations. For this example, this requirement is generally fulfilled by the limitations provided for in the thrust limitations.

3. Provide any monitoring or system state information the user would normally obtain from charts or tables.

Using these three guidelines, the task to determine if a parameter value is appropriate for the conditions may now become a simpler task; to compare the actual parameter value with the estimated value. It is also of interest that the task check for an unusual rate of change of a parameter is no longer required. From this and the previous example, it can be seen that the tasks resulting from information tailoring are either simpler or fewer in number than those tasks produced from the traditional design process.

At this point in a full design, all of the tasks would be reevaluated to determine if modification is appropriate. It should also be noted at this time that not all tasks may benefit from this design approach. For example, a status indicator, driven by raw sensor data, may be the most appropriate representation of information for a particular task. 
The second half of this task-oriented concept deals with providing information in a form that is more appropriate to the user's task. Often, less than ideal information forms (picture or display elements) are dictated by the characteristics of the available data. An alternative display element may be more appropriate, relative to the user's task (how the information is to be used), but may not be a viable choice because of the characteristics of the data. The concept proposed for this part of the design process is to determine if the data can be manipulated to match the requirements of this more appropriate display element.

At the start of the synthesis process, picture elements are again selected. The emphasis during this selection will be on choosing picture elements that best support the user's task, not the elements that best fit the data characteristics. (At this point, the designer's expertise in the application area is again critical to the design.) If a candidate picture element is selected that is not supported by the data characteristics, the process goes back to the information requirements to determine if the data may be manipulated to support the picture element selection (figure 13). It should be noted that this selection may affect the task definition (the level in the task decomposition chain that the lowest subtask is defined). That is, a picture element may provide the capability to present information at 
a higher, more relevant level in the task decomposition chain, much in the manner of the relevant information concept discussed previously. In this respect, the process is bottom-up, with the information form dictating the information characteristics as well as affecting the relative level of the task in the task decomposition chain. (See the task check for high or low condition in appendix D for an example of a task modification.)

For this example, it is assumed that the initial picture elements chosen are comparable to those of the traditional design. As the identified constraints are factored into the design, the defined picture must now, as in the traditional design, be modified to conform to the identified constraints. At this point, however, the process deviates from the traditional approach. The display elements are now selected, as with the picture elements, with the primary emphasis on supporting the user's task and little emphasis on the information characteristics.

Beginning the display definition phase, the first picture elements to reselect or modify will be those associated with the monitoring task. These elements $\left(N_{1}, N_{2}, E G T\right.$, fuel flow, oil pressure, oil temperature, and oil quantity) were chosen to be considered first because they comprise the majority of the picture. It should be recalled that although individual elements may be of an optimum design, the effect of the 
integrated display may be more important than the effect of any individual element. Therefore, a large design payoff may come from a concerted optimization of a large number of display elements.

Examining the monitoring task as a whole, the selected display elements should aid the user in the rapid detection of existing failures and support the user in predicting potential problems. To provide a rapid detection capability, status (binary) indicators are typically recommended. Status indicators, however, are not suitable for the prediction requirement. What is really needed for this task is a display element or set of display elements that provide quantitative information in a form that may be cognitively processed in a qualitative manner. That is, the most appropriate form for this task may be some display element or elements that provide quantitative information but are presented in a manner that takes advantage of the human's pattern recognition capabilities. By examining the existing literature for various graphical means of presenting multivariate data (Jacob, Egeth, \& Bevan 1976; Jacob 1978; Danchak 1981; Myers 1981; Mahaffey, Horst, \& Munson 1986; Munson \& Horst 1986), several likely display elements were found, the most promising being the column deviation graph. (An example of this display element is provided in figure 14.) 
FIGURE 14

AN EXAMPLE OF A COLUMN DEVIATION GRAPH

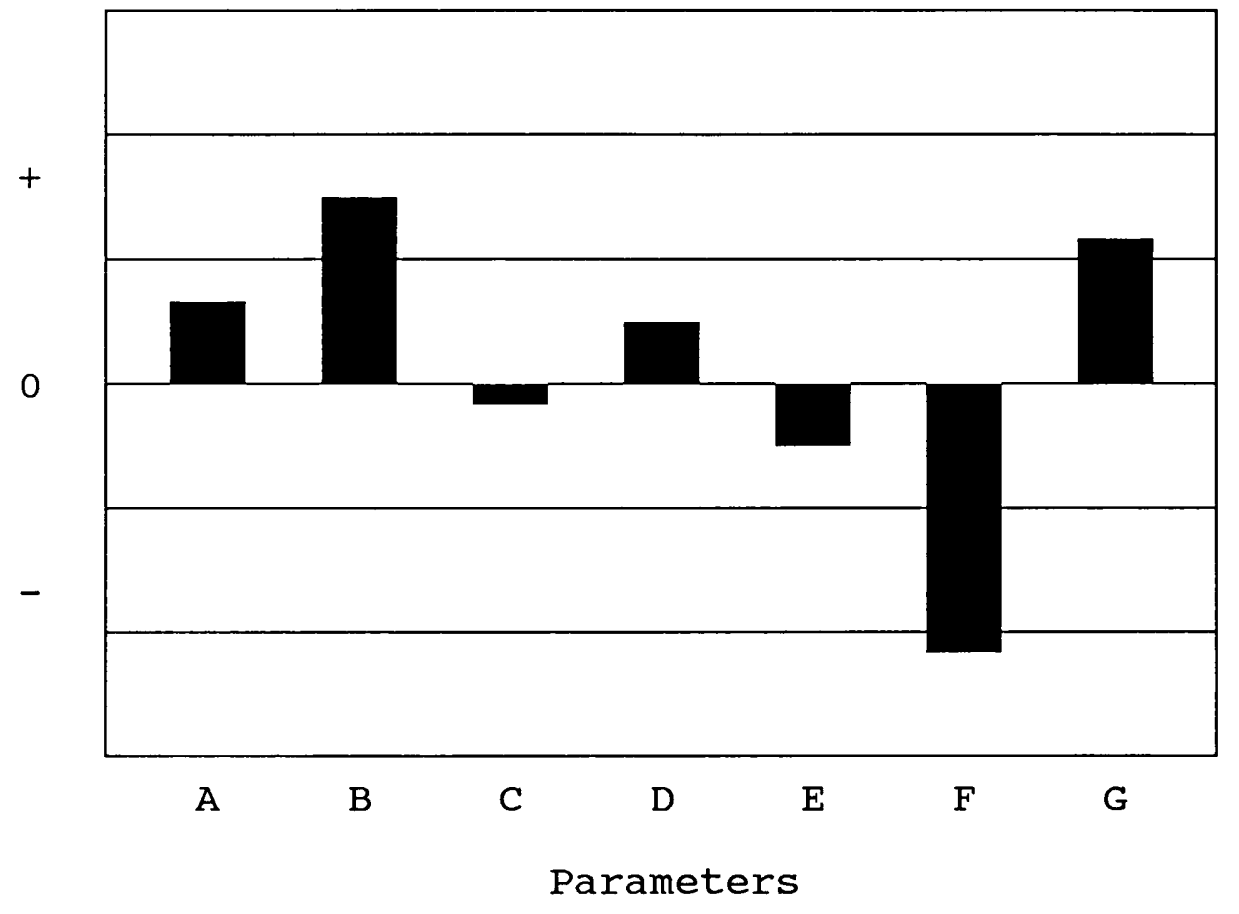


For several reasons, the column deviation graph appears to be an advantageous display element for the monitoring task. First and foremost, this type of display element allows for holistic processing (pattern recognition) by the human. That is, the reaction time for the detection of abnormal system status does not increase as the number of parameters is increased (Mahaffey, Horst, \& Munson 1986). secondly, the general form of presentation for each parameter is an analog column. Thus quantitative data, and therefore predictive capabilities, are provided. Finally, the value that the deviation is based on may be the estimated value (from the first part of this design process) for that parameter, thereby merging the form of the information with the content.

While the column deviation graph may seem to be an ideal presentation form for this monitoring task, it should be noted that this display element requires unidimensional data (single dimension, e.g., temperature, pressure, or time) (Banks, Hunter, \& Noviski 1985). Going back to the information requirements (figure 13), it was found that this display element could be supported by normalizing each parameter with its maximum estimated value (or range). Upon further examination, it was found that merging the physical limitations of each parameter (from table 1), as the parameter approached the limit, with the deviation values, provided an even more meaningful parameter than either the 
deviation value or the limitation. This implementation will be discussed in a subsequent chapter. Thus the information characteristics are modified to fit the information form (the display element).

A partial example of the final form for the monitoring element is shown in figure 15. In this figure, it can be seen that the deviation column graph was equally partitioned into upper and lower regions. These regions were themselves equally broken into normal, caution, and warning regions. The normal region was the closest to the vertical center of the graph and the warning region was the farthest from the center. As an additional cue, each column was color-coded to the associated value of the column (green, yellow, and red for the normal, caution, and warning regions respectively). This monitoring display element also included two features from the traditional design. First, a digital presentation of the actual value of each parameter is provided. Second, these digital display elements were color-coded relative to the associated column.

The other major display element to consider is the display element for the control task. This element is based on the thrust parameter. Like the traditional design, the element chosen to portray thrust information is an analog display element. Also like the traditional design, this selection was based on maintaining consistency between 
FIGURE 15

AN EXAMPLE OF THE MONITORING DISPLAY ELEMENT

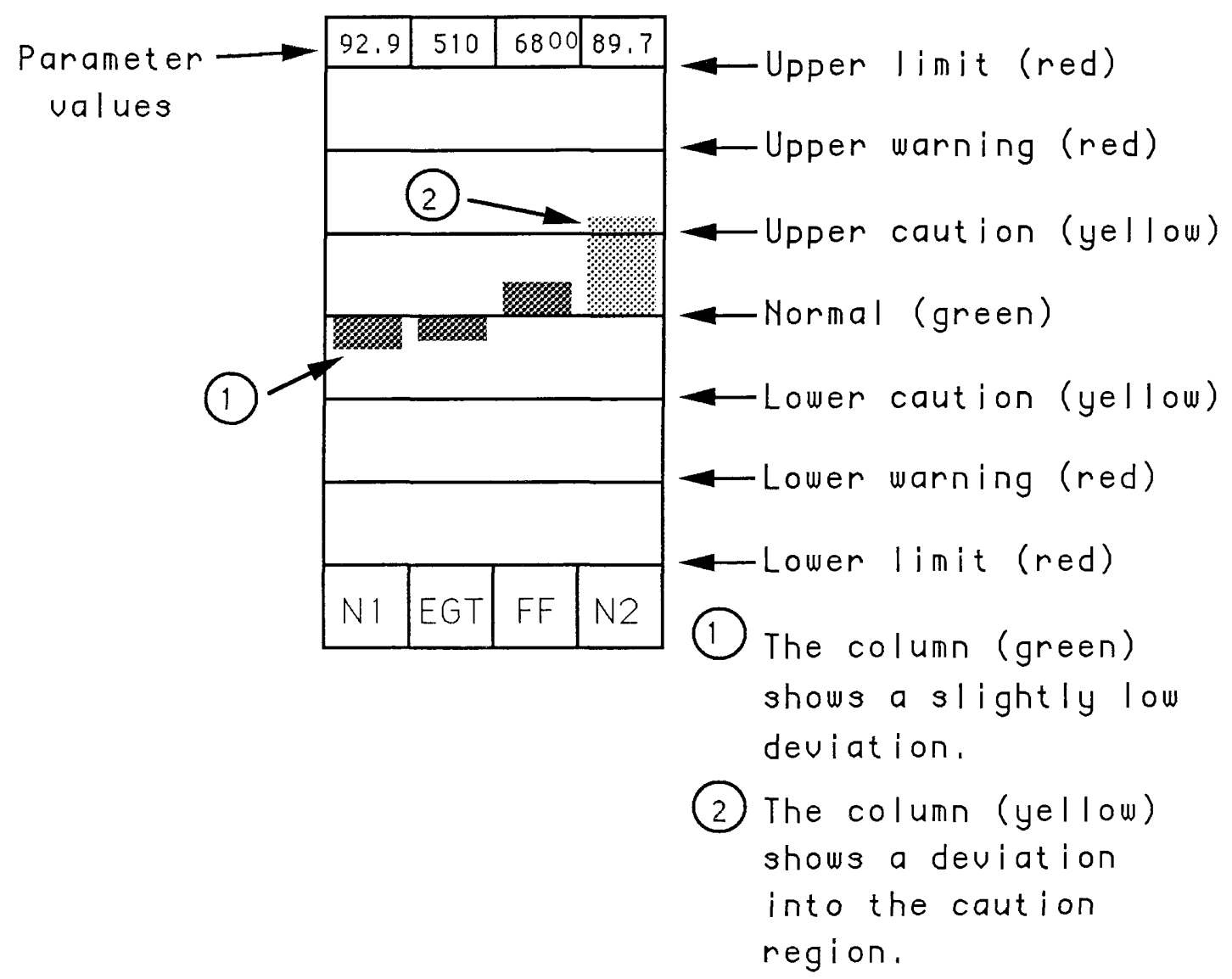


display elements. The element chosen was a column indicator. Both the thrust parameter and the predicted thrust parameter were portrayed in this manner. Additionally, the thrust column was color-coded relative to its operating region (green, yellow, and red for the normal, caution, and warning regions respectively), with the maximum region always beginning at the maximum available thrust value.

Because a fixed scale length was desired, between minimum thrust and maximum thrust, the parameters for this display element were normalized (somewhat like the parameters for the monitoring task). By fixing the scale length, the user then has a fixed, physical point on the display relative to the maximum thrust value. An example of this display element is given in figure 16 .

It should again be noted that an interesting relationship existed between the control and monitoring display elements. The thrust caution limit was based not only the maximum continuous limit from the EPR, but also on the $\mathrm{N}_{1}, \mathrm{~N}_{2}$, and EGT caution limits. Because of this, no other engine parameter $\left(\mathrm{N}_{1}, \mathrm{~N}_{2}\right.$, or $\left.\mathrm{EGT}\right)$ should be within a caution area due to high engine power unless the thrust value is in the caution area. A similar relationship existed for the warning limits.

These two primary display elements were then grouped, as 
AN EXAMPLE OF THE DISPLAY ELEMENT FOR CONTROL

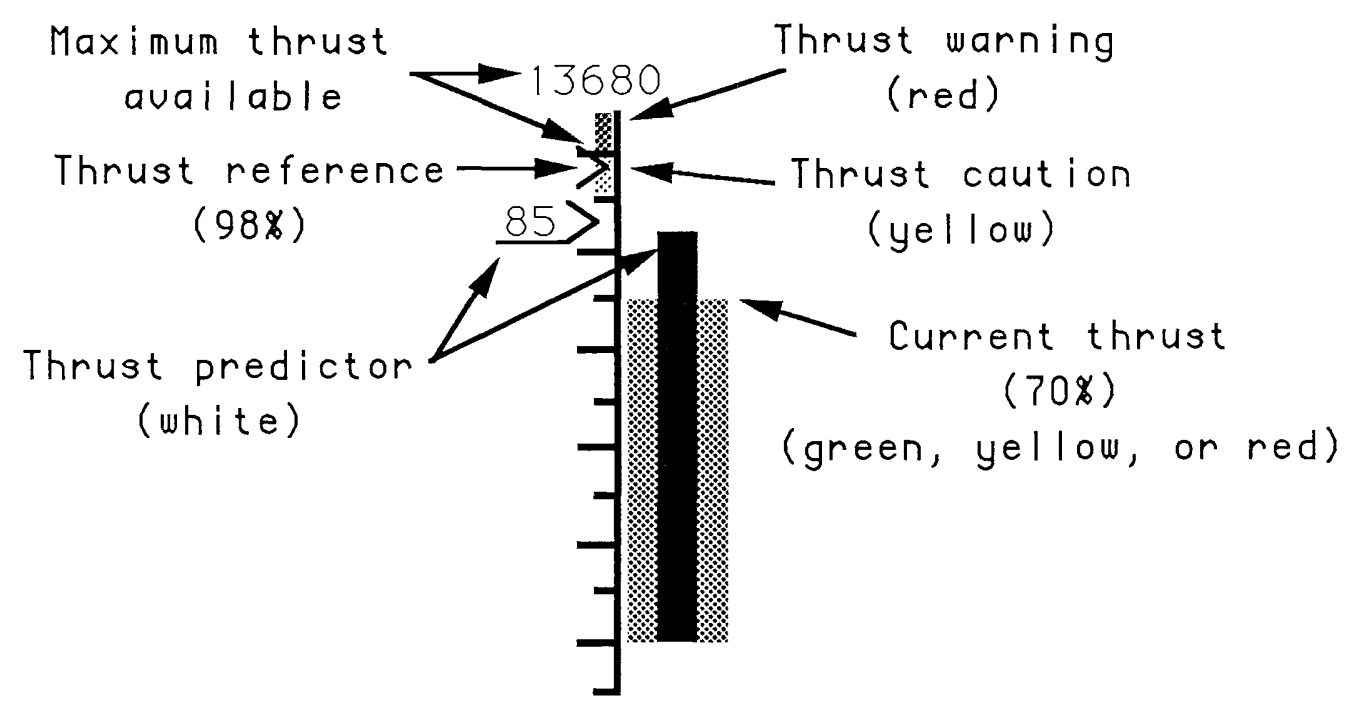


in the traditional design, by criticality and then by frequency of use. The arrangement is in a left to right order. Additionally, since the application is for a two engine aircraft, two sets of display elements were grouped by function, again like the traditional design. The completed product of this display design is shown in figures 17 and 18. The final set of tasks and the related information characteristics are provided in appendices $C$ and D, respectively. The display format is physically presented on two CRT displays in a left to right arrangement. It would have been preferred to place all of the monitoring display elements on a single CRT. For this to have been done, however, would have resulted in the digital presentations being too small for practical use.

At this point, the concepts of the task-oriented design process have been demonstrated. In this process, the user's task was decomposed only to a level where relevant information was identified (thrust instead of EPR). This is in contrast to the traditional process, where the user's task is usually decomposed to a level where a raw data source can be identified. The second, complementary half of this proposed concept dealt with providing information in a form that is more appropriate to the user's task. In doing so, it was necessary to process or synthesize data to support this implementation. This design concept, then, is directed toward providing task-oriented information, both in 


\section{FIGURE 17}

TASK-ORIENTED DISPLAY, LEFT SIDE

The following figure is approximately full size. To be viewed properly, the figure must be rotated $90^{\circ}$ in a clockwise direction. 

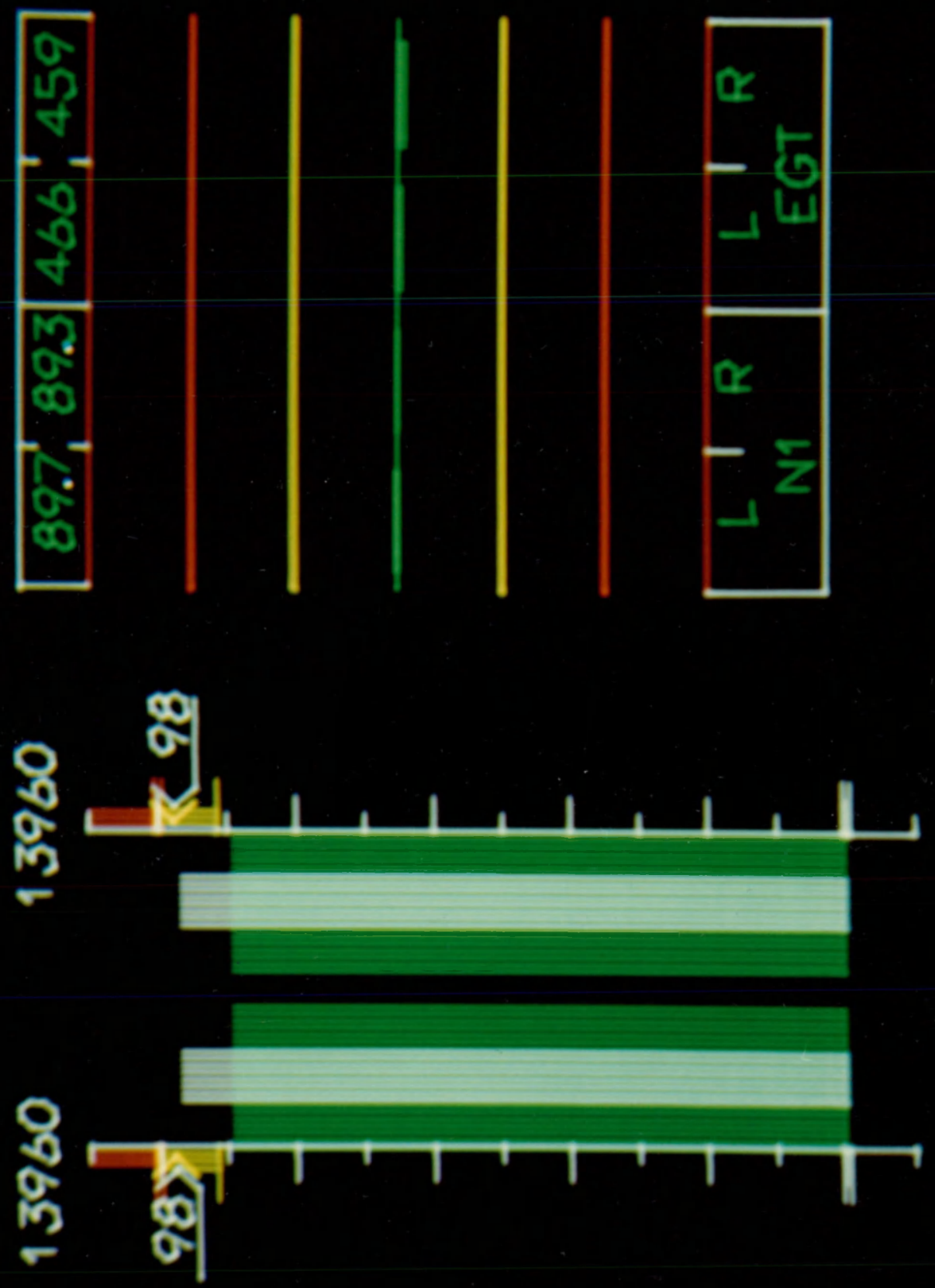
FIGURE 18

TASK-ORIENTED DISPLAY, RIGHT SIDE

The following figure is approximately full size. To be viewed properly, the figure must be rotated $90^{\circ}$ in a clockwise direction. 


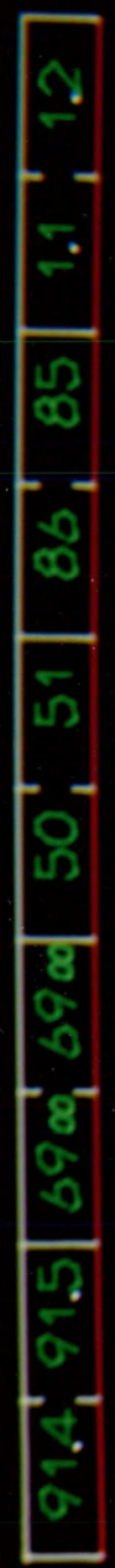
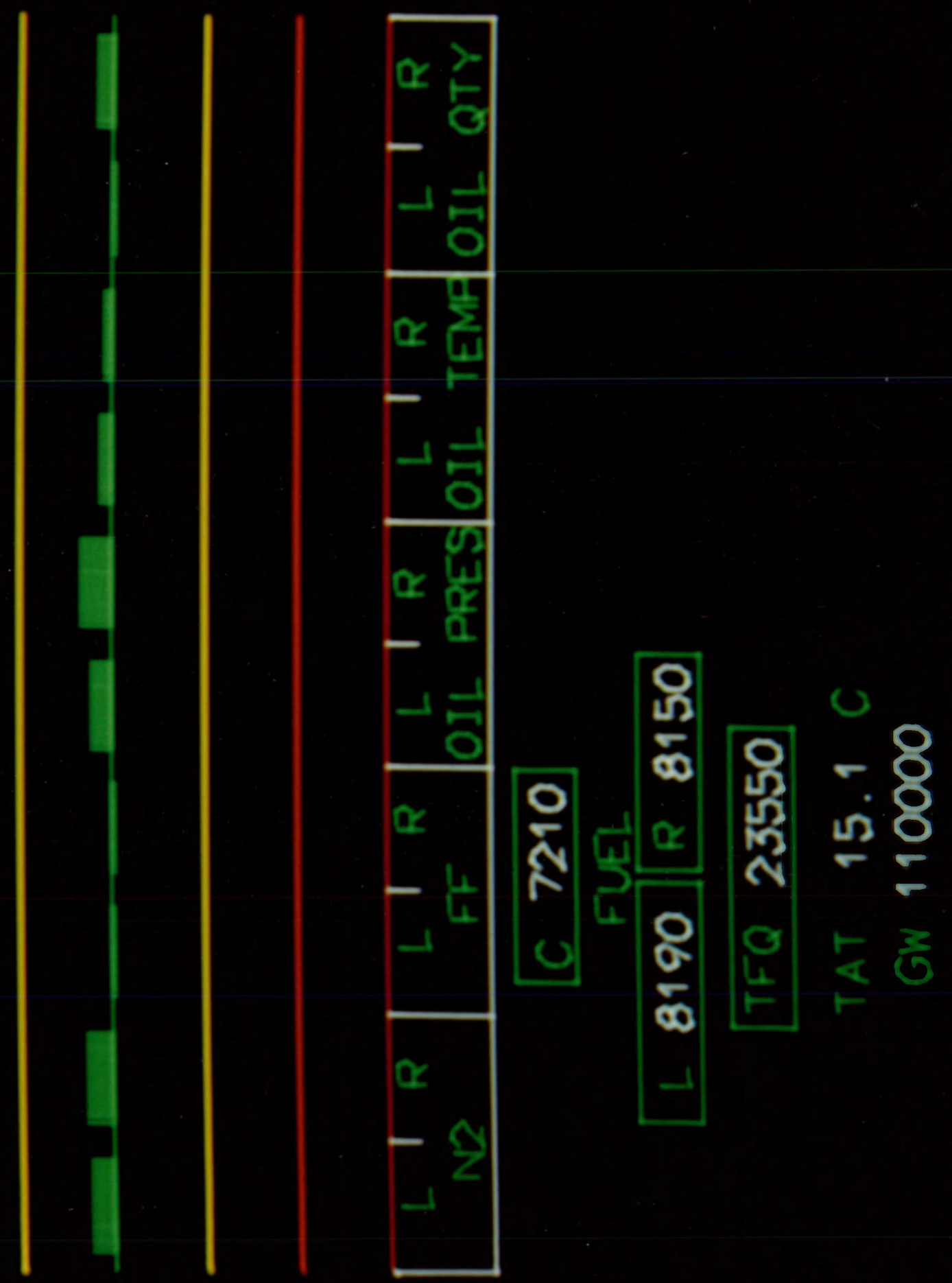
content and form, to support the user's needs. In doing so, a reduction of the user's cognitive workload associated with the use of this information should be possible. 
CHAPTER V

TEST CONDITIONS AND DISPLAY EVALUATION

As part of this thesis, the displays described in the preceding chapters were implemented and evaluated in a simulated flight environment. The aircraft simulator itself was a fixed-base cockpit configured as the research cockpit of the NASA Transport Systems Research Vehicle airplane (Reeder, Schmitz, \& Clark 1979). This simulation included a six-degree-of-freedom set of nonlinear equations of motion as well as functionally representing the aspects of the advanced flight control configuration of the airplane. The engine model included in this simulation was a nonlinear, engineering model of a Pratt and Whitney JT8D-7 turbofan engine.

Six electronic CRT displays were provided in the cockpit. Primary and navigation display formats (Reeder, Schmitz, \& Clark 1979; Steinmetz 1980; Abbott \& Steinmetz 1987; Abbott, Nataupsky, \& Steinmetz 1987) were provided in the form of an over-and-under arrangement for vehicle control and guidance, two to each side of the cockpit. Two side-by-side, center mounted CRT displays were provided for systems management. These latter CRT displays were used to present the engine formats relevant to this study. All of the CRT displays were approximately 8 inches diagonal in size. The formats for these displays were generated on an Adage AGT 340 graphics 
computer. The engine displays were stroke drawings utilizing 4 colors. Raster features were synthesized by strokefilling. The cockpit arrangement of these CRT displays can be seen in figure 19.

For a basis of comparison during the evaluation, the modern, state-of-the-art engine display format that was described in chapter III was used. For the evaluation part of this thesis, this display was designated as the modern format. The general form and function of this format is familiar to the commercial aircraft piloting community. The utility of this format over conventional electromechanical instruments and the unique features of this format were described in chapter III. This display format was evaluated against the display format described in chapter IV. The implementation considerations for the task-oriented display format, designated the advanced format, are given in appendix E. Further implementation details are provided in Abbott and Person (1988).

For the evaluation of these formats, sixteen pilot subjects were used. All of the subjects were qualified in multi-engine jet airplanes. Four of the subjects were NASA test pilots, one subject was a pilot for a commercial air carrier and the remaining eleven subjects were U. S. Air Force operational pilots. Each subject was briefed prior to the simulation test with respect to the display formats, the 


\section{FIGURE 19}

\section{SIMULATOR COCKPIT}

To be viewed properly, the following figure must be rotated $90^{\circ}$ in a clockwise direction. 


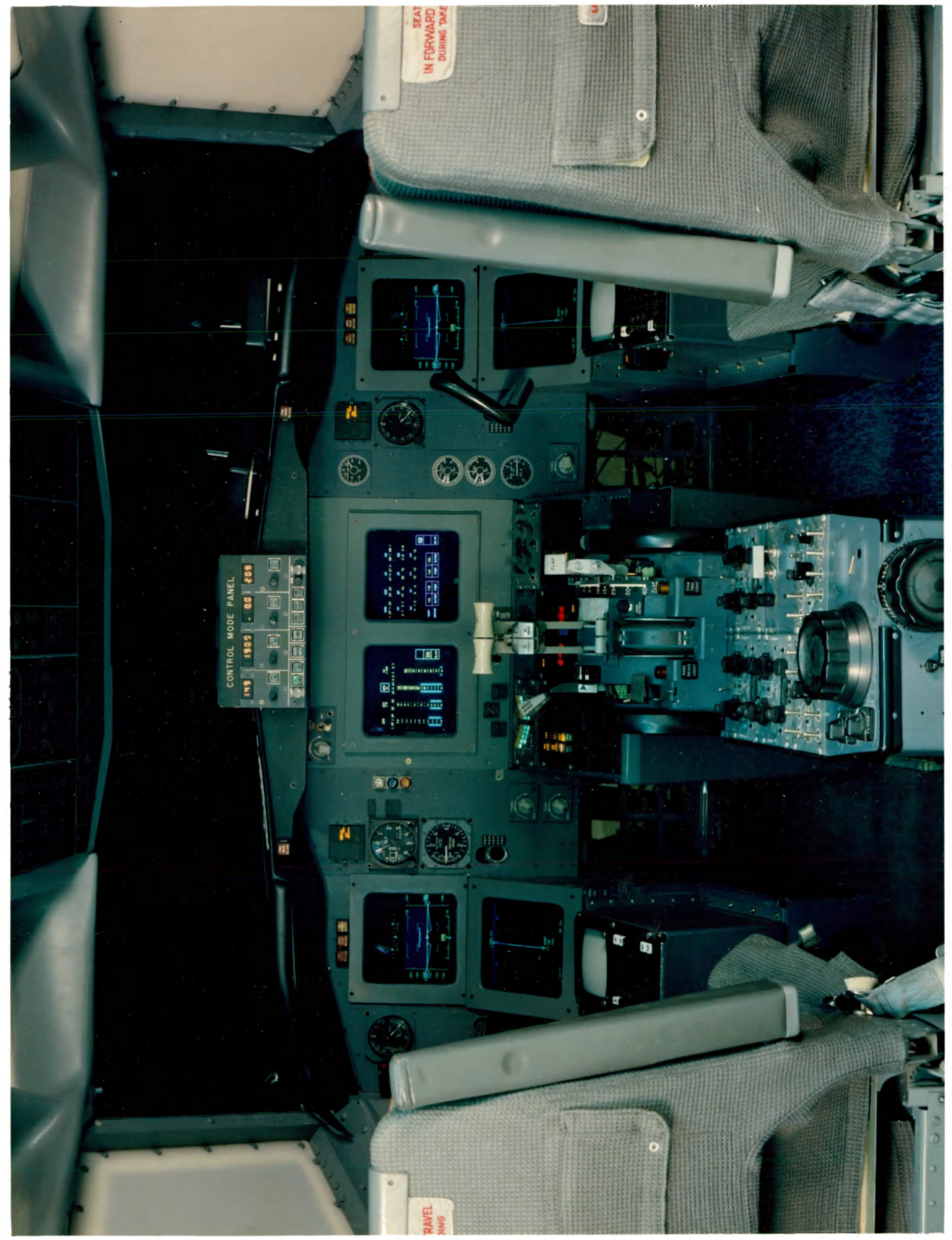


aircraft cockpit systems, and the evaluation tasks. Each briefing began with the subject reading a formal pilot briefing handout (appendix $F$ ). This reading was followed by the subject taking a written quiz (appendix G) on the critical engine parameters for the aircraft engine used in this study. The primary intent of this quiz was to assure that the subjects were familiar with the operating limitations of this engine. Each subject was then provided with an informal $11 / 2$ hour briefing on the simulator and on both sets of engine display formats.

The simulator evaluation began after the pilot briefing. The evaluation sequence was as follows:

1. Simulator familiarization and initial subjective evaluation of the modern format. This subjective evaluation required the completion of a written questionnaire (questionnaire $A$, shown in appendix $H$ ) specifically appraising the modern format. (Approximately 1 hour.)

2. Simulator familiarization and initial subjective evaluation of the advanced format. As part of this evaluation, the completion of a written questionnaire specifically appraising the advanced format was required (questionnaire B, shown in appendix H). Following this evaluation, a second 
questionnaire was administered (questionnaire $C$, shown in appendix $\mathrm{H}$ ). This second questionnaire required the subject to comparatively rate the two display formats. (Approximately 1 hour.)

3. Practice and quantitative evaluation of one of the engine formats. (Approximately 15 minutes.)

4. Practice and quantitative evaluation of the other engine format. (Approximately 15 minutes.)

5. Complete a final subjective questionnaire set. The comparative questionnaire (questionnaire $C$, of appendix H) was again administered. Following this, the subject was then requested to provide written comments regarding the advanced display only (questionnaire D of appendix H) .

Because no demands were placed on the subjects that were specific to the simulated aircraft, the simulator familiarization and subjective evaluations were performed concurrently. Additionally, because all the subjects were generally familiar with the modern format, all of the subjective evaluations began with this format.

For the initial, subjective evaluation of each display format, the subjects were provided with flight scenarios 
that included normal, degraded, and out-of-tolerance engine systems conditions. The majority of the scenarios involved a takeoff task, since this task is generally the most enginesystem critical. The takeoff conditions included a wide range of aircraft weights and airport elevations. These two factors significantly affect the acceleration potential of the aircraft and therefore significantly affect takeoff capabilities. The other scenarios were inflight, cruise situations. It should be noted that no caution or alerting system, expect what was provided by the displays, was provided. A list of these scenarios is provided in table 8 .

For the initial evaluations, the subjects were allowed to stop or "freeze" the simulator at any time to analyze a situation. Any situation or condition could be discussed with the test engineer. The subjects were always advised of any degraded or failure (out-of-tolerance) condition. As previously stated, they were required to rate each format as to its suitability at the end of each of these two evaluation phases (questionnaires A and B). Additionally, the subjects were required to comparatively evaluate the formats at the end of the second evaluation (questionnaire C) .

Following the initial subjective evaluations, a quantitative evaluation was performed for each of the two formats. During this part of the overall evaluation, one- 
TABLE 8

SCENARIOS FOR FAMILIARIZATION

AND THE SUBJECTIVE EVALUATIONS

\begin{tabular}{|c|l|c|c|c|c|}
\hline $\begin{array}{c}\text { Scenario } \\
\text { number }\end{array}$ & Condition & $\begin{array}{c}\text { Altitude } \\
\text { (feet) }\end{array}$ & $\begin{array}{c}\text { CAS } \\
\text { (kts) }\end{array}$ & $\begin{array}{c}\text { Weight } \\
\text { (lbs) }\end{array}$ & $\begin{array}{c}\text { Fault } \\
\text { number }\end{array}$ \\
\hline F1 & takeoff & 0 & 0 & 80000 & - \\
F2 & takeoff & 0 & 0 & 80000 & 1 \\
F3 & takeoff & 0 & 0 & 80000 & 4 \\
F4 & takeoff & 0 & 0 & 80000 & 2 \\
F5 & takeoff & 0 & 0 & 80000 & 5 \\
F6 & takeoff & 0 & 0 & 112000 & - \\
F7 & takeoff & 5333 & 0 & 80000 & - \\
F8 & takeoff & 5333 & 0 & 102000 & - \\
F9 & cruise & 18000 & 290 & 91000 & - \\
F10 & cruise & 18000 & 290 & 91000 & 3 \\
F11 & cruise & 18000 & 290 & 91000 & 4 \\
\hline
\end{tabular}


TABLE 8 (continued)

\begin{tabular}{|c|c|}
\hline $\begin{array}{l}\text { Fault } \\
\text { number }\end{array}$ & Description \\
\hline - & No fault, normal operation. \\
\hline 1 & $\begin{array}{l}\text { Low oil pressure on the left engine. Problem is } \\
\text { a function of } \mathrm{N}_{2} \text {, with oil pressure decreasing } \\
\text { from normal into the caution area above } 60 \% \mathrm{~N}_{2} \text {. }\end{array}$ \\
\hline 2 & $\begin{array}{l}\text { Oil leak, both engine. Problem begins after } 45 \\
\text { seconds of operation. Potential outcome is total } \\
\text { loss of oil from the system. }\end{array}$ \\
\hline 3 & $\begin{array}{l}\text { oil leak on the left engine. The problem } \\
\text { develops from normal to o quantity over a } 90 \\
\text { second period. Potential outcome is total loss } \\
\text { of oil from the system. }\end{array}$ \\
\hline 4 & $\begin{array}{l}\text { High EGT for both engines. The problem is a bias } \\
\text { in engine temperature ( } 100 \text { degrees } C) \text { with the } \\
\text { potential result of an engine over-temperature } \\
\text { condition. }\end{array}$ \\
\hline 5 & $\begin{array}{l}\text { Low oil pressure on both engines with the left } \\
\text { engine decreasing the faster. Problem is a } \\
\text { function of time, with oil pressure decreasing } \\
\text { from normal into the caution area within } 1 \\
\text { second. }\end{array}$ \\
\hline
\end{tabular}


half of the subjects began with the modern display format and the other one-half began with the advanced format. For each display format, the subjects were required to perform two takeoff and two inflight tasks. The subjects were advised that system failure scenarios would be randomly included in these tasks. In actuality, the order of the failure scenarios was random but one failure and one nonfailure scenario was included in each task pair (takeoff and inflight). No scenarios were repeated for any one subject.

The scenarios used for this portion of the evaluation were similar to those used earlier with the following noteworthy exception, the displays were only shown for set periods of time; except for those time periods, the CRT displays were electronically blanked. This switching of the displays on and off was done to reduce the effect of the subjects giving excessive emphasis to the engine control and monitoring tasks. That is, the engine control and monitoring tasks are not the pilot's primary tasks during actual, operational situations. If the aircraft takeoff task is considered the pilot's primary task, during which engine control and performance are critical, it may be observed that the time devoted to engine control and monitoring is fairly small relative to the overall task.

To determine an appropriate time period for the viewing of the engine displays, a preliminary test was conducted 
several months prior to this evaluation. For this preliminary test, three subjects (none of the sixteen used for this evaluation) were each provided with takeoff and inflight scenarios similar to those used in the actual evaluation. The intent of this test was to determine when the subject viewed the engine displays during the performance of an overall flight task (a takeoff task or an inflight task requiring an increase in power). The subjects were not advised as to the intent of this preliminary test. A record of the subjects' viewing periods of the engine displays was kept. The resulting average viewing periods from this preliminary test were used during the evaluation of the display formats. For the takeoff scenarios, this resulted in a four-second period following the initial throttle advance, a two-second period beginning at 55 knots (for the 60 knot power check), and a two-second period beginning 5 knots prior to $v_{1}$. For the takeoff scenarios, the displays were initially on. For the inflight scenarios, a single three-second period was used. For these scenarios, the displays were initially off.

To reduce the effect of subject inattention to the engine control and monitoring tasks during these quantitative evaluations, the subjects were not allowed to perform any other task (flight task, e.g., the control of the aircraft's flight path). Additionally, the test engineer provided all of the aircraft speed callouts (55 knots and 5 knots prior 
to $\mathrm{V}_{1}$ ). During the evaluation, the subjects were advised that if an engine problem developed, the task was to be immediately terminated and the failure reported. The subjects were not informed of the nature of a failure for these scenarios either before, during, or after the test. The scenarios for this part of the evaluation and their order of use are given in tables 9 and 10, respectively.

Following the quantitative evaluations, the subjects were again required to comparatively rate the formats (questionnaire $c$, for the second time). A final questionnaire was then administered, where the subjects were required to provide brief comments relative to the attributes of the advanced display format.

The product of this evaluation was a set of test data from each subject that included the following: questionnaire results individually rating each display format (questionnaires $\mathrm{A}$ and $\mathrm{B}$ ); questionnaire results from two comparative questionnaires (questionnaire C), one administered prior to the quantitative test and one administered afterward; quantitative results from eight nofailure scenarios and eight failure scenarios; and a set of general comments.

In analyzing the test data, differences in the results of the qualitative data from the initial subjective 
TABLE 9

SCENARIOS FOR THE QUANTITATIVE EVALUATION

\begin{tabular}{|c|l|c|r|r|c|}
\hline $\begin{array}{c}\text { Scenario } \\
\text { number }\end{array}$ & Condition & $\begin{array}{c}\text { Altitude } \\
\text { (feet) }\end{array}$ & $\begin{array}{c}\text { CAS } \\
\text { (kts) }\end{array}$ & $\begin{array}{c}\text { Weight } \\
\text { (lbs) }\end{array}$ & $\begin{array}{l}\text { Fault } \\
\text { number }\end{array}$ \\
\hline 1 & takeoff & 0 & 0 & 108000 & - \\
2 & takeoff & 0 & 0 & 85000 & 1 \\
3 & takeoff & 4900 & 0 & 108000 & - \\
4 & takeoff & 4900 & 0 & 85000 & 2 \\
5 & cruise & 16000 & 270 & 85000 & - \\
6 & cruise & 16000 & 270 & 85000 & 4 \\
7 & cruise & 16000 & 300 & 85000 & - \\
8 & cruise & 16000 & 300 & 85000 & 3 \\
\hline
\end{tabular}

\begin{tabular}{|c|l|}
\hline $\begin{array}{c}\text { Fault } \\
\text { number }\end{array}$ & \multicolumn{1}{|c|}{ Description } \\
\hline- & $\begin{array}{l}\text { No fault, normal operation. } \\
\text { EPR sensor error, high EPR values for both } \\
\text { engines. Simulation of a blocked P1 pressure } \\
\text { probe leading to higher than true EPR readings } \\
\text { above } 1.0 \text { EPR. The potential result is } \\
\text { insufficient power for the flight condition. }\end{array}$ \\
2 & $\begin{array}{l}\text { High oil temperature on the left engine. } \\
\text { Problem is a function of } \mathrm{N}_{2}, \text { with oil } \\
\text { temperature increasing from normal into the } \\
\text { Caution area above } 60 \% \mathrm{~N}_{2} \cdot\end{array}$ \\
& $\begin{array}{l}\text { High } \mathrm{N}_{2} \text { speeds on both engines. The problem is } \\
\text { higher than normal gain on } \mathrm{N}_{2}, \text { with the } \\
\text { potential result of an } \mathrm{N}_{2} \text { overspeed condition. }\end{array}$ \\
& $\begin{array}{l}\text { High EGT for both engines. The problem is a bias } \\
\text { in engine temperature (t } 75 \text { and }+83 \text { degrees } \mathrm{C} \\
\text { for the left and right engine, respectively) } \\
\text { with the potential result of an engine over- } \\
\text { temperature condition. }\end{array}$ \\
\hline
\end{tabular}


TABLE 10

SCENARIO SEQUENCE FOR THE QUANTITATIVE EVALUATION

\begin{tabular}{|c|c|c|c|c|c|c|c|c|c|c|c|c|c|c|c|c|}
\hline Sequence & \multicolumn{16}{|c|}{ Scenario numbers } \\
\hline & \multicolumn{8}{|c|}{ Pilot } & \multicolumn{8}{|c|}{ number } \\
\hline & 1 & 2 & 3 & 4 & 5 & 6 & 7 & 8 & 9 & 10 & 11 & 12 & 13 & 14 & 15 & 16 \\
\hline & \multicolumn{8}{|c|}{ modern format } & \multicolumn{8}{|c|}{ advanced format } \\
\hline 1 & 1 & 4 & 4 & 2 & 3 & 1 & 2 & 3 & 4 & 4 & 3 & 3 & 2 & 1 & 1 & 2 \\
\hline 2 & 2 & 1 & 3 & 1 & 4 & 2 & 3 & 4 & 1 & 3 & 2 & 4 & 1 & 4 & 2 & 3 \\
\hline 3 & 6 & 7 & 8 & 8 & 5 & 6 & 5 & 7 & 6 & 7 & 6 & 5 & 8 & 5 & 7 & 8 \\
\hline 4 & 5 & 6 & 7 & 5 & 6 & 7 & 8 & 8 & 5 & 8 & 5 & 8 & 7 & 6 & 6 & 7 \\
\hline & \multicolumn{8}{|c|}{ advanced format } & \multicolumn{8}{|c|}{ modern format } \\
\hline 5 & 3 & 3 & 2 & 4 & 1 & 4 & 1 & 2 & 3 & 1 & 1 & 2 & 4 & 2 & 3 & 4 \\
\hline 6 & 4 & 2 & 1 & 3 & 2 & 3 & 4 & 1 & 2 & 2 & 4 & 1 & 3 & 3 & 4 & 1 \\
\hline 7 & 8 & 5 & 6 & 7 & 7 & 8 & 6 & 5 & 8 & 5 & 7 & 7 & 6 & 8 & 5 & 6 \\
\hline 8 & 7 & 8 & 5 & 6 & 8 & 5 & 7 & 6 & 7 & 6 & 8 & 6 & 5 & 7 & 8 & 5 \\
\hline
\end{tabular}


evaluations, questionnaires $A$ and $B$, were deemed experimentally significant only if the difference in mean values for relevant questions on the questionnaires was greater than 20-percent. (The 20-percent value was chosen prior to the data analysis as a level for practical significance. The 20-percent was equivalent to one block on the questionnaire response.) For example, the difference between the average response to question 1 of questionnaire A and question 1 of questionnaire B had to exceed 20-percent for one to be considered better than the other. Similarly, the results of the comparative evaluations, questionnaire $C$, were deemed experimentally significant only if the average rating was at least 20-percent to the left or right (favoring the modern or advanced display) of the center, "no difference" rating.

The responses to questionnaires $A$ and $B$, questions 1 through 6, are shown graphically in figures 20 to 25 , respectively. No differences between the responses were obtained for the first four questions. The last two questions, the questions pertaining to the monitoring task, showed a more favorable rating of the advanced display. For questions 5 and 6 , an average rating of 1.2 and 1.3 for the advanced display was obtained versus an average rating of 3.9 and 2.9 for the modern display. The ratings were on a scale of 1 to 5 , with 1 being the most favorable and 5 being the least favorable. 
FIGURE 20

RESPONSES TO QUESTION 1 OF QUESTIONNAIRES A AND B Question 1. Overall, how easy did you find this display format to use?
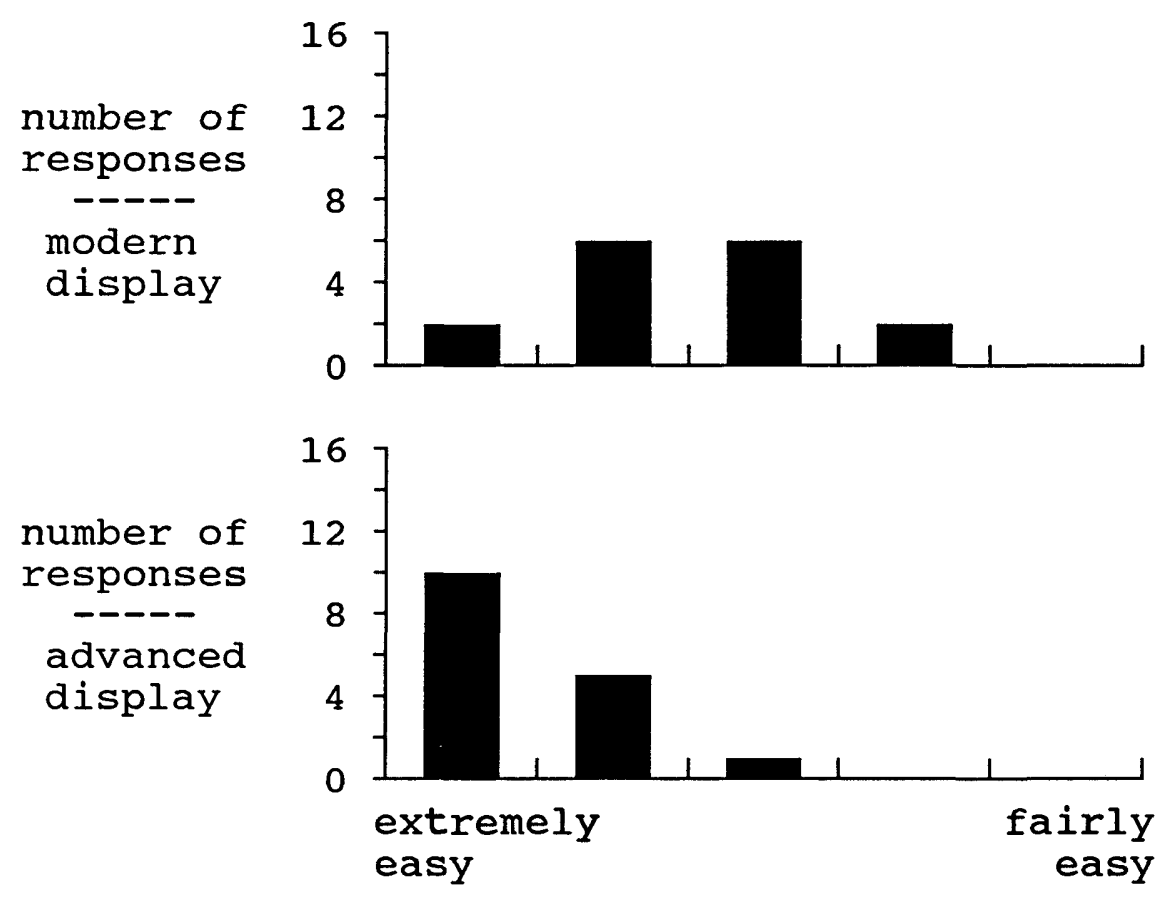
FIGURE 21

RESPONSES TO QUESTION 2 OF QUESTIONNAIRES A AND B

Question 2. How easy did you find the display element for control to use?
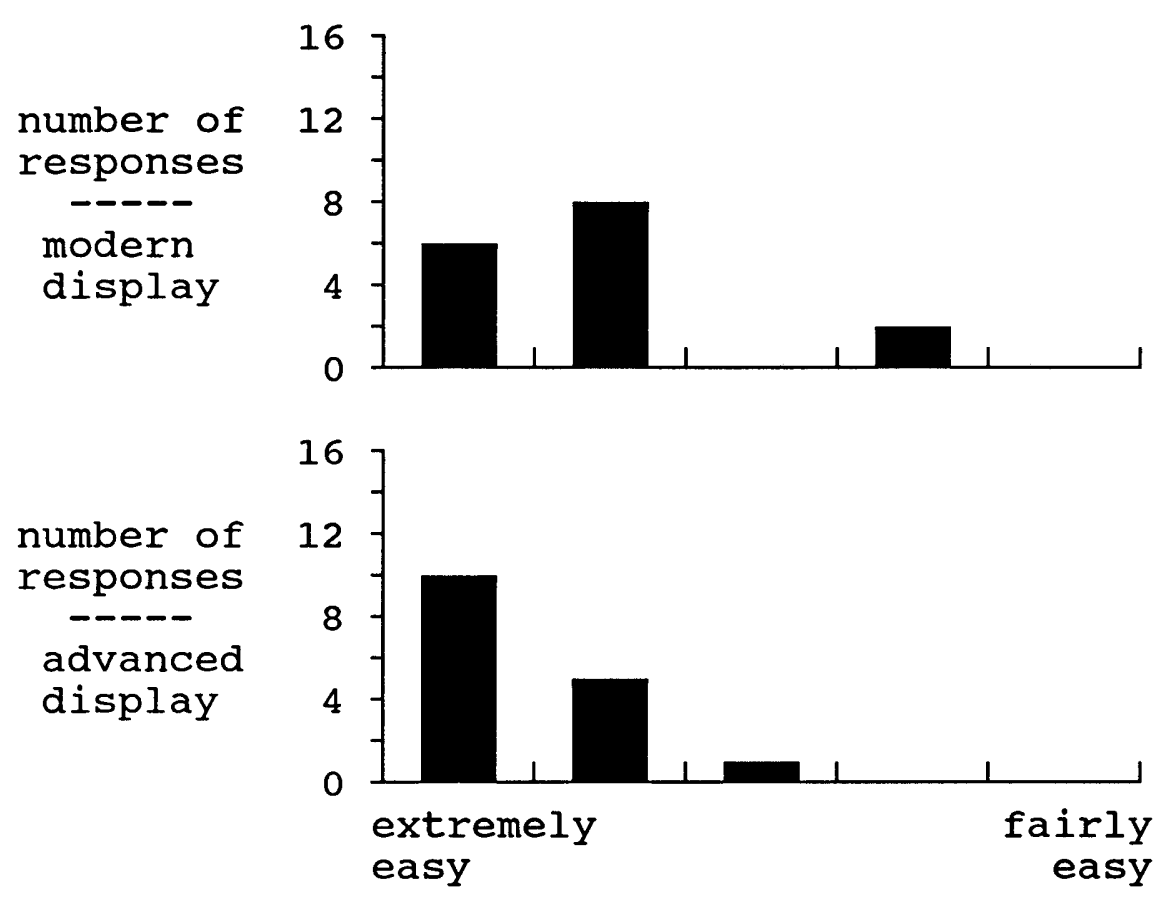
FIGURE 22

RESPONSES TO QUESTION 3 OF QUESTIONNAIRES A AND B Question 3. How rapidly were you able to set engine power?
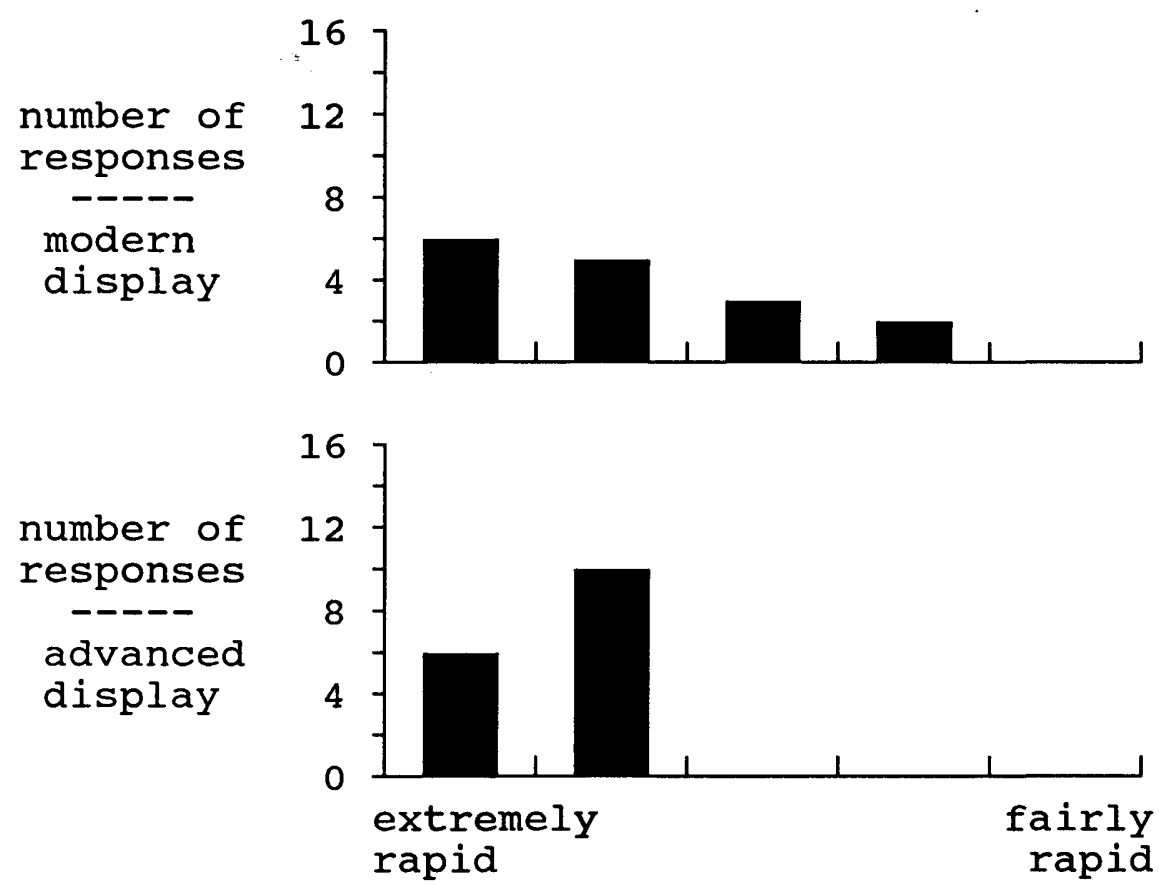
FIGURE 23

RESPONSES TO QUESTION 4 OF QUESTIONNAIRES A AND B Question 4. How accurately were you able to set engine power?
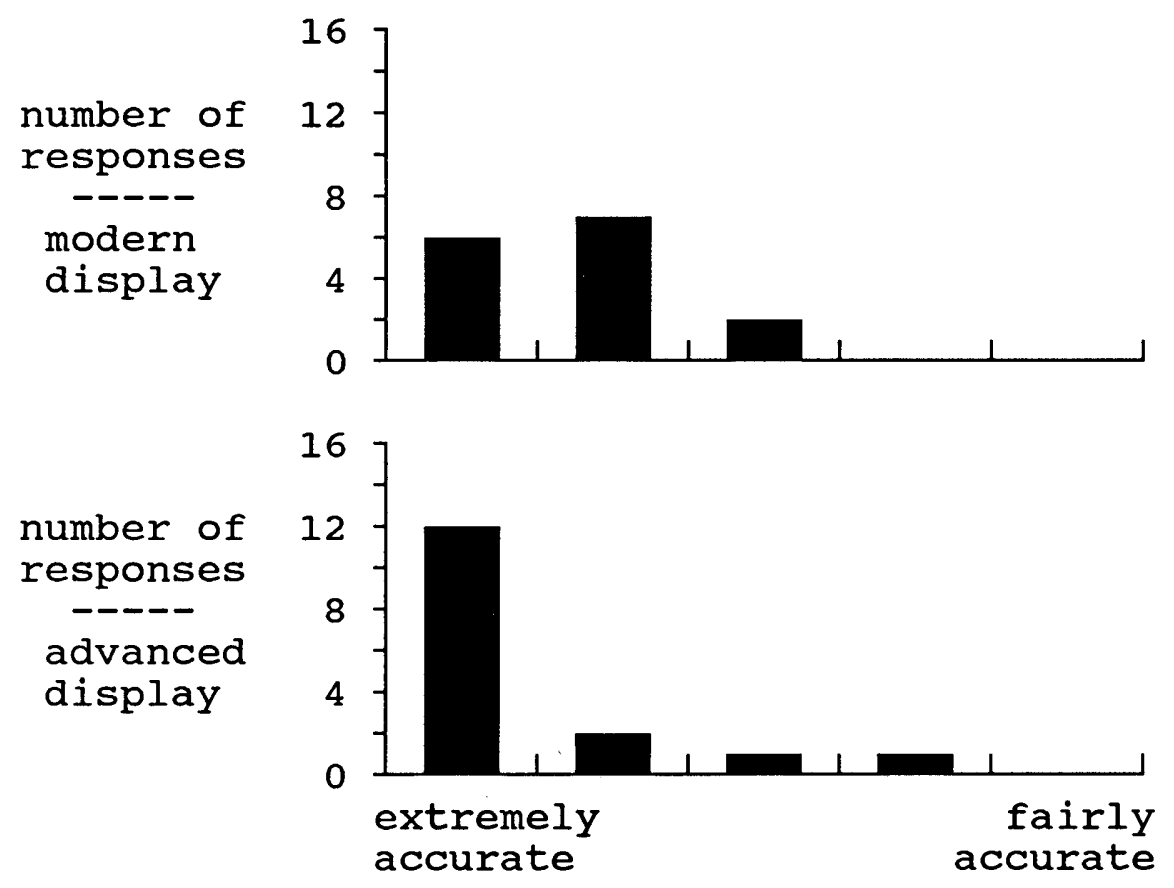
FIGURE 24

RESPONSES TO QUESTION 5 OF QUESTIONNAIRES A AND B

Question 5. How easy did you find the display elements for monitoring engine health to use?
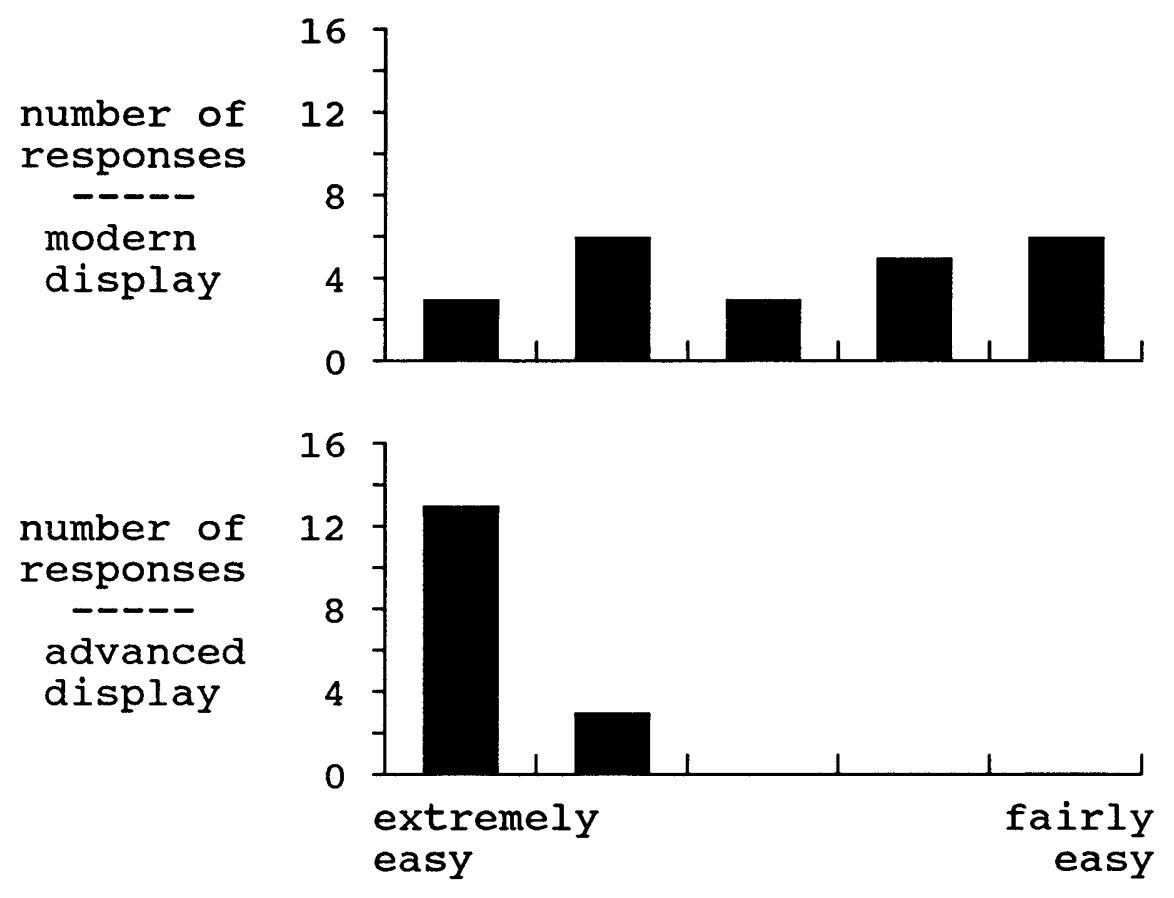
FIGURE 25

RESPONSES TO QUESTION 6 OF QUESTIONNAIRES A AND B

Question 6. How rapidly were you able to detect an out-oftolerance condition?
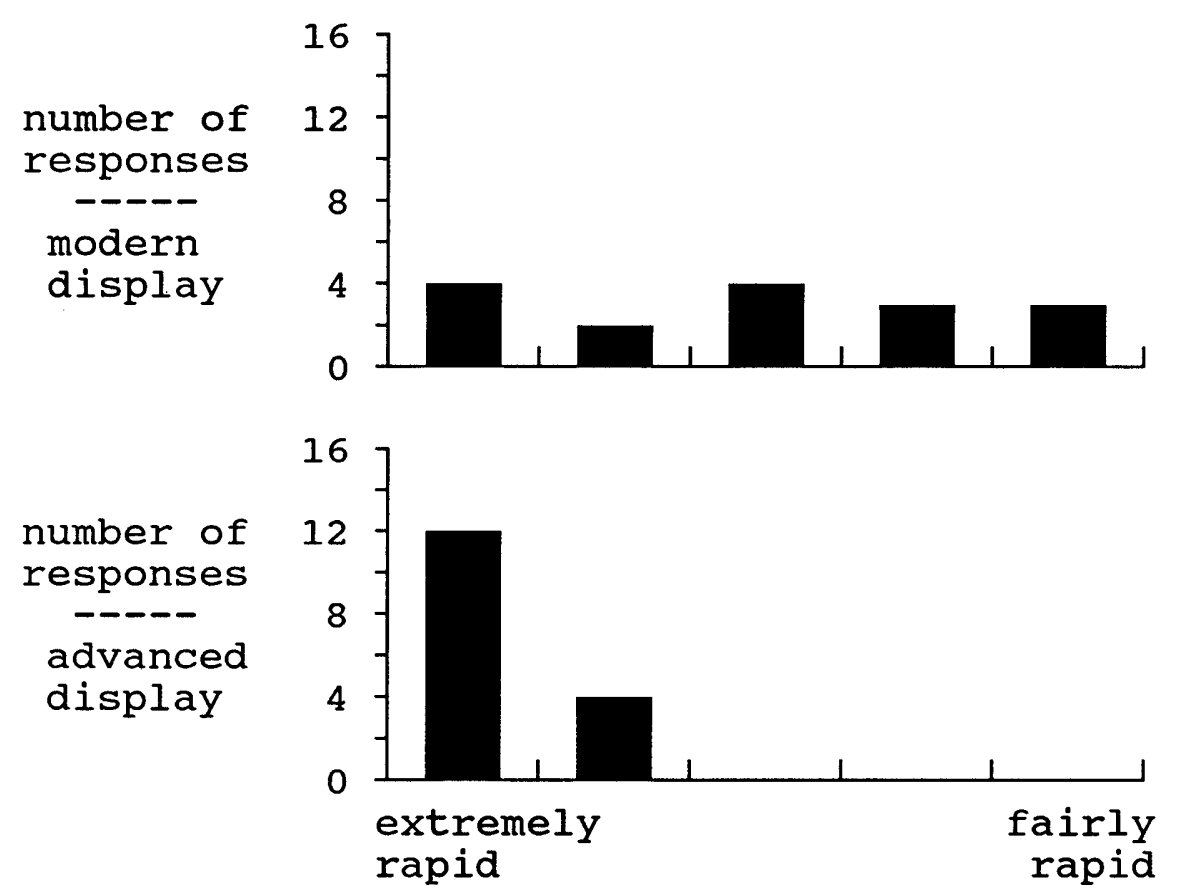
The comparative questionnaire was administered twice, once just prior the quantitative evaluation (the timed test) and once immediately after this test. Examining the responses to the questionnaires administered prior to the quantitative evaluation, preferences were shown for the advanced display. A general preference (question 1), with regard to ease of use, was observed for this display with an average rating of 4.2 on a scale of 1 to 5 ; with a rating of 1 defined as a total preference for the modern display and a rating of 5 defined as a total preference for the advanced display. Preferences were also shown for the advanced display regarding the monitoring task, questions 5 and 6 , with ratings of 4.4 and 4.5 , respectively.

Examining the responses to questionnaire $\mathrm{C}$ administered after the quantitative evaluation, a interesting trend was noted. Preferences were again shown for the advanced display but in all cases (all questions) with a more favorable rating. All of the responses were experimentally significant, with ratings of $4.7,4.4,4.2,4.3,4.8$, and 4.9 for questions 1 to 6 , respectively. (These results are shown graphically in figures 26 to 31.) It is assumed that forcing the subjects into time critical situations, as was done for the quantitative evaluations, caused the subjects to have a greater appreciation for the advanced display. This was especially true for the monitoring portion of the display, where the ability to perform the monitoring task, 
FIGURE 26

RESPONSES TO QUESTION 1 OF QUESTIONNAIRE C

Question 1. Overall, which display format did you find easier to use?
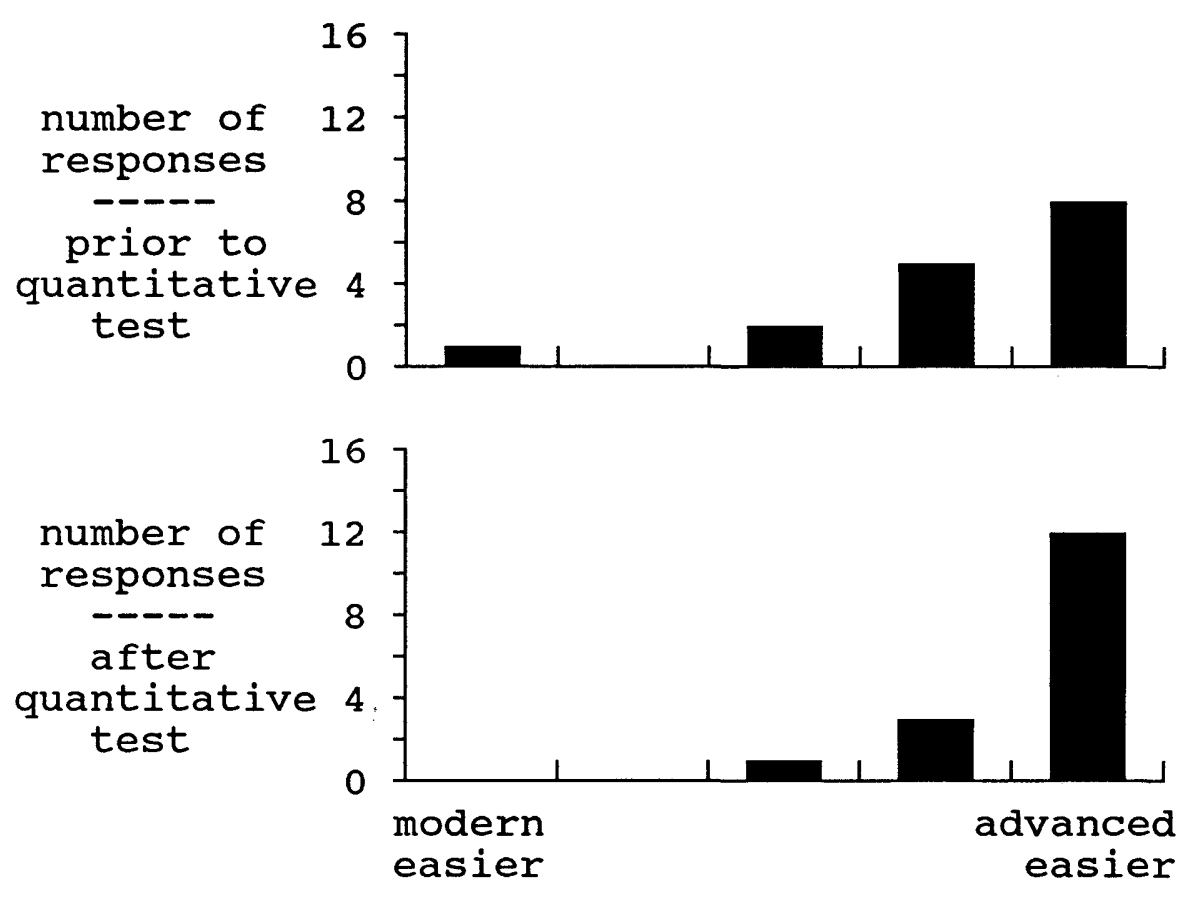
FIGURE 27

RESPONSES TO QUESTION 2 OF QUESTIONNAIRE C

Question 2. For which display format did you find engine control easier?
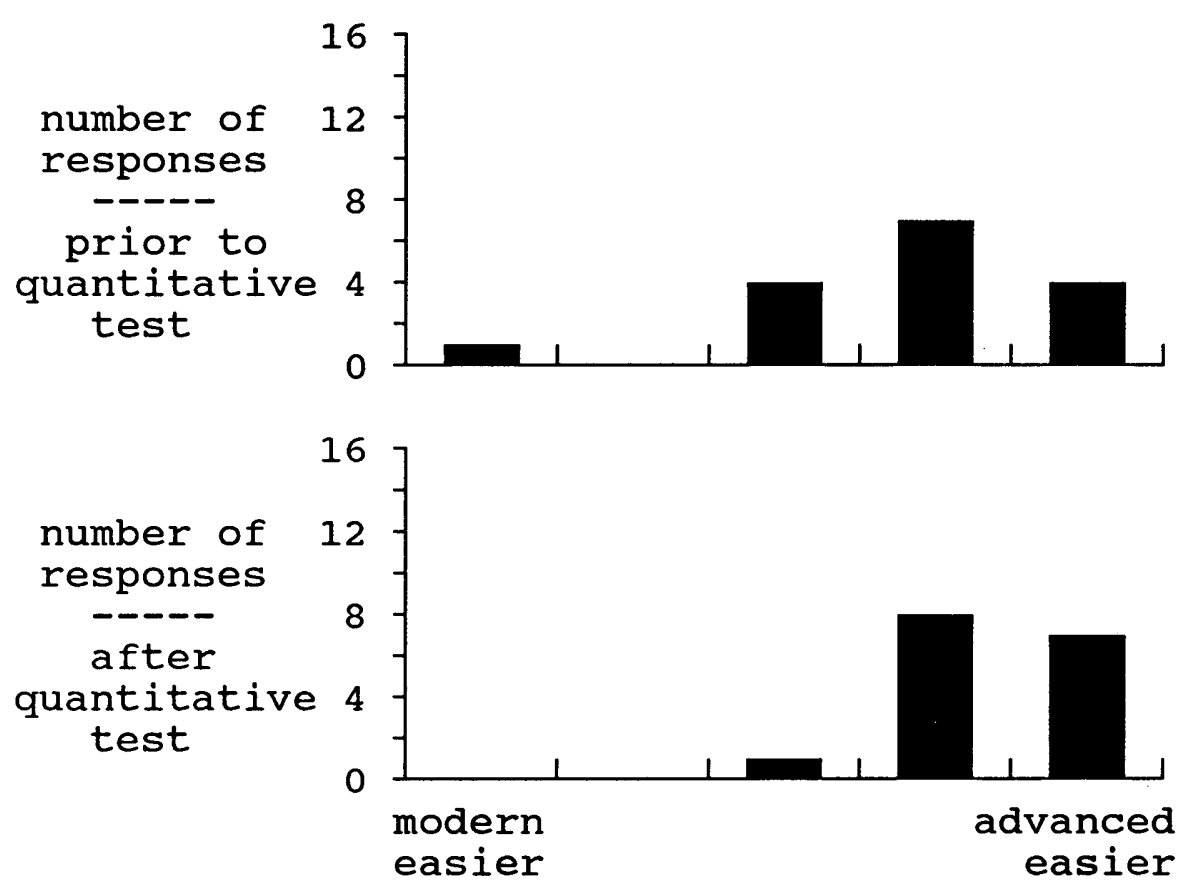
FIGURE 28

RESPONSES TO QUESTION 3 OF QUESTIONNAIRE C

Question 3. Which display format allowed the faster setting of engine power?
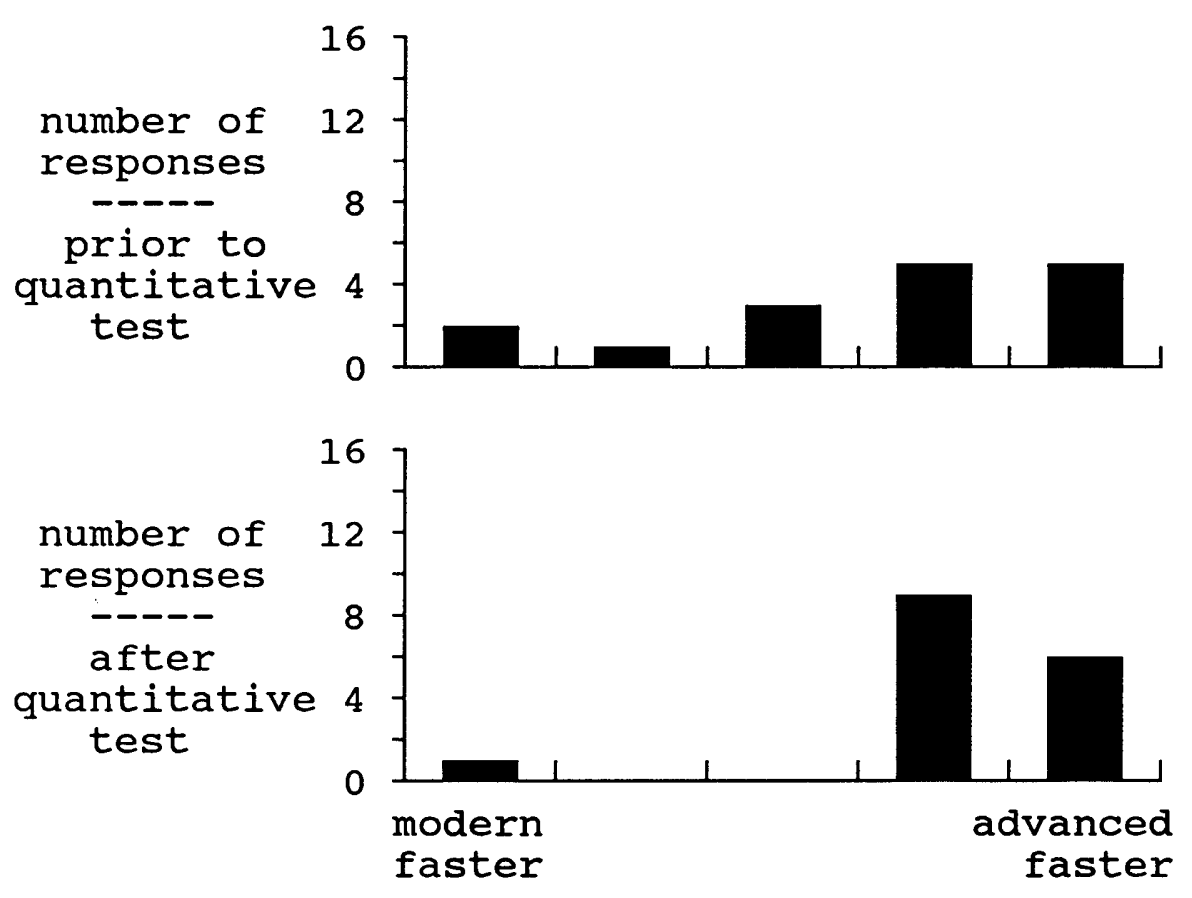
FIGURE 29

RESPONSES TO QUESTION 4 OF QUESTIONNAIRE C

Question 4 . Which display format allowed the more accurate setting of engine power?
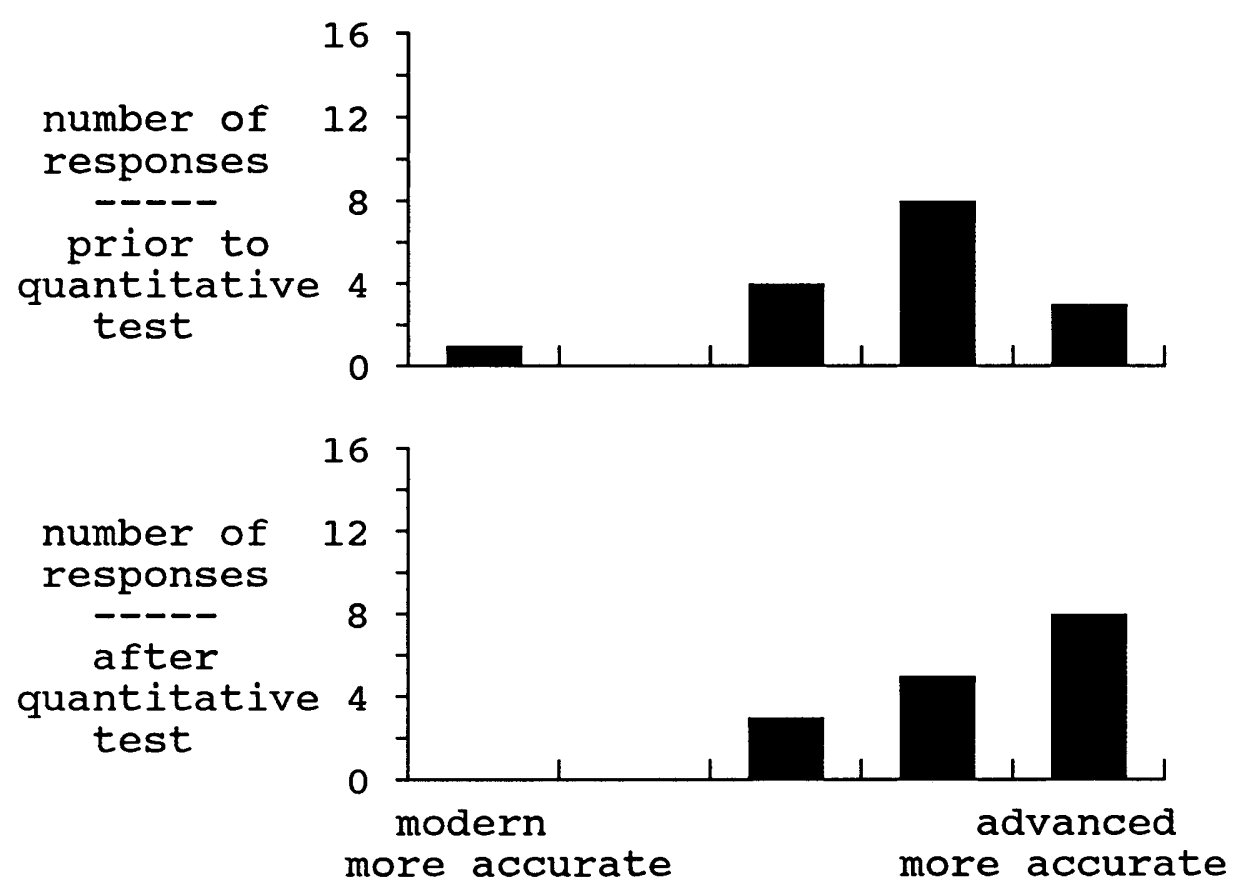
FIGURE 30

RESPONSES TO QUESTION 5 OF QUESTIONNAIRE C

Question 5. For which display format did you find engine monitoring easier?
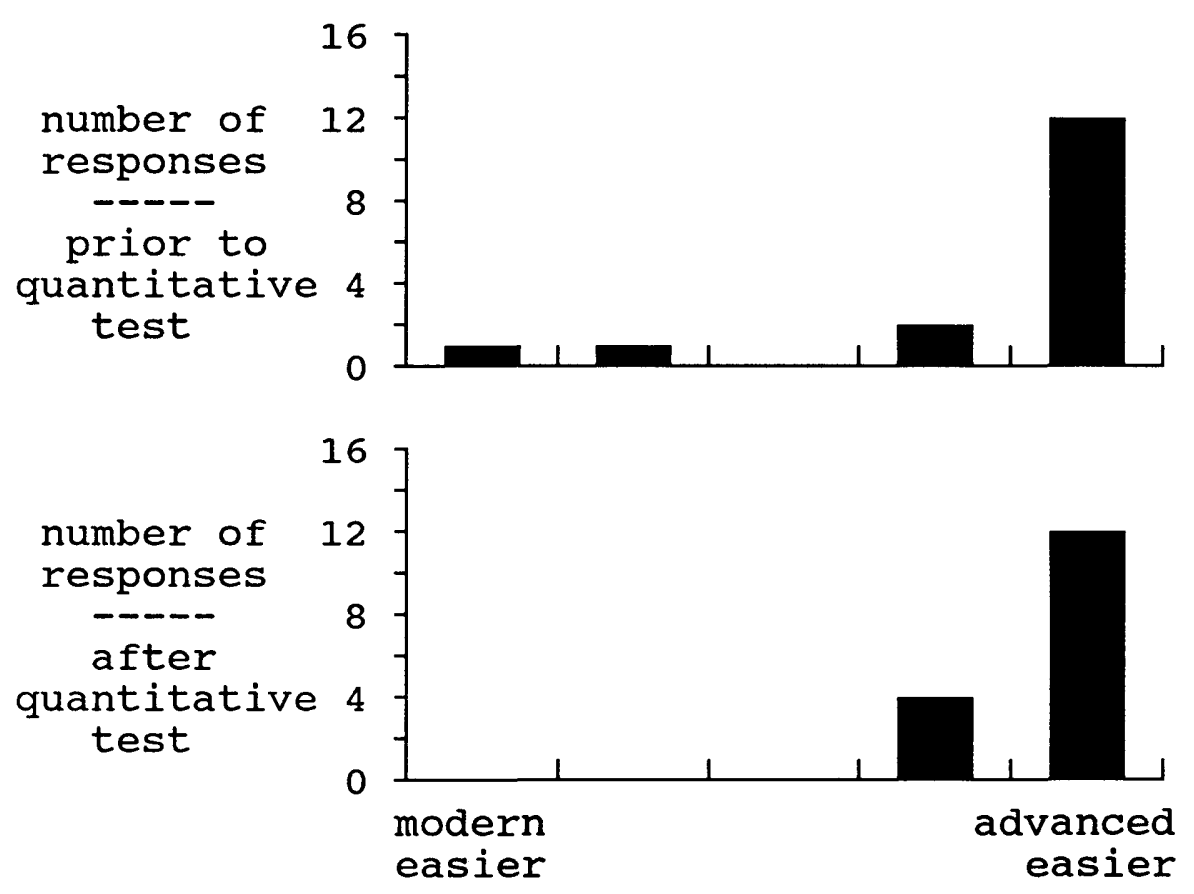
FIGURE 31

RESPONSES TO QUESTION 6 OF QUESTIONNAIRE C Question 6. Which display format allowed the faster detection of out-of-tolerance conditions?
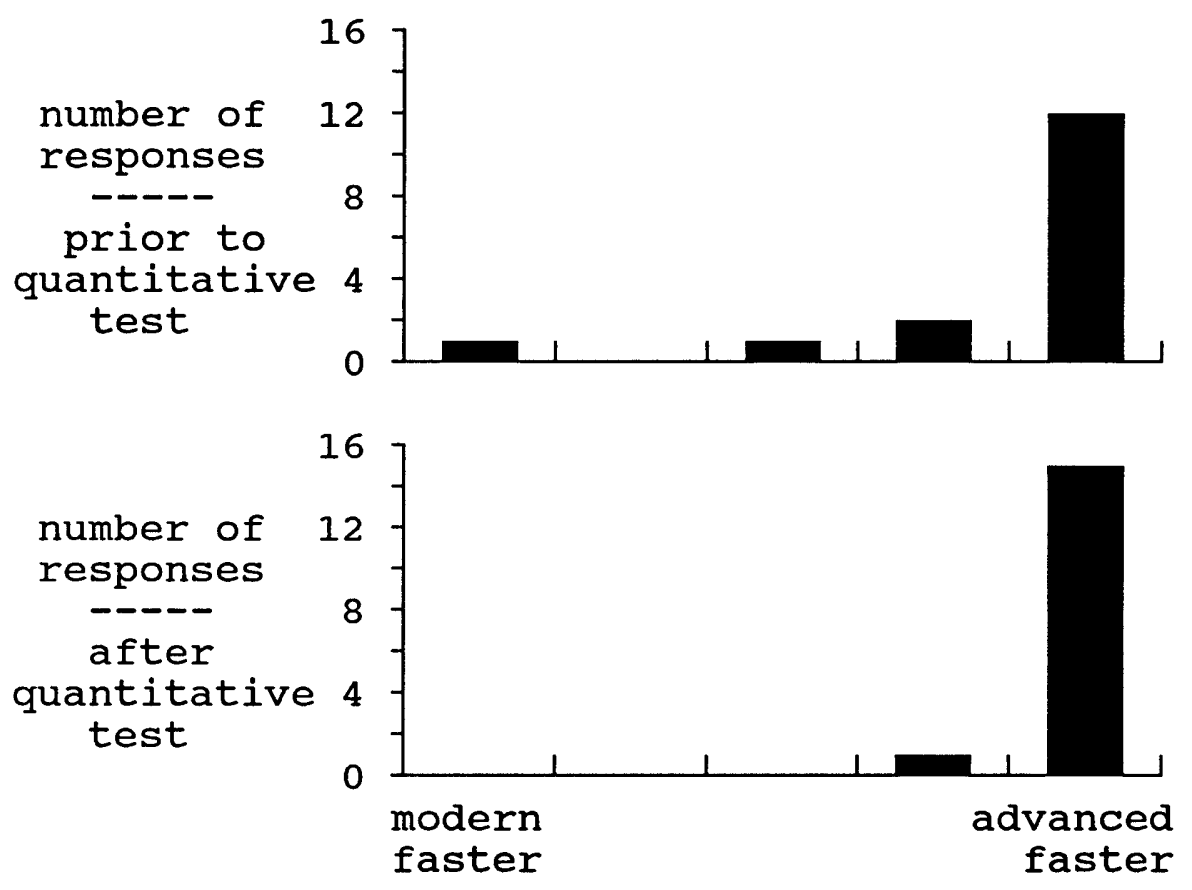
questions 5 and 6 , was rated 4.8 and 4.9 on a scale of 5 .

The analysis of the quantitative data substantiated the qualitative results. During the quantitative testing, a total of 32 degraded or out-of-tolerance conditions were presented for each display. When the subjects were using the advanced display, all 32 failure cases were properly identified. With the modern format, 14 failure cases were not identified; four of the cases were out-of-tolerance conditions and the remaining 10 were degraded conditions. The differences in the overall detection of failures, the detection of degraded conditions, and the detection of outof-tolerance conditions between the two displays were statistically significant at the 95 percent confidence level (where the hypothesis that there was no difference between the displays yielded a chi-square of $17.92,14.55$, and 4.57 , respectively, where chi-square $0.05 ; 1=3.84)$. The inability to detect degraded conditions using the modern display was not unexpected since most of the subjects were not highly experienced with this particular engine system. It is noteworthy that of the 10 degraded conditions that were not identified with the modern format, 8 of these conditions involved an abnormally high EPR or thrust reading (failure condition 1 ). This condition was never identified when the modern format was used. It is also noteworthy in that this particular degradation was modelled after a recent commercial aircraft accident (National Transportation Safety 
Board 1982) .

The overall results of this evaluation showed a favorable increase of both the user's subjective assessment and failure detection rate (and therefore a reduction in what is typically termed "operator error") for the task-oriented display. These results confirm the premise that providing information that is tailored to the user's task, both in content and form, increases the user's ability to utilize that information. 
CONCLUSIONS

The intent of this thesis was to define and assess a display design concept oriented toward providing information at a level that is more relevant to the task the user is to perform. This concept is a modification of the traditional design process and was based on the premise that the computational capabilities of modern, graphics-based display systems should be considered in the display design process. The primary modification to the design process was to decompose the user's task only to a level where relevant information can be identified. This relevant information, if not directly provided by the system sensors, should be provided by synthesis from the underlying data of the system.

A second, complementary part of this concept dealt with providing information in a form that is more appropriate to the user's task. Often, picture elements chosen to support a particular task are less than optimum, from a user's standpoint, for that task. Frequently, this less than optimum choice is predicated on the characteristics of the available data. If a better picture element choice is possible, then data should be processed or synthesized to support this implementation. In this respect, the design process is bottom-up, with the information form dictating the information characteristics. 
A description of this proposed concept with a design example was provided in chapter IV. This example was then evaluated against a functionally similar, traditional display. The results of this evaluation showed that a taskoriented approach to design is a viable concept with regard to reducing user error, increasing acceptance, and reducing cognitive workload. The goal of this design process, providing task-oriented information to the user, both in content and form, appears to be a feasible mechanism for increasing the overall performance of a man-machine system. 


\section{APPENDIX A}

\section{ABBREVIATIONS AND DEFINITIONS}

\section{Abbreviations}

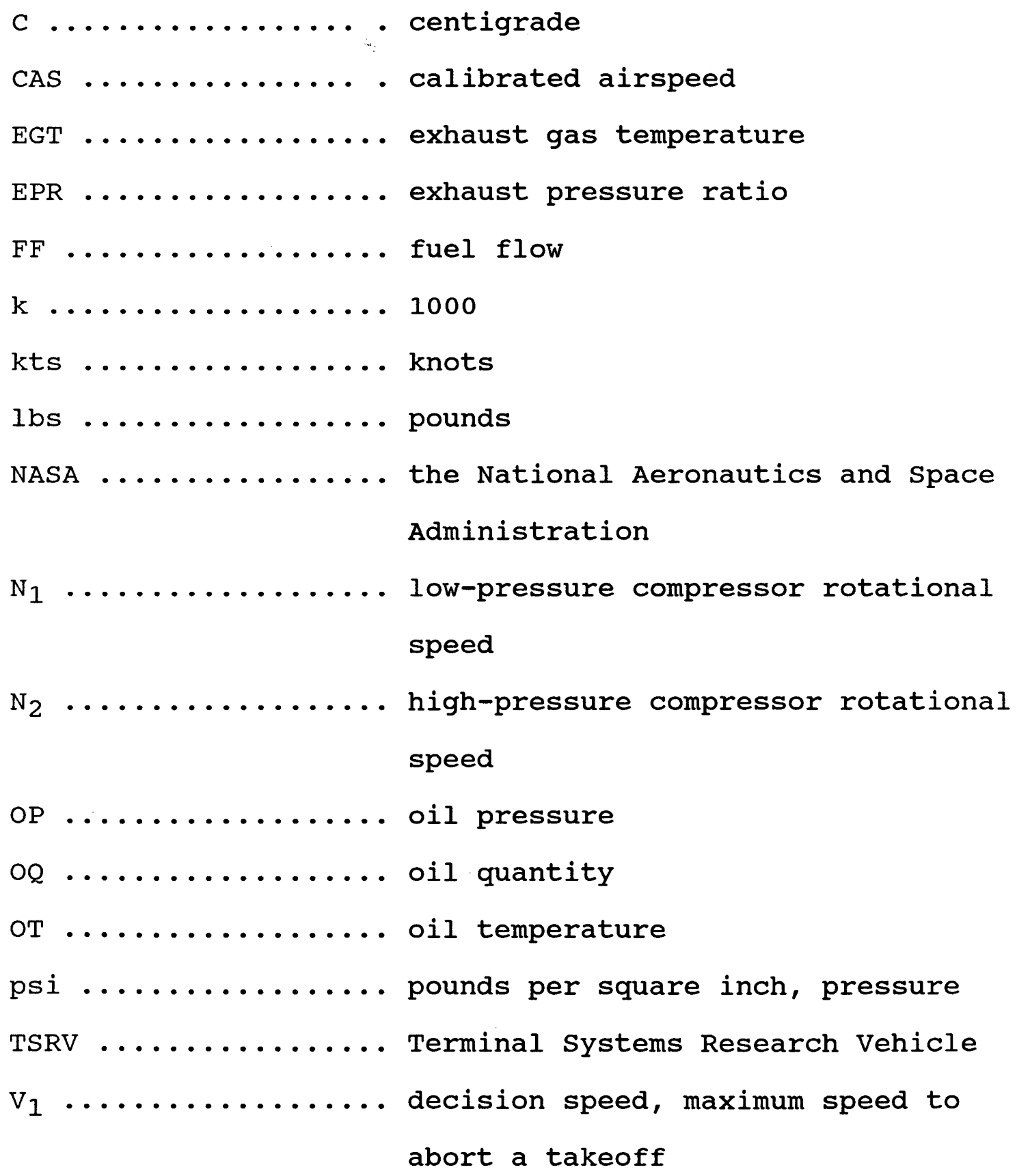




\title{
Definitions
}

\begin{abstract}
abnormal condition ... a condition where a component or system is not operating properly but is within its normal operating limits advanced format ..... engine display format designed for this study

caution limit ....... component operation in this region is time critical

modern format ....... current technology, state-of-the-art, engine display format

out-of-tolerance ..... a condition where a component or condition system is not operating within its normal operating limits warning limit ...... continued component operation in this region will result in failure
\end{abstract}


APPENDIX B

INFORMATION CHARACTERISTICS 


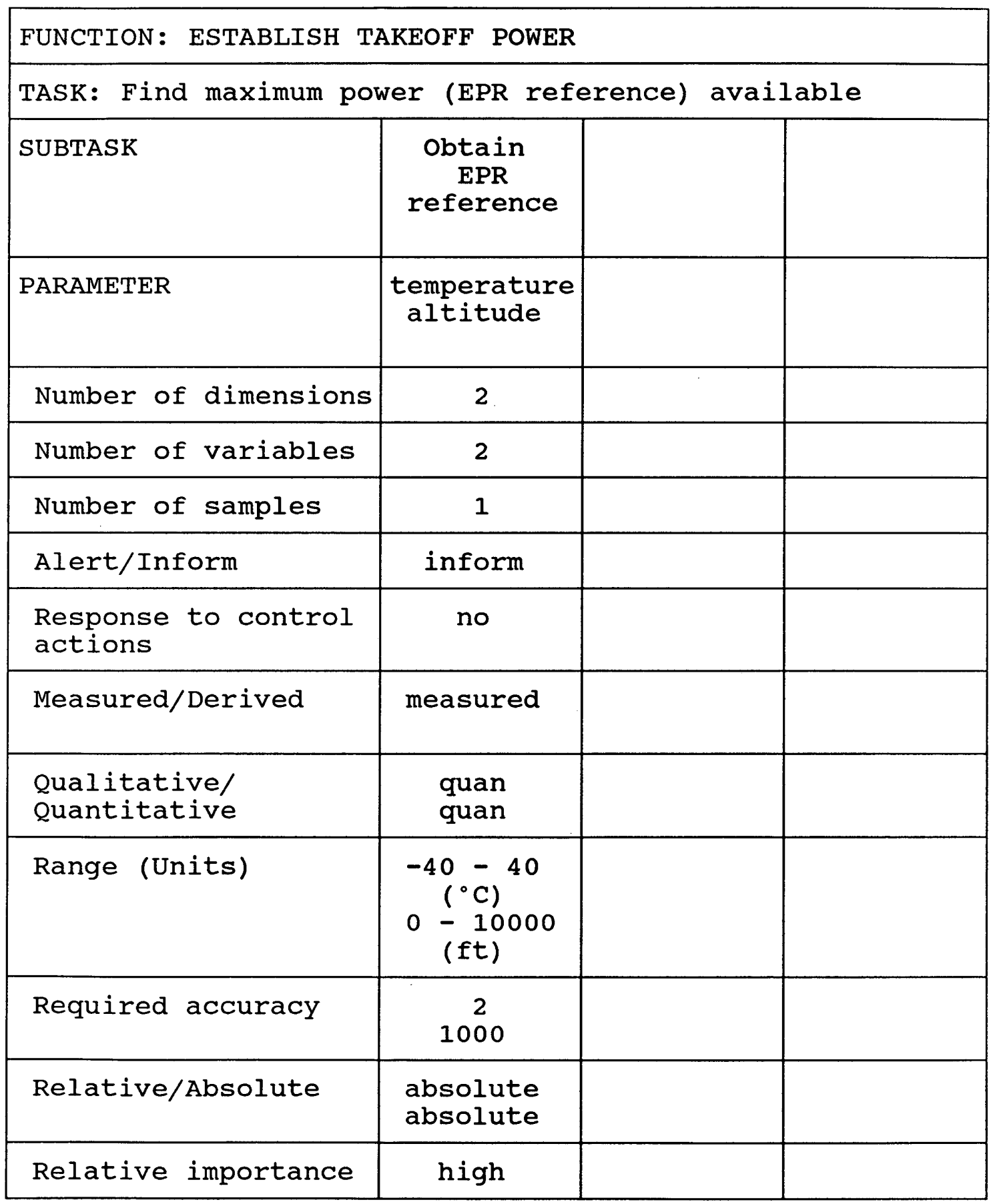




\begin{tabular}{|c|c|c|c|}
\hline \multicolumn{4}{|l|}{ TASK: Set takeoff power } \\
\hline SUBTASK & $\begin{array}{l}\text { Set EPR to } \\
\text { reference }\end{array}$ & $\begin{array}{l}\text { Check for } \\
\text { EPR } \\
\text { decrease }\end{array}$ & $\begin{array}{c}\text { Adjust } \mathrm{EPR} \\
\text { at } 60 \mathrm{kts} \\
\text { to } \\
\text { reference }\end{array}$ \\
\hline PARAMETER & $\begin{array}{c}\mathrm{EPR} \\
\mathrm{EPR} \text { ref } * *\end{array}$ & EPR & $\begin{array}{l}\text { EPR } \\
\text { EPR ref ** } \\
\text { airspeed * }\end{array}$ \\
\hline Number of dimensions & 1 & 1 & 1 \\
\hline Number of variables & 2 & 1 & 2 \\
\hline Number of samples & 1 & $2-3$ & 1 \\
\hline Alert/Inform & inform & inform & inform \\
\hline $\begin{array}{l}\text { Response to control } \\
\text { actions }\end{array}$ & yes & no & no \\
\hline Measured/Derived & $\begin{array}{r}\text { measured } \\
\text { derived }\end{array}$ & measured & $\begin{array}{r}\text { measured } \\
\text { derived }\end{array}$ \\
\hline $\begin{array}{l}\text { Qualitative/ } \\
\text { Quantitative }\end{array}$ & $\begin{array}{l}\text { both } \\
\text { quan }\end{array}$ & quan & $\begin{array}{l}\text { both } \\
\text { quan }\end{array}$ \\
\hline Range (Units) & $\begin{array}{l}0.8-2.5 \\
(4 \text { psi) } \\
1.7-2.5 \\
(4 \text { psi) }\end{array}$ & $\begin{array}{l}0.8-2.5 \\
(\Delta \text { psi) }\end{array}$ & $\begin{array}{l}0.8-2.5 \\
(4 \text { psi) } \\
1.7-2.5 \\
(4 \text { psi) }\end{array}$ \\
\hline Required accuracy & $\begin{array}{l}0.01 \\
0.01\end{array}$ & 0.03 & $\begin{array}{l}0.01 \\
0.01\end{array}$ \\
\hline Relative/Absolute & $\begin{array}{l}\text { relative } \\
\text { relative }\end{array}$ & absolute & $\begin{array}{l}\text { relative } \\
\text { relative }\end{array}$ \\
\hline Relative importance & medium & low & high \\
\hline
\end{tabular}

* external source.

** computed by the user. the reference is lower than the maximum limit. 


\begin{tabular}{|c|c|c|c|}
\hline \multicolumn{4}{|c|}{ TASK: Confirm takeoff power } \\
\hline SUBTASK & $\begin{array}{c}\text { Check for } \\
\text { EPR } \\
\text { decrease }\end{array}$ & $\begin{array}{c}\text { Check EPR } \\
\text { at } V_{1} \\
\text { with } \\
\text { reference }\end{array}$ & \\
\hline PARAMETER & EPR & $\begin{array}{l}\text { EPR } \\
\text { EPR ref ** } \\
\text { airspeed * }\end{array}$ & \\
\hline Number of dimensions & 1 & 1 & \\
\hline Number of variables & 1 & 2 & \\
\hline Number of samples & $2-3$ & 1 & \\
\hline Alert/Inform & inform & both & \\
\hline $\begin{array}{l}\text { Response to control } \\
\text { actions }\end{array}$ & no & no & \\
\hline Measured/Derived & measured & $\begin{array}{l}\text { measured } \\
\text { derived }\end{array}$ & \\
\hline $\begin{array}{l}\text { Qualitative/ } \\
\text { Quantitative }\end{array}$ & both & $\begin{array}{l}\text { both } \\
\text { quan }\end{array}$ & \\
\hline Range (Units) & $\begin{array}{l}0.8-2.5 \\
(4 \operatorname{psi})\end{array}$ & $\begin{array}{c}0.8-2.5 \\
\quad(4 \text { psi) } \\
1.7-2.5 \\
(4 \text { psi) }\end{array}$ & \\
\hline Required accuracy & 0.03 & $\begin{array}{l}0.01 \\
0.01\end{array}$ & \\
\hline Relative/Absolute & absolute & $\begin{array}{l}\text { relative } \\
\text { relative }\end{array}$ & \\
\hline Relative importance & low & high & \\
\hline
\end{tabular}

* external source.

** computed by the user. the reference is lower than the maximum limit. 


\begin{tabular}{|c|c|c|c|}
\hline TASK: Adjust power to & establish $/ \mathrm{m}$ & intain spe & \\
\hline SUBTASK & $\begin{array}{l}\text { Set EPR to } \\
\text { provide } \\
\text { power for } \\
\text { speed }\end{array}$ & $\begin{array}{l}\text { Check for } \\
\text { improper } \\
\text { EPR } \\
\text { response }\end{array}$ & $\begin{array}{l}\text { Compare } \\
\text { EPR with } \\
\text { continuous } \\
\text { limits }\end{array}$ \\
\hline PARAMETER & $\begin{array}{c}E P R \\
\text { airspeed * }\end{array}$ & EPR & $\begin{array}{ll} & \text { EPR } \\
\text { EPR } & \text { limit** }\end{array}$ \\
\hline Number of dimensions & 1 & 1 & 1 \\
\hline Number of variables & 1 & 1 & 2 \\
\hline Number of samples & 1 & $2-3$ & 1 \\
\hline Alert/Inform & inform & inform & both \\
\hline $\begin{array}{l}\text { Response to control } \\
\text { actions }\end{array}$ & yes & no & no \\
\hline Measured/Derived & measured & measured & $\begin{array}{r}\text { measured } \\
\text { derived }\end{array}$ \\
\hline $\begin{array}{l}\text { Qualitative/ } \\
\text { Quantitative }\end{array}$ & quan & quan & $\begin{array}{l}\text { quan } \\
\text { quan }\end{array}$ \\
\hline Range (Units) & $\begin{array}{c}0.8-2.5 \\
(4 \mathrm{psi}) \\
0-600 \\
(\mathrm{kts})\end{array}$ & $\begin{array}{c}0.8-2.5 \\
(\Delta \text { psi) }\end{array}$ & $\begin{array}{l}0.8-2.5 \\
\quad(\Delta p s i) \\
1.5-2.5 \\
(4 \text { psi) }\end{array}$ \\
\hline Required accuracy & - & - & 0.01 \\
\hline Relative/Absolute & absolute & absolute & $\begin{array}{l}\text { relative } \\
\text { relative }\end{array}$ \\
\hline Relative importance & medium & low & high \\
\hline
\end{tabular}

* external source.

** computed or estimated by the user. 


\begin{tabular}{|c|c|c|c|}
\hline \multicolumn{4}{|c|}{ FUNCTION: CHECK FOR OUT-OF-TOLERANCE CONDITIONS } \\
\hline \multicolumn{4}{|l|}{ TASK: Check for high $\mathrm{N}_{1}$} \\
\hline SUBTASK & $\begin{array}{l}\text { Check for } \\
\mathrm{N}_{1} \text { in high } \\
\text { caution } \\
\text { region }\end{array}$ & $\begin{array}{l}\text { Determine } \\
\text { if in } \\
\text { high power } \\
\text { condition }\end{array}$ & $\begin{array}{l}\text { Check for } \\
\mathrm{N}_{1} \text { in high } \\
\text { warning } \\
\text { region }\end{array}$ \\
\hline PARAMETER & $\mathrm{N}_{1} \stackrel{\mathrm{N}_{1}}{\text { limit }}$ & EPR & $\mathrm{N}_{1} \stackrel{\mathrm{N}_{1}}{1 \text { imit }}$ \\
\hline Number of dimensions & 1 & 1 & 1 \\
\hline Number of variables & 2 & 1 & 2 \\
\hline Number of samples & 1 & 1 & 1 \\
\hline Alert/Inform & both & inform & both \\
\hline $\begin{array}{l}\text { Response to control } \\
\text { actions }\end{array}$ & no & no & no \\
\hline Measured/Derived & $\begin{array}{l}\text { measured } \\
\text { measured }\end{array}$ & measured & $\begin{array}{l}\text { measured } \\
\text { measured }\end{array}$ \\
\hline $\begin{array}{l}\text { Qualitative/ } \\
\text { Quantitative }\end{array}$ & $\begin{array}{l}\text { both } \\
\text { quan }\end{array}$ & qual & $\begin{array}{l}\text { both } \\
\text { quan }\end{array}$ \\
\hline Range (Units) & $\begin{array}{c}0-100.1 \\
(\% \mathrm{rpm}) \\
94-100.1 \\
(\% \mathrm{rpm})\end{array}$ & $\begin{array}{l}0.8-2.5 \\
(\Delta \mathrm{psi})\end{array}$ & $\begin{array}{c}0-115 \\
(\% \mathrm{rpm}) \\
100.1-115 \\
(\% \mathrm{rpm})\end{array}$ \\
\hline Required accuracy & $\begin{array}{l}0.1 \\
0.1\end{array}$ & - & $\begin{array}{l}0.1 \\
0.1\end{array}$ \\
\hline Relative/Absolute & $\begin{array}{l}\text { relative } \\
\text { relative }\end{array}$ & absolute & $\begin{array}{l}\text { relative } \\
\text { relative }\end{array}$ \\
\hline Relative importance & medium & low & high \\
\hline
\end{tabular}




\begin{tabular}{|c|c|c|c|}
\hline FUNCTION: CHECK FOR OU & T-OF-TOLERAI & JCE CONDITIC & \\
\hline TASK: Check for high $N$ & & & \\
\hline SUBTASK & $\begin{array}{l}\text { Check for } \\
\mathrm{N}_{2} \text { in high } \\
\text { caution } \\
\text { region }\end{array}$ & $\begin{array}{l}\text { Determine } \\
\text { if in } \\
\text { high power } \\
\text { condition }\end{array}$ & $\begin{array}{l}\text { Check for } \\
\mathrm{N}_{2} \text { in high } \\
\text { warning } \\
\text { region }\end{array}$ \\
\hline PARAMETER & $\mathrm{N}_{2} \stackrel{\mathrm{N}_{2}}{\text { limit }}$ & EPR & $\mathrm{N}_{2} \stackrel{\mathrm{N}_{2}}{\text { limit }}$ \\
\hline Number of dimensions & 1 & 1 & 1 \\
\hline Number of variables & 2 & 1 & 2 \\
\hline Number of samples & 1 & 1 & 1 \\
\hline Alert/Inform & both & inform & both \\
\hline $\begin{array}{l}\text { Response to control } \\
\text { actions }\end{array}$ & no & no & no \\
\hline Measured/Derived & $\begin{array}{l}\text { measured } \\
\text { measured }\end{array}$ & measured & $\begin{array}{l}\text { measured } \\
\text { measured }\end{array}$ \\
\hline $\begin{array}{l}\text { Qualitative/ } \\
\text { Quantitative }\end{array}$ & $\begin{array}{l}\text { both } \\
\text { quan }\end{array}$ & qual & $\begin{array}{l}\text { both } \\
\text { quan }\end{array}$ \\
\hline Range (Units) & $\begin{array}{c}0-100 \\
(\% \mathrm{rpm}) \\
94-100 \\
(\% \mathrm{rpm})\end{array}$ & $\begin{array}{c}0.8-2.5 \\
(\wedge \mathrm{psi})\end{array}$ & $\begin{array}{c}0-115 \\
(\% \mathrm{rpm}) \\
100-115 \\
(\% \mathrm{rpm})\end{array}$ \\
\hline Required accuracy & $\begin{array}{l}0.1 \\
0.1\end{array}$ & - & $\begin{array}{l}0.1 \\
0.1\end{array}$ \\
\hline Relative/Absolute. & $\begin{array}{l}\text { relative } \\
\text { relative }\end{array}$ & absolute & $\begin{array}{l}\text { relative } \\
\text { relative }\end{array}$ \\
\hline Relative importance & medium & low & high \\
\hline
\end{tabular}




\begin{tabular}{|c|c|c|c|}
\hline \multicolumn{4}{|c|}{ FUNCTION: CHECK FOR OUT-OF-TOLERANCE CONDITIONS } \\
\hline \multicolumn{4}{|c|}{ TASK: Check for high EGT } \\
\hline SUBTASK & $\begin{array}{l}\text { Check for } \\
\text { EGT in high } \\
\text { caution } \\
\text { region }\end{array}$ & $\begin{array}{l}\text { Determine } \\
\text { if in } \\
\text { high power } \\
\text { condition }\end{array}$ & $\begin{array}{l}\text { Check for } \\
\text { EGT in high } \\
\text { warning } \\
\text { region }\end{array}$ \\
\hline PARAMETER & EGT limit & EPR & EGT Iimit \\
\hline Number of dimensions & 1 & 1 & 1 \\
\hline Number of variables & 2 & 1 & 2 \\
\hline Number of samples & 1 & 1 & 1 \\
\hline Alert/Inform & both & inform & both \\
\hline $\begin{array}{l}\text { Response to control } \\
\text { actions }\end{array}$ & no & no & no \\
\hline Measured/Derived & $\begin{array}{l}\text { measured } \\
\text { measured }\end{array}$ & measured & $\begin{array}{l}\text { measured } \\
\text { measured }\end{array}$ \\
\hline $\begin{array}{l}\text { Qualitative/ } \\
\text { Quantitative }\end{array}$ & $\begin{array}{l}\text { both } \\
\text { quan }\end{array}$ & qual & $\begin{array}{l}\text { both } \\
\text { quan }\end{array}$ \\
\hline Range (Units) & $\begin{array}{l}290-600 \\
\left({ }^{\circ} \mathrm{C}\right) \\
535-570 \\
\left({ }^{\circ} \mathrm{C}\right)\end{array}$ & $\begin{array}{l}0.8-2.5 \\
(\Delta \text { psi) }\end{array}$ & $\begin{array}{l}290-600 \\
\left({ }^{\circ} \mathrm{C}\right) \\
570-600 \\
\left({ }^{\circ} \mathrm{C}\right)\end{array}$ \\
\hline Required accuracy & $\begin{array}{l}2 \\
2\end{array}$ & - & $\begin{array}{l}2 \\
2\end{array}$ \\
\hline Relative/Absolute & $\begin{array}{l}\text { relative } \\
\text { relative }\end{array}$ & absolute & $\begin{array}{l}\text { relative } \\
\text { relative }\end{array}$ \\
\hline Relative importance & medium & low & high \\
\hline
\end{tabular}




\begin{tabular}{|c|c|c|c|}
\hline \multicolumn{4}{|c|}{ FUNCTION: CHECK FOR OUT-OF-TOLERANCE CONDITIONS } \\
\hline \multicolumn{4}{|c|}{ TASK: Check for high or low oil pressure (OP) } \\
\hline SUBTASK & $\begin{array}{l}\text { Check for } \\
\text { op in low } \\
\text { warning } \\
\text { region }\end{array}$ & $\begin{array}{l}\text { Check for } \\
\text { op in low } \\
\text { caution } \\
\text { region }\end{array}$ & $\begin{array}{l}\text { Check for } \\
\text { OP in high } \\
\text { warning } \\
\text { region }\end{array}$ \\
\hline PARAMETER & $\begin{array}{ll}\text { OP } \\
\text { OP limit }\end{array}$ & oP limit & oP limit \\
\hline Number of dimensions & 1 & 1 & 1 \\
\hline Number of variables & 2 & 2 & 2 \\
\hline Number of samples & 1 & 1 & 1 \\
\hline Alert/Inform & both & both & both \\
\hline $\begin{array}{l}\text { Response to control } \\
\text { actions }\end{array}$ & no & no & no \\
\hline Measured/Derived & $\begin{array}{l}\text { measured } \\
\text { measured }\end{array}$ & $\begin{array}{l}\text { measured } \\
\text { measured }\end{array}$ & $\begin{array}{l}\text { measured } \\
\text { measured }\end{array}$ \\
\hline $\begin{array}{l}\text { Qualitative/ } \\
\text { Quantitative }\end{array}$ & $\begin{array}{l}\text { quan } \\
\text { quan }\end{array}$ & $\begin{array}{l}\text { quan } \\
\text { quan }\end{array}$ & $\begin{array}{l}\text { quan } \\
\text { quan }\end{array}$ \\
\hline Range (Units) & $\begin{array}{c}0-100 \\
(p s i) \\
0-35 \\
(p s i)\end{array}$ & $\begin{array}{c}0-100 \\
(p s i) \\
35-40 \\
(p s i)\end{array}$ & $\begin{array}{c}0-100 \\
(p s i) \\
55-100 \\
(p s i)\end{array}$ \\
\hline Required accuracy & $\begin{array}{l}1 \\
1\end{array}$ & $\begin{array}{l}1 \\
1\end{array}$ & $\begin{array}{l}1 \\
1\end{array}$ \\
\hline Relative/Absolute & $\begin{array}{l}\text { relative } \\
\text { relative }\end{array}$ & $\begin{array}{l}\text { relative } \\
\text { relative }\end{array}$ & $\begin{array}{l}\text { relative } \\
\text { relative }\end{array}$ \\
\hline Relative importance & high & medium & high \\
\hline
\end{tabular}




\begin{tabular}{|c|c|c|c|}
\hline \multicolumn{4}{|c|}{ FUNCTION: CHECK FOR OUT-OF-TOLERANCE CONDITIONS } \\
\hline \multicolumn{4}{|c|}{ TASK: Check for high or low oil temperature (OT) } \\
\hline SUBTASK & $\begin{array}{l}\text { Check for } \\
\text { oT in low } \\
\text { warning } \\
\text { region }\end{array}$ & $\begin{array}{l}\text { Check for } \\
\text { OT in high } \\
\text { caution } \\
\text { region }\end{array}$ & $\begin{array}{l}\text { Check for } \\
\text { OT in high } \\
\text { warning } \\
\text { region }\end{array}$ \\
\hline PARAMETER & $\begin{array}{ll}\text { OT } \\
\text { OT limit }\end{array}$ & $\begin{array}{ll}\text { OT } \\
\text { OT limit }\end{array}$ & $\begin{array}{ll}\text { OT } \\
\text { OT limit }\end{array}$ \\
\hline Number of dimensions & 1 & 1 & 1 \\
\hline Number of variables & 2 & 2 & 2 \\
\hline Number of samples & 1 & 1 & 1 \\
\hline Alert/Inform & both & both & both \\
\hline $\begin{array}{l}\text { Response to control } \\
\text { actions }\end{array}$ & no & no & no \\
\hline Measured/Derived & $\begin{array}{l}\text { measured } \\
\text { measured }\end{array}$ & $\begin{array}{l}\text { measured } \\
\text { measured }\end{array}$ & $\begin{array}{l}\text { measured } \\
\text { measured }\end{array}$ \\
\hline $\begin{array}{l}\text { Qualitative/ } \\
\text { Quantitative }\end{array}$ & $\begin{array}{l}\text { quan } \\
\text { quan }\end{array}$ & $\begin{array}{l}\text { quan } \\
\text { quan }\end{array}$ & $\begin{array}{l}\text { quan } \\
\text { quan }\end{array}$ \\
\hline Range (Units) & $\begin{array}{c}0-180 \\
\left({ }^{\circ} \mathrm{C}\right) \\
0-40 \\
\left({ }^{\circ} \mathrm{C}\right)\end{array}$ & $\begin{array}{c}0-180 \\
\left({ }^{\circ} \mathrm{C}\right) \\
120-157 \\
\left({ }^{\circ} \mathrm{C}\right)\end{array}$ & $\begin{array}{c}0-180 \\
\left({ }^{\circ} \mathrm{C}\right) \\
157-180 \\
\left({ }^{\circ} \mathrm{C}\right)\end{array}$ \\
\hline Required accuracy & $\begin{array}{l}1 \\
1\end{array}$ & $\begin{array}{l}1 \\
1\end{array}$ & $\begin{array}{l}1 \\
1\end{array}$ \\
\hline Relative/Absolute & $\begin{array}{l}\text { relative } \\
\text { relative }\end{array}$ & $\begin{array}{l}\text { relative } \\
\text { relative }\end{array}$ & $\begin{array}{l}\text { relative } \\
\text { relative }\end{array}$ \\
\hline Relative importance & high & medium & high \\
\hline
\end{tabular}




\begin{tabular}{|c|c|c|}
\hline \multicolumn{3}{|c|}{ FUNCTION: CHECK FOR OUT-OF-TOLERANCE CONDITIONS } \\
\hline \multicolumn{3}{|c|}{ TASK: Check low oil quantity (OQ) } \\
\hline SUBTASK & $\begin{array}{l}\text { Check for } \\
\text { OQ in low } \\
\text { warning } \\
\text { region }\end{array}$ & \\
\hline PARAMETER & $\begin{array}{ll} & O Q \\
O Q & \text { limit }\end{array}$ & \\
\hline Number of dimensions & 1 & \\
\hline Number of variables & 2 & \\
\hline Number of samples & 1 & \\
\hline Alert/Inform & both & \\
\hline $\begin{array}{l}\text { Response to control } \\
\text { actions }\end{array}$ & no & \\
\hline Measured/Derived & $\begin{array}{l}\text { measured } \\
\text { measured }\end{array}$ & \\
\hline $\begin{array}{l}\text { Qualitative/ } \\
\text { Quantitative }\end{array}$ & $\begin{array}{l}\text { quan } \\
\text { quan }\end{array}$ & \\
\hline Range (Units) & $\begin{array}{l}0-5 \\
(g a l) \\
0-1 \\
(g a l)\end{array}$ & \\
\hline Required accuracy & $\begin{array}{l}1 \\
1\end{array}$ & \\
\hline Relative/Absolute & $\begin{array}{l}\text { relative } \\
\text { relative }\end{array}$ & \\
\hline Relative importance & high & \\
\hline
\end{tabular}




\begin{tabular}{|c|c|c|c|}
\hline \multicolumn{4}{|c|}{ FUNCTION: CHECK FOR DEGRADED CONDITIONS } \\
\hline \multicolumn{4}{|c|}{ TASK: Check for an unusual rate of change of a parameter } \\
\hline SUBTASK & $\begin{array}{c}\text { Check EPR } \\
\text { for } \\
\text { change }\end{array}$ & $\begin{array}{c}\text { Check } \mathrm{N}_{1} \\
\text { for } \\
\text { change }\end{array}$ & $\begin{array}{c}\text { Check } \mathrm{N}_{2} \\
\text { for } \\
\text { change }\end{array}$ \\
\hline PARAMETER & EPR & $\mathrm{N}_{1}$ & $\mathrm{~N}_{2}$ \\
\hline Number of dimensions & 1 & 1 & 1 \\
\hline Number of variables & 1 & 1 & 1 \\
\hline Number of samples & $2-5$ & $2-5$ & $2-5$ \\
\hline Alert/Inform & alert & alert & alert \\
\hline $\begin{array}{l}\text { Response to control } \\
\text { actions }\end{array}$ & no & no & no \\
\hline Measured/Derived & measured & measured & measured \\
\hline $\begin{array}{l}\text { Qualitative/ } \\
\text { Quantitative }\end{array}$ & quan & quan & quan \\
\hline Range (Units) & $\begin{array}{l}0.8-2.5 \\
(4 \mathrm{psi})\end{array}$ & $\begin{array}{l}0-115 \\
(\% \mathrm{rpm})\end{array}$ & $\begin{array}{l}0-115 \\
(\% \mathrm{rpm})\end{array}$ \\
\hline Required accuracy & 0.03 & 0.5 & 0.5 \\
\hline Relative/Absolute & absolute & absolute & absolute \\
\hline Relative importance & low & low & low \\
\hline
\end{tabular}




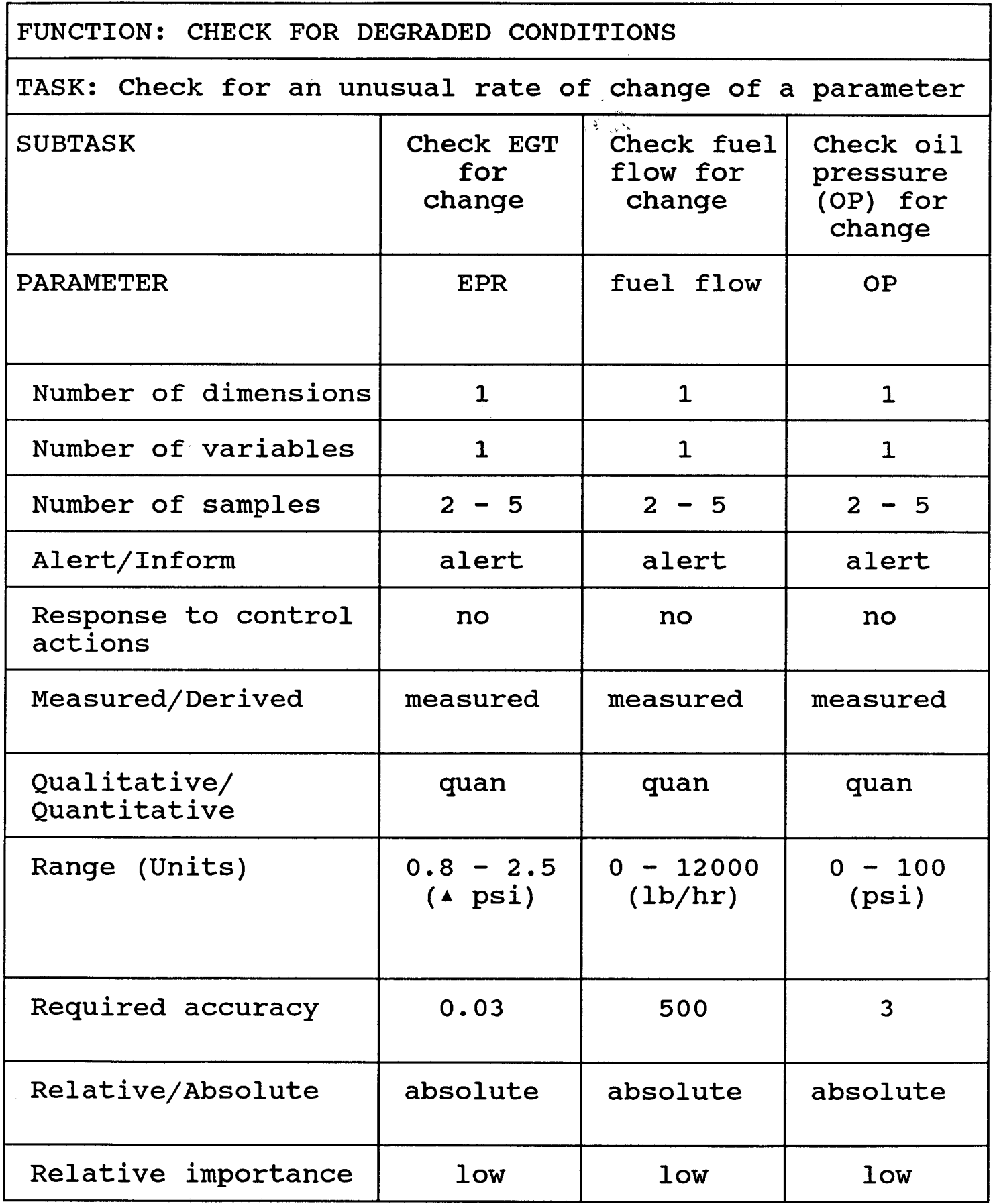




\begin{tabular}{|c|c|c|c|}
\hline \multicolumn{4}{|c|}{ FUNCTION: CHECK FOR DEGRADED CONDITIONS } \\
\hline \multicolumn{4}{|c|}{ TASK: Check for an unusual rate of change of a parameter } \\
\hline SUBTASK & $\begin{array}{l}\text { Check oil } \\
\text { temperature } \\
\text { (OT) for } \\
\text { change }\end{array}$ & $\begin{array}{l}\text { Check oil } \\
\text { quantity } \\
\text { (OQ) for } \\
\text { change }\end{array}$ & \\
\hline PARAMETER & OT & OQ & \\
\hline Number of dimensions & 1 & 1 & \\
\hline Number of variables & 1 & 1 & \\
\hline Number of samples & $2-5$ & $2-5$ & \\
\hline Alert/Inform & alert & alert & \\
\hline $\begin{array}{l}\text { Response to control } \\
\text { actions }\end{array}$ & no & no & \\
\hline Measured/Derived & measured & measured & \\
\hline $\begin{array}{l}\text { Qualitative/ } \\
\text { Quantitative }\end{array}$ & quan & quan & \\
\hline Range (Units) & $0-180$ & $\begin{array}{l}0-5 \\
(g a l)\end{array}$ & \\
\hline Required accuracy & 2 & 0.1 & \\
\hline Relative/Absolute & absolute & absolute & \\
\hline Relative importance & low & low & \\
\hline
\end{tabular}




\begin{tabular}{|c|c|c|c|}
\hline \multicolumn{4}{|c|}{ FUNCTION: CHECK FOR DEGRADED CONDITIONS } \\
\hline \multicolumn{4}{|c|}{ TASK: Determine if EPR value is appropriate } \\
\hline SUBTASK & $\begin{array}{c}\text { Compare } \\
\text { EPR value } \\
\text { with } \\
\text { nominal }\end{array}$ & & \\
\hline PARAMETER & $\begin{array}{ll}\text { actual } & E P R \\
\text { nominal } & \text { EPR }\end{array}$ & & \\
\hline Number of dimensions & 1 & & \\
\hline Number of variables & 2 & & \\
\hline Number of samples & 1 & & \\
\hline Alert/Inform & inform & & \\
\hline $\begin{array}{l}\text { Response to control } \\
\text { actions }\end{array}$ & no & & \\
\hline Measured/Derived & $\begin{array}{l}\text { measured } \\
\text { estimated }\end{array}$ & & \\
\hline $\begin{array}{l}\text { Qualitative/ } \\
\text { Quantitative }\end{array}$ & $\begin{array}{l}\text { quan } \\
\text { quan }\end{array}$ & & \\
\hline Range (Units) & 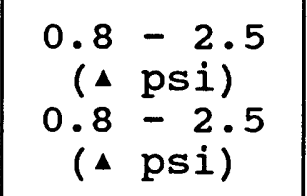 & & \\
\hline Required accuracy & $\begin{array}{l}0.2 \\
0.2\end{array}$ & & \\
\hline Relative/Absolute & $\begin{array}{l}\text { relative } \\
\text { relative }\end{array}$ & & \\
\hline Relative importance & medium & & \\
\hline
\end{tabular}




\begin{tabular}{|c|c|c|c|}
\hline \multicolumn{4}{|c|}{ FUNCTION: CHECK FOR DEGRADED CONDITIONS } \\
\hline TASK: Determine if $\mathrm{N}_{1}$ & value is ap & ropriate & \\
\hline SUBTASK & $\begin{array}{l}\text { Compare } \\
\mathrm{N}_{1} \text { value } \\
\text { with } \\
\text { nominal }\end{array}$ & & \\
\hline PARAMETER & $\begin{aligned} \operatorname{actual} & \mathrm{N}_{1} \\
\text { nominal } & \mathrm{N}_{1}\end{aligned}$ & & \\
\hline Number of dimensions & 1 & & \\
\hline Number of variables & 2 & & \\
\hline Number of samples & 1 & & \\
\hline Alert/Inform & inform & & \\
\hline $\begin{array}{l}\text { Response to control } \\
\text { actions }\end{array}$ & no & & \\
\hline Measured/Derived & $\begin{array}{l}\text { measured } \\
\text { estimated }\end{array}$ & & \\
\hline $\begin{array}{l}\text { Qualitative/ } \\
\text { Quantitative }\end{array}$ & $\begin{array}{l}\text { quan } \\
\text { quan }\end{array}$ & & \\
\hline Range (Units) & $\begin{array}{c}0-100.1 \\
(\% \text { rpm }) \\
0-100.1 \\
(\% \text { rpm })\end{array}$ & & \\
\hline Required accuracy & $\begin{array}{l}3 \\
3\end{array}$ & & \\
\hline Relative/Absolute & $\begin{array}{l}\text { relative } \\
\text { relative }\end{array}$ & & \\
\hline Relative importance & medium & & \\
\hline
\end{tabular}




\begin{tabular}{|c|c|c|c|}
\hline \multicolumn{4}{|c|}{ FUNCTION: CHECK FOR DEGRADED CONDITIONS } \\
\hline TASK: Determine if $\mathrm{N}_{2}$ & value is ap & oropriate & \\
\hline SUBTASK & $\begin{array}{l}\text { Compare } \\
\mathrm{N}_{2} \text { value } \\
\text { with } \\
\text { nominal }\end{array}$ & & \\
\hline PARAMETER & $\begin{aligned} \operatorname{actual} & \mathrm{N}_{2} \\
\text { nominal } & \mathrm{N}_{2}\end{aligned}$ & & \\
\hline Number of dimensions & 1 & & \\
\hline Number of variables & 2 & & \\
\hline Number of samples & 1 & & \\
\hline Alert/Inform & inform & & \\
\hline $\begin{array}{l}\text { Response to control } \\
\text { actions }\end{array}$ & no & & \\
\hline Measured/Derived & $\begin{array}{l}\text { measured } \\
\text { estimated }\end{array}$ & & \\
\hline $\begin{array}{l}\text { Qualitative/ } \\
\text { Quantitative }\end{array}$ & $\begin{array}{l}\text { quan } \\
\text { quan }\end{array}$ & & \\
\hline Range (Units) & $\begin{array}{l}0-100 \\
(\% \text { rpm }) \\
0-100 \\
(\% \text { rpm })\end{array}$ & & \\
\hline Required accuracy & $\begin{array}{l}3 \\
3\end{array}$ & & \\
\hline Relative/Absolute & $\begin{array}{l}\text { relative } \\
\text { relative }\end{array}$ & & \\
\hline Relative importance & medium & & \\
\hline
\end{tabular}




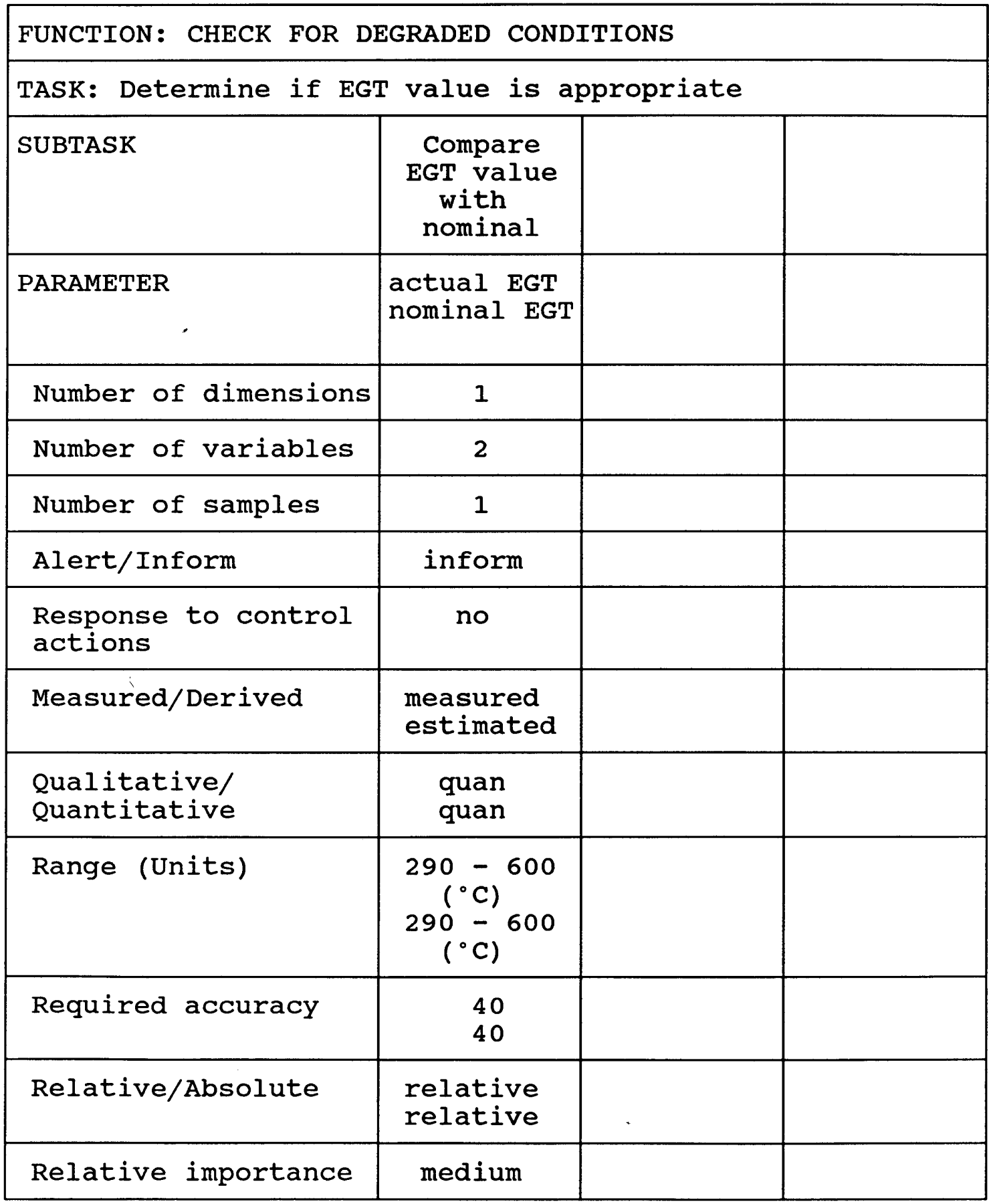




\begin{tabular}{|c|c|c|}
\hline \multicolumn{3}{|c|}{ FUNCTION: CHECK FOR DEGRADED CONDITIONS } \\
\hline TASK: Determine if fue & 1 flow (FF) & value is appropriate \\
\hline SUBTASK & $\begin{array}{c}\text { Compare } \\
\text { FF value } \\
\text { with } \\
\text { nominal }\end{array}$ & \\
\hline PARAMETER & $\begin{aligned} \text { actual } & F F \\
\text { nominal } & F F\end{aligned}$ & \\
\hline Number of dimensions & 1 & \\
\hline Number of variables & 2 & \\
\hline Number of samples & 1 & \\
\hline Alert/Inform & inform & \\
\hline $\begin{array}{l}\text { Response to control } \\
\text { actions }\end{array}$ & no & \\
\hline Measured/Derived & $\begin{array}{l}\text { measured } \\
\text { estimated }\end{array}$ & \\
\hline $\begin{array}{l}\text { Qualitative/ } \\
\text { Quantitative }\end{array}$ & $\begin{array}{l}\text { quan } \\
\text { quan }\end{array}$ & \\
\hline Range (Units) & $\begin{array}{c}0-12000 \\
(1 \mathrm{~b} / \mathrm{hr}) \\
0-12000 \\
(1 \mathrm{~b} / \mathrm{hr})\end{array}$ & \\
\hline Required accuracy & $\begin{array}{l}300 \\
300\end{array}$ & \\
\hline Relative/Absolute & $\begin{array}{l}\text { relative } \\
\text { relative }\end{array}$ & \\
\hline Relative importance & medium & \\
\hline
\end{tabular}


APPENDIX C

MODIFIED TASK SET 
FIGURE CI

TASKS FOR THE FUNCTION ESTABLISH TAKEOFF POWER

TASK

Check system/ component operation
SUBTASK

See the

Monitoring Function

for this set of

tasks
SUBTASK

Advance or adjust power levers until the thrust value is the same as the reference

$( \pm 2 \%)$

Compare thrust with predictor

Adjust thrust at 60 kts

[obtain airspeed, external task]

Compare thrust with the predictor

Check thrust at $v_{1}$ [obtain airspeed, external task] Confirm takeoff
power $\quad\left[\begin{array}{l}\text { Compare power } \\ \text { output with the } \\ \text { reference }\end{array}\right.$
Set the engine obtain takeoff

thrust 
FIGURE C2

TASKS FOR THE FUNCTION ADJUST INFLIGHT POWER

TASK

Check system/ component operation
SUBTASK

See the

Monitoring Function

for this set of

tasks
Adjust power

as necessary to establish/

maintain speed

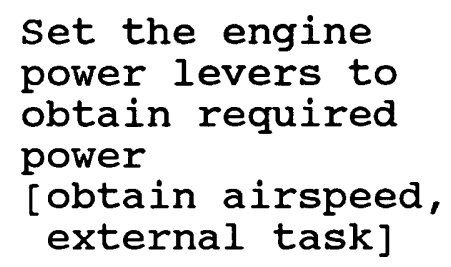

\author{
Adjust power \\ levers until the \\ provided power \\ produces the \\ required speed or \\ speed change \\ [experience] \\ Compare thrust \\ with predictor \\ Check that thrust \\ does not exceed \\ maximum continuous
}




\section{FIGURE C3}

\section{TASKS FOR THE FUNCTIONS CHECK FOR OUT-OF-TOLERANCE CONDITIONS AND CHECK FOR DEGRADED CONDITIONS}
TASK
SUBTASK
SUBTASK
Check for thrust
Check for thrust in out-of-tolerance high caution region
Check for thrust in high warning region
Check for abnormal thrust Compare thrust value against predicted value 
FIGURE C3 (continued)

TASK

\section{SUBTASK}

Check for $\mathrm{N}_{1}$ out-of-tolerance

check for abnormal $\mathrm{N}_{1}$

Check for $\mathrm{N}_{2}$ out-of-tolerance

Check for abnormal $\mathrm{N}_{2}$

Check for EGT out-of-tolerance

Check for abnormal EGT

Check for abnormal

fuel flow

Check of high or low conditions
Check for oil pressure out-of-tolerance

check for abnormal oil pressure

Check for oil temperature out-of-tolerance

Check for abnormal oil temperature

Check for oil quantity out-of-tolerance

check for abnormal oil quantity
SUBTASK

- see subtask

[ Determine if outof-tolerance; if not, abnormal

$\{$ see subtask

[ Determine if out- of-tolerance; if not, abnormal

$\{$ see subtask

$\left\{\begin{array}{l}\text { Determine if out- } \\ \text { of-tolerance; if }\end{array}\right.$ not, abnormal

$\{$ see subtask

[ Determine if outof-tolerance; if not, abnormal

$\{$ see subtask

[ Determine if outof-tolerance; if not, abnormal

$\{$ see subtask

$\left\{\begin{array}{l}\text { Determine if out- } \\ \text { of-tolerance; if }\end{array}\right.$ not, abnormal 


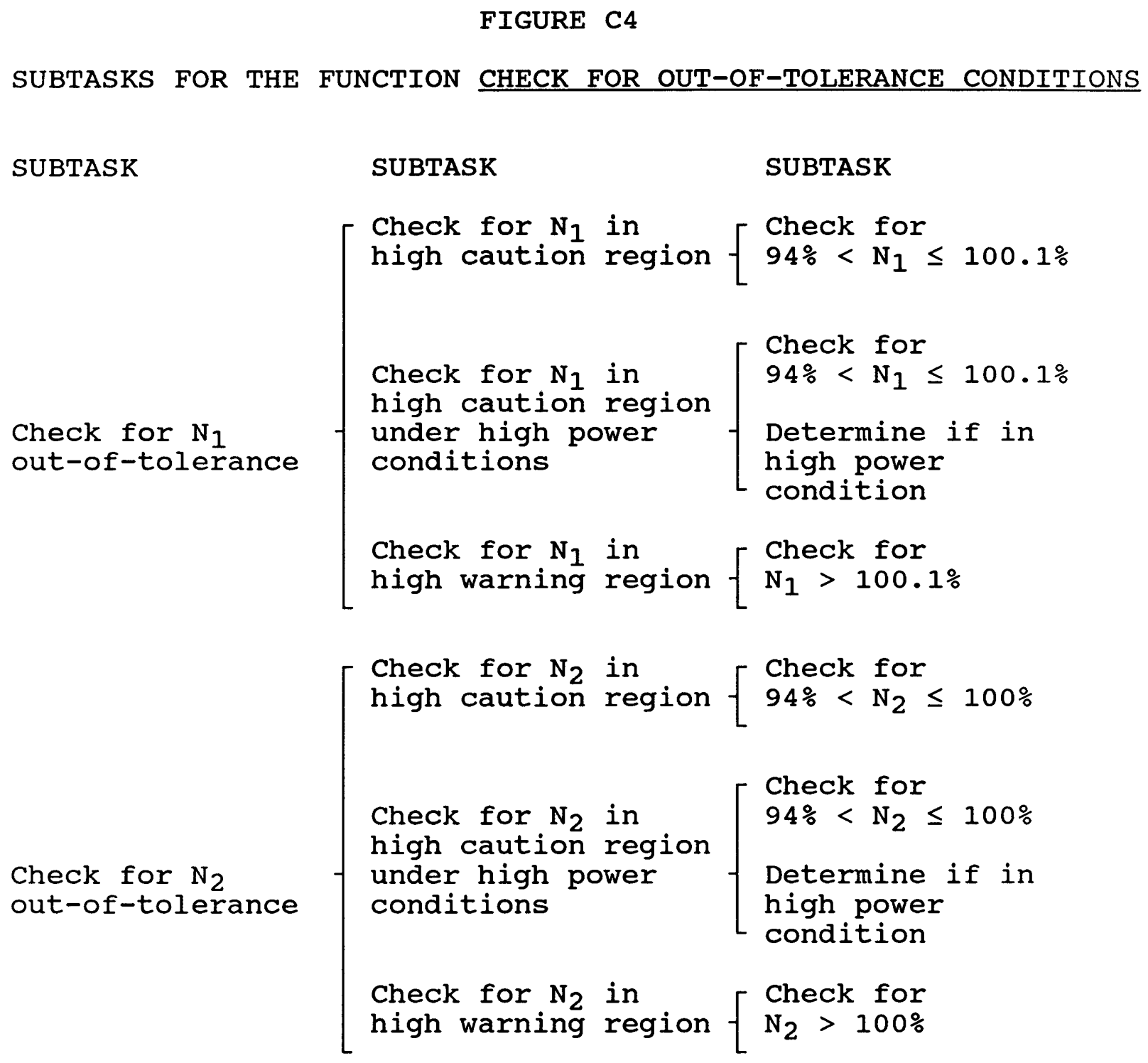


FIGURE C4 (continued)

SUBTASK

Check for EGT

out-of-tolerance

Check for oil

pressure (OP)

out-of-tolerance

Check for oil

temperature (OT)

out-of-tolerance

\section{SUBTASK}

Check for EGT in high caution region

Check for EGT in
high caution region
under high power
conditions

Check for EGT in

Check for op in

low warning region

Check for oP in

Check for op in
Check for $535^{\circ}<\mathrm{EGT} \leq 570^{\circ}$

Check for

$535^{\circ}<\mathrm{EGT} \leq 570^{\circ}$

Determine if in

high power

condition high warning region $-\left[\right.$ EGT $>570^{\circ}$

Check for

$\{$ OP $<35 \mathrm{psi}$ low caution region $\left\{\begin{array}{l}35 \mathrm{ps} i<\mathrm{OP}<40 \mathrm{psi} \\ \hline\end{array}\right.$

high warning region $\left\{\begin{array}{l}\text { CPeck for } \\ \text { OP }>55 i\end{array}\right.$

Check for OT in
low warning region $\left[\right.$ Check for OT $<40^{\circ}$

Check for OT in $\quad[$ Check for

high caution region $\left\{120^{\circ}<\mathrm{OT} \leq 157^{\circ}\right.$

Check for OT in

high warning region $\left\{\begin{array}{l}\text { CTeck for } \\ \text { OT }>157^{\circ}\end{array}\right.$

Check for oil quantity (OQ) out-of-tolerance
Check for $O Q$ in $\quad$ Check for low warning region $[O Q<1$ gal 
APPENDIX D

MODIFIED INFORMATION CHARACTERISTICS 


\begin{tabular}{|c|c|c|c|}
\hline \multicolumn{4}{|c|}{ FUNCTION: ESTABLISH TAKEOFF POWER } \\
\hline \multicolumn{4}{|l|}{ TASK: Set takeoff power } \\
\hline SUBTASK & $\begin{array}{c}\text { Set thrust } \\
\text { predictor } \\
\text { to } \\
\text { reference }\end{array}$ & $\begin{array}{l}\text { Compare } \\
\text { thrust } \\
\text { with } \\
\text { predictor }\end{array}$ & $\begin{array}{l}\text { Adjust } \\
\text { predictor } \\
\text { at 60kts to } \\
\text { reference }\end{array}$ \\
\hline PARAMETER & $\begin{array}{l}\text { predictor } \\
\text { reference }\end{array}$ & $\begin{array}{l}\text { thrust } \\
\text { predictor }\end{array}$ & $\begin{array}{l}\text { predictor } \\
\text { reference } \\
\text { airspeed** }\end{array}$ \\
\hline Number of dimensions & 1 & 1 & 1 \\
\hline Number of variables & 2 & 2 & 2 \\
\hline Number of samples & 1 & 1 & 1 \\
\hline Alert/Inform & inform & inform & inform \\
\hline $\begin{array}{l}\text { Response to control } \\
\text { actions }\end{array}$ & yes & no & no \\
\hline Measured/Derived & $\begin{array}{l}\text { derived } \\
\text { derived }\end{array}$ & $\begin{array}{l}\text { derived } \\
\text { derived }\end{array}$ & $\begin{array}{l}\text { derived } \\
\text { derived }\end{array}$ \\
\hline $\begin{array}{l}\text { Qualitative/ } \\
\text { Quantitative }\end{array}$ & $\begin{array}{l}\text { both } \\
\text { quan }\end{array}$ & $\begin{array}{l}\text { both } \\
\text { both }\end{array}$ & $\begin{array}{l}\text { both } \\
\text { quan }\end{array}$ \\
\hline Range (Units) & $\begin{array}{c}-10-110 \\
(\%) \\
85-110 \\
(\%)\end{array}$ & $\begin{array}{l}-10-110 \\
-10 \frac{(\%)}{(\%)} 110\end{array}$ & $\begin{array}{c}-10-110 \\
(\%) \\
85-110 \\
(\%)\end{array}$ \\
\hline Required accuracy & $\begin{array}{l}2 \\
2\end{array}$ & $\begin{array}{l}4 \\
4\end{array}$ & $\begin{array}{l}2 \\
2\end{array}$ \\
\hline Relative/Absolute & $\begin{array}{l}\text { relative } \\
\text { relative }\end{array}$ & $\begin{array}{l}\text { relative } \\
\text { relative }\end{array}$ & $\begin{array}{l}\text { relative } \\
\text { relative }\end{array}$ \\
\hline Relative importance & medium & medium & high \\
\hline
\end{tabular}

** external source. 


\begin{tabular}{|c|c|c|c|}
\hline \multicolumn{4}{|c|}{ FUNCTION: ESTABLISH TAKEOFF POWER } \\
\hline \multicolumn{4}{|c|}{ TASK: Confirm takeoff power } \\
\hline SUBTASK & $\begin{array}{l}\text { Compare } \\
\text { thrust } \\
\text { with } \\
\text { predictor }\end{array}$ & $\begin{array}{l}\text { Compare } \\
\text { predictor } \\
\text { at } V_{1} \text { with } \\
\text { reference }\end{array}$ & \\
\hline PARAMETER & $\begin{array}{l}\text { thrust } \\
\text { predictor }\end{array}$ & $\begin{array}{l}\text { predictor } \\
\text { reference } \\
\text { airspeed** }\end{array}$ & \\
\hline Number of dimensions & 1 & 1 & \\
\hline Number of variables & 2 & 2 & \\
\hline Number of samples & 1 & 1 & \\
\hline Alert/Inform & inform & inform & \\
\hline $\begin{array}{l}\text { Response to control } \\
\text { actions }\end{array}$ & no & no & \\
\hline Measured/Derived & $\begin{array}{l}\text { derived } \\
\text { derived }\end{array}$ & $\begin{array}{l}\text { derived } \\
\text { derived }\end{array}$ & \\
\hline $\begin{array}{l}\text { Qualitative/ } \\
\text { Quantitative }\end{array}$ & $\begin{array}{l}\text { both } \\
\text { both }\end{array}$ & $\begin{array}{l}\text { both } \\
\text { quan }\end{array}$ & \\
\hline Range (Units) & $\begin{array}{c}-10-110 \\
-10 \frac{(\%)}{(\%)} 110\end{array}$ & $\begin{array}{c}-10-110 \\
(\%) \\
85-110 \\
(\%)\end{array}$ & \\
\hline Required accuracy & $\begin{array}{l}4 \\
4\end{array}$ & $\begin{array}{l}2 \\
2\end{array}$ & \\
\hline Relative/Absolute & $\begin{array}{l}\text { relative } \\
\text { relative }\end{array}$ & $\begin{array}{l}\text { relative } \\
\text { relative }\end{array}$ & \\
\hline Relative importance & medium & high & \\
\hline
\end{tabular}

** external source. 


\begin{tabular}{|c|c|c|c|}
\hline \multicolumn{4}{|c|}{ FUNCTION: ADJUST INFLIGHT POWER } \\
\hline \multicolumn{4}{|c|}{ TASK: Adjust power to establish/maintain speed } \\
\hline SUBTASK & $\begin{array}{l}\text { Set thrust } \\
\text { to provide } \\
\text { power } \\
\text { for speed }\end{array}$ & $\begin{array}{l}\text { Compare } \\
\text { thrust } \\
\text { with } \\
\text { predictor }\end{array}$ & $\begin{array}{l}\text { Compare } \\
\text { thrust with } \\
\text { limits }\end{array}$ \\
\hline PARAMETER & $\begin{array}{l}\text { thrust } \\
\text { airspeed** }\end{array}$ & $\begin{array}{l}\text { thrust } \\
\text { predictor }\end{array}$ & $\begin{array}{l}\text { thrust } \\
\text { limits }\end{array}$ \\
\hline Number of dimensions & 1 & 1 & 1 \\
\hline Number of variables & 1 & 2 & 2 \\
\hline Number of samples & 1 & 1 & 1 \\
\hline Alert/Inform & inform & inform & both \\
\hline $\begin{array}{l}\text { Response to control } \\
\text { actions }\end{array}$ & yes & no & no \\
\hline Measured/Derived & derived & $\begin{array}{l}\text { derived } \\
\text { derived }\end{array}$ & $\begin{array}{l}\text { derived } \\
\text { derived }\end{array}$ \\
\hline $\begin{array}{l}\text { Qualitative/ } \\
\text { Quantitative }\end{array}$ & quan & $\begin{array}{l}\text { both } \\
\text { both }\end{array}$ & $\begin{array}{l}\text { quan } \\
\text { quan }\end{array}$ \\
\hline Range (Units) & $\begin{array}{c}-10-110 \\
(\%) \\
0-600 \\
(\mathrm{kts})\end{array}$ & $\begin{array}{l}-10-110 \\
(\%) \\
-10-110 \\
(\%)\end{array}$ & $\begin{array}{c}-10-110 \\
(\%) \\
83-110 \\
(\%)\end{array}$ \\
\hline Required accuracy & - & $\begin{array}{l}4 \\
4\end{array}$ & $\begin{array}{l}2 \\
2\end{array}$ \\
\hline Relative/Absolute & absolute & $\begin{array}{l}\text { relative } \\
\text { relative }\end{array}$ & $\begin{array}{l}\text { relative } \\
\text { relative }\end{array}$ \\
\hline Relative importance & medium & medium & high \\
\hline
\end{tabular}

** external source. 


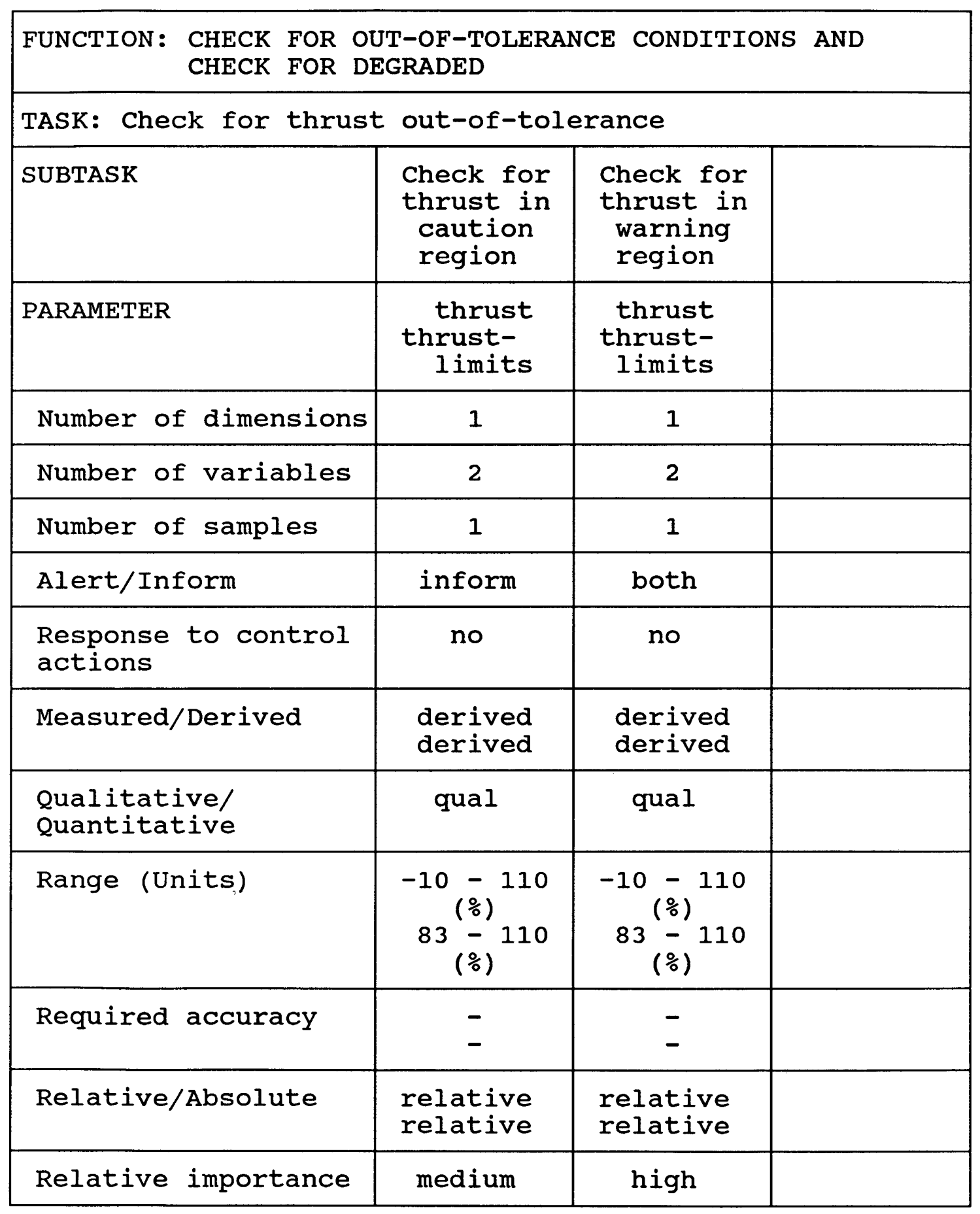




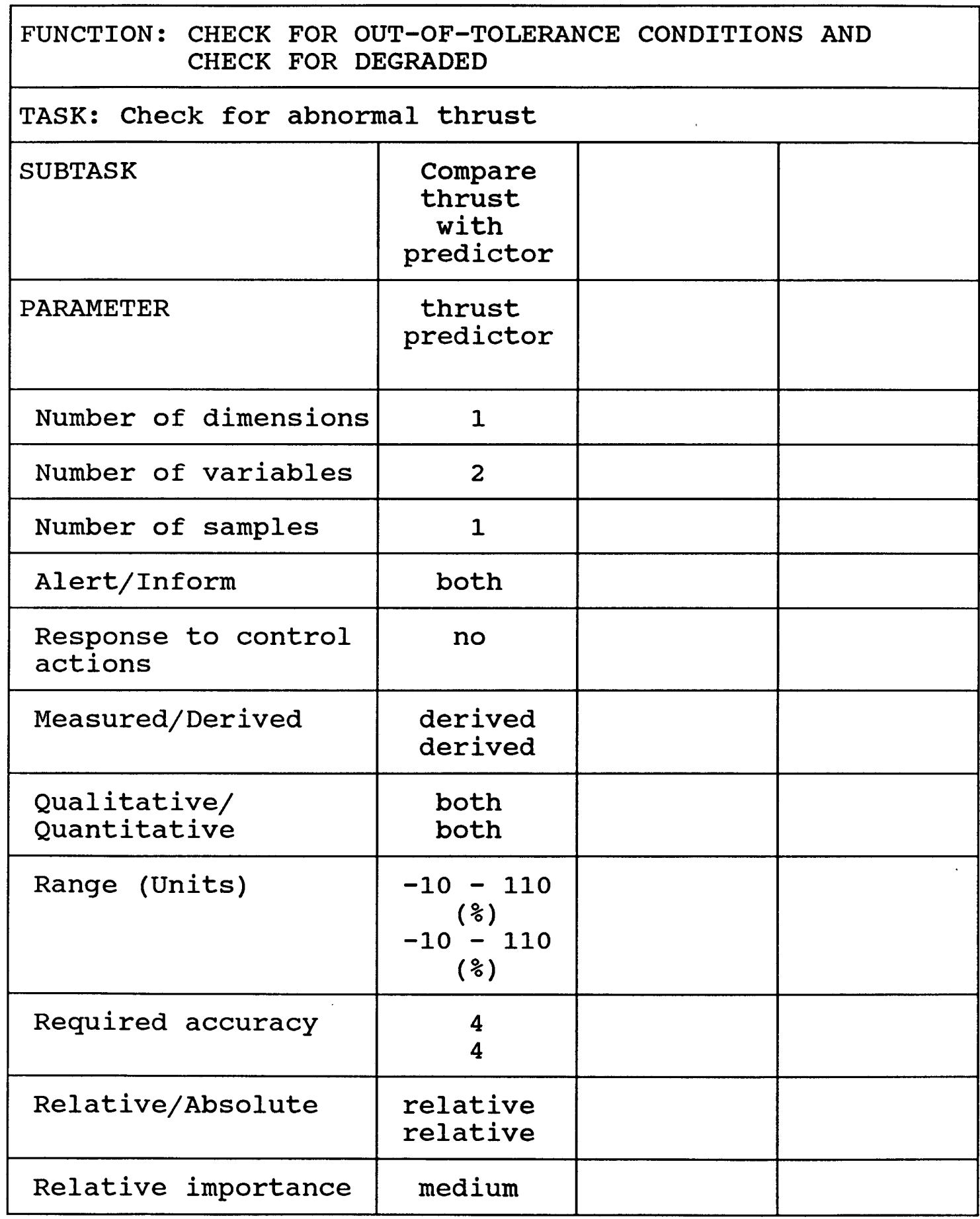




\begin{tabular}{|c|c|c|c|}
\hline $\begin{aligned} \text { FUNCTION: } & \text { CHECK FOR OL } \\
& \text { CHECK FOR DE }\end{aligned}$ & $\begin{array}{l}\text { JT-OF-TOLERA } \\
\text { SGRADED }\end{array}$ & NCE CONDITION & NS AND \\
\hline TASK: Check for high 0 & or low condi & Eions & \\
\hline SUBTASK & & $\begin{array}{l}\text { Check for } \\
\text { out-of- } \\
\text { tolerance } \\
\text { conditions }\end{array}$ & $\begin{array}{l}\text { Check for } \\
\text { degraded } \\
\text { conditions }\end{array}$ \\
\hline PARAMETER & $\begin{array}{l}\text { deviation } \\
\text { limits }\end{array}$ & see subtask & see subtask \\
\hline Number of dimensions & 1 & & \\
\hline Number of variables & 14 & & \\
\hline Number of samples & 1 & & \\
\hline Alert/Inform & both & & \\
\hline $\begin{array}{l}\text { Response to control } \\
\text { actions }\end{array}$ & no & & \\
\hline Measured/Derived & $\begin{array}{l}\text { derived } \\
\text { derived }\end{array}$ & & \\
\hline $\begin{array}{l}\text { Qualitative/ } \\
\text { Quantitative }\end{array}$ & both & & \\
\hline Range (Units) & $\begin{array}{c} \pm 100 \\
(\%) \\
\pm 33, \quad 67 \\
(\%)\end{array}$ & & \\
\hline Required accuracy & $\begin{array}{l}3 \\
3\end{array}$ & & \\
\hline Relative/Absolute & $\begin{array}{l}\text { relative } \\
\text { relative }\end{array}$ & & \\
\hline Relative importance & medium & & \\
\hline
\end{tabular}




\begin{tabular}{|c|c|c|c|}
\hline \multicolumn{4}{|c|}{ FUNCTION: CHECK FOR OUT-OF-TOLERANCE CONDITIONS } \\
\hline \multicolumn{4}{|l|}{ TASK: Check for high $\mathrm{N}_{1}$} \\
\hline SUBTASK & $\begin{array}{l}\text { Check for } \\
\mathrm{N}_{1} \text { in high } \\
\text { caution } \\
\text { region }\end{array}$ & $\begin{array}{l}\text { Determine } \\
\text { if in } \\
\text { high power } \\
\text { condition }\end{array}$ & $\begin{array}{l}\text { Check for } \\
\mathrm{N}_{1} \text { in high } \\
\text { warning } \\
\text { region }\end{array}$ \\
\hline PARAMETER & $\mathrm{N}_{1} \stackrel{\mathrm{N}_{1}}{\mathrm{l}} \stackrel{\text { imit }}{ }$ & $\begin{array}{l}\text { thrust } \\
\text { thrust- } \\
\text { limits }\end{array}$ & $\mathrm{N}_{1} \stackrel{\mathrm{N}_{1}}{1}{ }_{\text {imit }}$ \\
\hline Number of dimensions & 1 & 1 & 1 \\
\hline Number of variables & 2 & 2 & 2 \\
\hline Number of samples & 1 & 1 & 1 \\
\hline Alert/Inform & both & inform & both \\
\hline $\begin{array}{l}\text { Response to control } \\
\text { actions }\end{array}$ & no & no & no \\
\hline Measured/Derived & $\begin{array}{l}\text { both } \\
\text { derived }\end{array}$ & $\begin{array}{l}\text { derived } \\
\text { derived }\end{array}$ & $\begin{array}{l}\text { both } \\
\text { derived }\end{array}$ \\
\hline $\begin{array}{l}\text { Qualitative/ } \\
\text { Quantitative }\end{array}$ & $\begin{array}{l}\text { both } \\
\text { quan }\end{array}$ & qual & $\begin{array}{l}\text { both } \\
\text { quan }\end{array}$ \\
\hline Range (Units) & $\begin{array}{c}0-100.1 * \\
(\% \mathrm{rpm}) * \\
94-100.1 * \\
(\% \text { rpm)* }\end{array}$ & $\begin{array}{c}-10-110 \\
(\%) \\
83 \frac{\%}{(\%)} 110\end{array}$ & $\begin{array}{c}0-115 * \\
(\% \mathrm{rpm}) * \\
100.1-115 \\
(\% \mathrm{rpm}) *\end{array}$ \\
\hline Required accuracy & $\begin{array}{l}0.1 \\
0.1\end{array}$ & - & $\begin{array}{l}0.1 \\
0.1\end{array}$ \\
\hline Relative/Absolute & $\begin{array}{l}\text { relative } \\
\text { relative }\end{array}$ & $\begin{array}{l}\text { relative } \\
\text { relative }\end{array}$ & $\begin{array}{l}\text { relative } \\
\text { relative }\end{array}$ \\
\hline Relative importance & medium & low & high \\
\hline
\end{tabular}

* also presented as a derived, normalized value. 


\begin{tabular}{|c|c|c|c|}
\hline \multicolumn{4}{|c|}{ FUNCTION: CHECK FOR OUT-OF-TOLERANCE CONDITIONS } \\
\hline \multicolumn{4}{|l|}{ TASK: Check for high $\mathrm{N}_{2}$} \\
\hline SUBTASK & $\begin{array}{l}\text { Check for } \\
\mathrm{N}_{2} \text { in high } \\
\text { caution } \\
\text { region }\end{array}$ & $\begin{array}{l}\text { Determine } \\
\text { if in } \\
\text { high power } \\
\text { condition }\end{array}$ & $\begin{array}{l}\text { Check for } \\
\mathrm{N}_{2} \text { in high } \\
\text { warning } \\
\text { region }\end{array}$ \\
\hline PARAMETER & $\mathrm{N}_{2} \stackrel{\mathrm{N}_{2}}{\text { limit }}$ & $\begin{array}{l}\text { thrust } \\
\text { thrust- } \\
\text { limits }\end{array}$ & $\mathrm{N}_{2} \stackrel{\mathrm{N}_{2}}{\text { limit }}$ \\
\hline Number of dimensions & 1 & 1 & 1 \\
\hline Number of variables & 2 & 2 & 2 \\
\hline Number of samples & 1 & 1 & 1 \\
\hline Alert/Inform & both & inform & both \\
\hline $\begin{array}{l}\text { Response to control } \\
\text { actions }\end{array}$ & no & no & no \\
\hline Measured/Derived & $\begin{array}{l}\text { both } \\
\text { derived }\end{array}$ & $\begin{array}{l}\text { derived } \\
\text { derived }\end{array}$ & $\begin{array}{l}\text { both } \\
\text { derived }\end{array}$ \\
\hline $\begin{array}{l}\text { Qualitative/ } \\
\text { Quantitative }\end{array}$ & $\begin{array}{l}\text { both } \\
\text { quan }\end{array}$ & qual & $\begin{array}{l}\text { both } \\
\text { quan }\end{array}$ \\
\hline Range (Units) & $\begin{array}{c}0-100 * \\
(\% \mathrm{rpm}) * \\
94-100 * \\
(\% \mathrm{rpm}) *\end{array}$ & $\begin{array}{c}-10-110 \\
(\%) \\
83 \frac{\%}{(\%)} 110\end{array}$ & $\begin{array}{c}0-115 * \\
(\% \mathrm{rpm}) * \\
100-115 * \\
(\% \mathrm{rpm}) *\end{array}$ \\
\hline Required accuracy & $\begin{array}{l}0.1 \\
0.1\end{array}$ & - & $\begin{array}{l}0.1 \\
0.1\end{array}$ \\
\hline Relative/Absolute & $\begin{array}{l}\text { relative } \\
\text { relative }\end{array}$ & $\begin{array}{l}\text { relative } \\
\text { relative }\end{array}$ & $\begin{array}{l}\text { relative } \\
\text { relative }\end{array}$ \\
\hline Relative importance & medium & low & high \\
\hline
\end{tabular}

* also presented as a derived, normalized value. 


\begin{tabular}{|c|c|c|c|}
\hline \multicolumn{4}{|c|}{ FUNCTION: CHECK FOR OUT-OF-TOLERANCE CONDITIONS } \\
\hline \multicolumn{4}{|c|}{ TASK: Check for high EGT } \\
\hline SUBTASK & $\begin{array}{l}\text { Check for } \\
\text { EGT in high } \\
\text { caution } \\
\text { region }\end{array}$ & $\begin{array}{l}\text { Determine } \\
\text { if in } \\
\text { high power } \\
\text { condition }\end{array}$ & $\begin{array}{l}\text { Check for } \\
\text { EGT in high } \\
\text { warning } \\
\text { region }\end{array}$ \\
\hline PARAMETER & EGT $\stackrel{\text { EGT }}{\text { limit }}$ & $\begin{array}{l}\text { thrust } \\
\text { thrust- } \\
\text { limits }\end{array}$ & EGT $\mathrm{EGT}$ \\
\hline Number of dimensions & 1 & 1 & 1 \\
\hline Number of variables & 2 & 2 & 2 \\
\hline Number of samples & 1 & 1 & 1 \\
\hline Alert/Inform & both & inform & both \\
\hline $\begin{array}{l}\text { Response to control } \\
\text { actions }\end{array}$ & no & no & no \\
\hline Measured/Derived & $\begin{array}{l}\text { both } \\
\text { derived }\end{array}$ & $\begin{array}{l}\text { derived } \\
\text { derived }\end{array}$ & $\begin{array}{l}\text { both } \\
\text { derived }\end{array}$ \\
\hline $\begin{array}{l}\text { Qualitative/ } \\
\text { Quantitative }\end{array}$ & $\begin{array}{l}\text { both } \\
\text { quan }\end{array}$ & qual & $\begin{array}{l}\text { both } \\
\text { quan }\end{array}$ \\
\hline Range (Units) & $\begin{array}{l}290-600 * \\
\left({ }^{\circ} \mathrm{C}\right) * \\
535-570 * \\
\left({ }^{\circ} \mathrm{C}\right) *\end{array}$ & $\begin{array}{c}-10-110 \\
(\%) \\
83-110 \\
(\%)\end{array}$ & $\begin{array}{l}290-600 * \\
\left({ }^{\circ} \mathrm{C}\right) * \\
570-600 * \\
\left({ }^{\circ} \mathrm{C}\right) *\end{array}$ \\
\hline Required accuracy & $\begin{array}{l}2 \\
2\end{array}$ & - & $\begin{array}{l}2 \\
2\end{array}$ \\
\hline Relative/Absolute & $\begin{array}{l}\text { relative } \\
\text { relative }\end{array}$ & $\begin{array}{l}\text { relative } \\
\text { relative }\end{array}$ & $\begin{array}{l}\text { relative } \\
\text { relative }\end{array}$ \\
\hline Relative importance & medium & low & high \\
\hline
\end{tabular}

* also presented as a derived, normalized value. 


\begin{tabular}{|c|c|c|c|}
\hline FUNCTION: CHECK FOR OL & T-OF-TOLER & CE CONDITIC & \\
\hline TASK: Check for high & low oil & essure (OP) & \\
\hline SUBTASK & $\begin{array}{l}\text { Check for } \\
\text { op in low } \\
\text { warning } \\
\text { region }\end{array}$ & $\begin{array}{l}\text { Check for } \\
\text { op in low } \\
\text { caution } \\
\text { region }\end{array}$ & $\begin{array}{l}\text { Check for } \\
\text { op in high } \\
\text { warning } \\
\text { region }\end{array}$ \\
\hline PARAMETER & $\begin{array}{ll} & \text { OP } \\
\text { OP } & \text { limit }\end{array}$ & OP limit & $\begin{array}{ll} & \text { OP } \\
\text { oP } & \text { limit }\end{array}$ \\
\hline Number of dimensions & 1 & 1 & 1 \\
\hline Number of variables & 2 & 2 & 2 \\
\hline Number of samples & 1 & 1 & 1 \\
\hline Alert/Inform & both & both & both \\
\hline $\begin{array}{l}\text { Response to control } \\
\text { actions }\end{array}$ & no & no & no \\
\hline Measured/Derived & $\begin{array}{l}\text { both } \\
\text { derived }\end{array}$ & $\begin{array}{l}\text { derived } \\
\text { derived }\end{array}$ & $\begin{array}{l}\text { both } \\
\text { derived }\end{array}$ \\
\hline $\begin{array}{l}\text { Qualitative/ } \\
\text { Quantitative }\end{array}$ & $\begin{array}{l}\text { both } \\
\text { quan }\end{array}$ & $\begin{array}{l}\text { both } \\
\text { quan }\end{array}$ & $\begin{array}{l}\text { both } \\
\text { quan }\end{array}$ \\
\hline Range (Units) & $\begin{array}{c}0-100 * \\
(p s i) * \\
0-35 * \\
(p s i) *\end{array}$ & $\begin{array}{c}0-100 \\
(p s i) \\
35-40 \\
(p s i)\end{array}$ & $\begin{array}{c}0-100 * \\
(p s i) * \\
55-100 * \\
(p s i) *\end{array}$ \\
\hline Required accuracy & $\begin{array}{l}1 \\
1\end{array}$ & $\begin{array}{l}1 \\
1\end{array}$ & $\begin{array}{l}1 \\
1\end{array}$ \\
\hline Relative/Absolute & $\begin{array}{l}\text { relative } \\
\text { relative }\end{array}$ & $\begin{array}{l}\text { relative } \\
\text { relative }\end{array}$ & $\begin{array}{l}\text { relative } \\
\text { relative }\end{array}$ \\
\hline Relative importance & high & medium & high \\
\hline
\end{tabular}

* also presented as a derived, normalized value. 


\begin{tabular}{|c|c|c|c|}
\hline \multicolumn{4}{|c|}{ FUNCTION: CHECK FOR OUT-OF-TOLERANCE CONDITIONS } \\
\hline \multicolumn{4}{|c|}{ TASK: Check for high or low oil temperature (OT) } \\
\hline SUBTASK & $\begin{array}{l}\text { Check for } \\
\text { oT in low } \\
\text { warning } \\
\text { region }\end{array}$ & $\begin{array}{l}\text { Check for } \\
\text { OT in high } \\
\text { caution } \\
\text { region }\end{array}$ & $\begin{array}{l}\text { Check for } \\
\text { oT in high } \\
\text { warning } \\
\text { region }\end{array}$ \\
\hline PARAMETER & OT limit & OT limit & OT limit \\
\hline Number of dimensions & 1 & 1 & 1 \\
\hline Number of variables & 2 & 2 & 2 \\
\hline Number of samples & 1 & 1 & 1 \\
\hline Alert/Inform & both & both & both \\
\hline $\begin{array}{l}\text { Response to control } \\
\text { actions }\end{array}$ & no & no & no \\
\hline Measured/Derived & $\begin{array}{l}\text { both } \\
\text { derived }\end{array}$ & $\begin{array}{l}\text { derived } \\
\text { derived }\end{array}$ & $\begin{array}{l}\text { both } \\
\text { derived }\end{array}$ \\
\hline $\begin{array}{l}\text { Qualitative/ } \\
\text { Quantitative }\end{array}$ & $\begin{array}{l}\text { both } \\
\text { quan }\end{array}$ & $\begin{array}{l}\text { both } \\
\text { quan }\end{array}$ & $\begin{array}{l}\text { both } \\
\text { quan }\end{array}$ \\
\hline Range (Units) & $\begin{array}{c}0-180 * \\
\left({ }^{\circ} \mathrm{C}\right) * \\
0-40 * \\
\left({ }^{\circ} \mathrm{C}\right) *\end{array}$ & $\begin{array}{c}0-180 * \\
\left({ }^{\circ} \mathrm{C}\right) * \\
120-157 * \\
\left({ }^{\circ} \mathrm{C}\right) *\end{array}$ & $\begin{array}{c}0-180 * \\
\left({ }^{\circ} \mathrm{C}\right) * \\
157-180 * \\
\left({ }^{\circ} \mathrm{C}\right) *\end{array}$ \\
\hline Required accuracy & $\begin{array}{l}1 \\
1\end{array}$ & $\begin{array}{l}1 \\
1\end{array}$ & $\begin{array}{l}1 \\
1\end{array}$ \\
\hline Relative/Absolute & $\begin{array}{l}\text { relative } \\
\text { relative }\end{array}$ & $\begin{array}{l}\text { relative } \\
\text { relative }\end{array}$ & $\begin{array}{l}\text { relative } \\
\text { relative }\end{array}$ \\
\hline Relative importance & high & medium & high \\
\hline
\end{tabular}

* also presented as a derived, normalized value. 


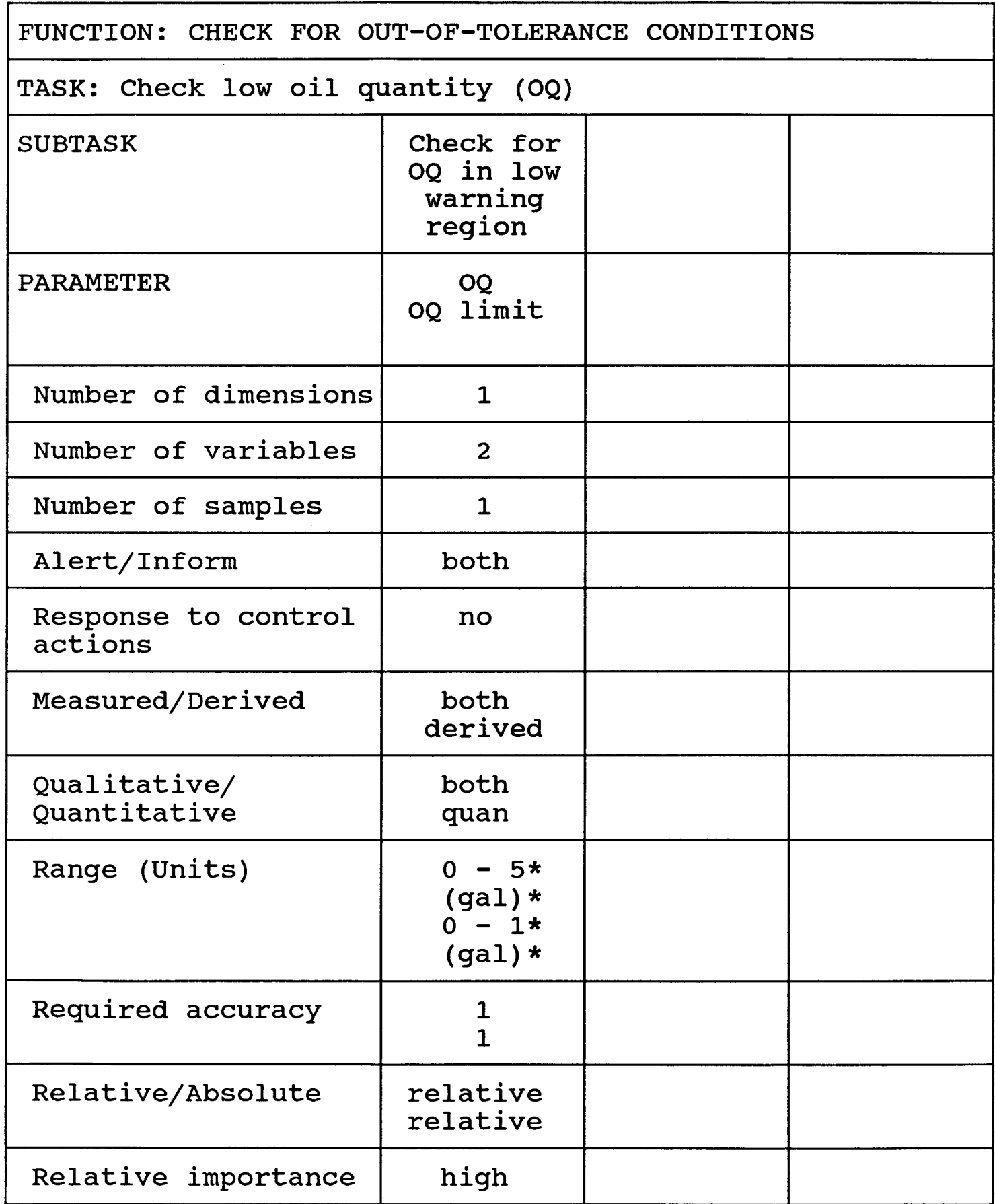

* also presented as a derived, normalized value. 


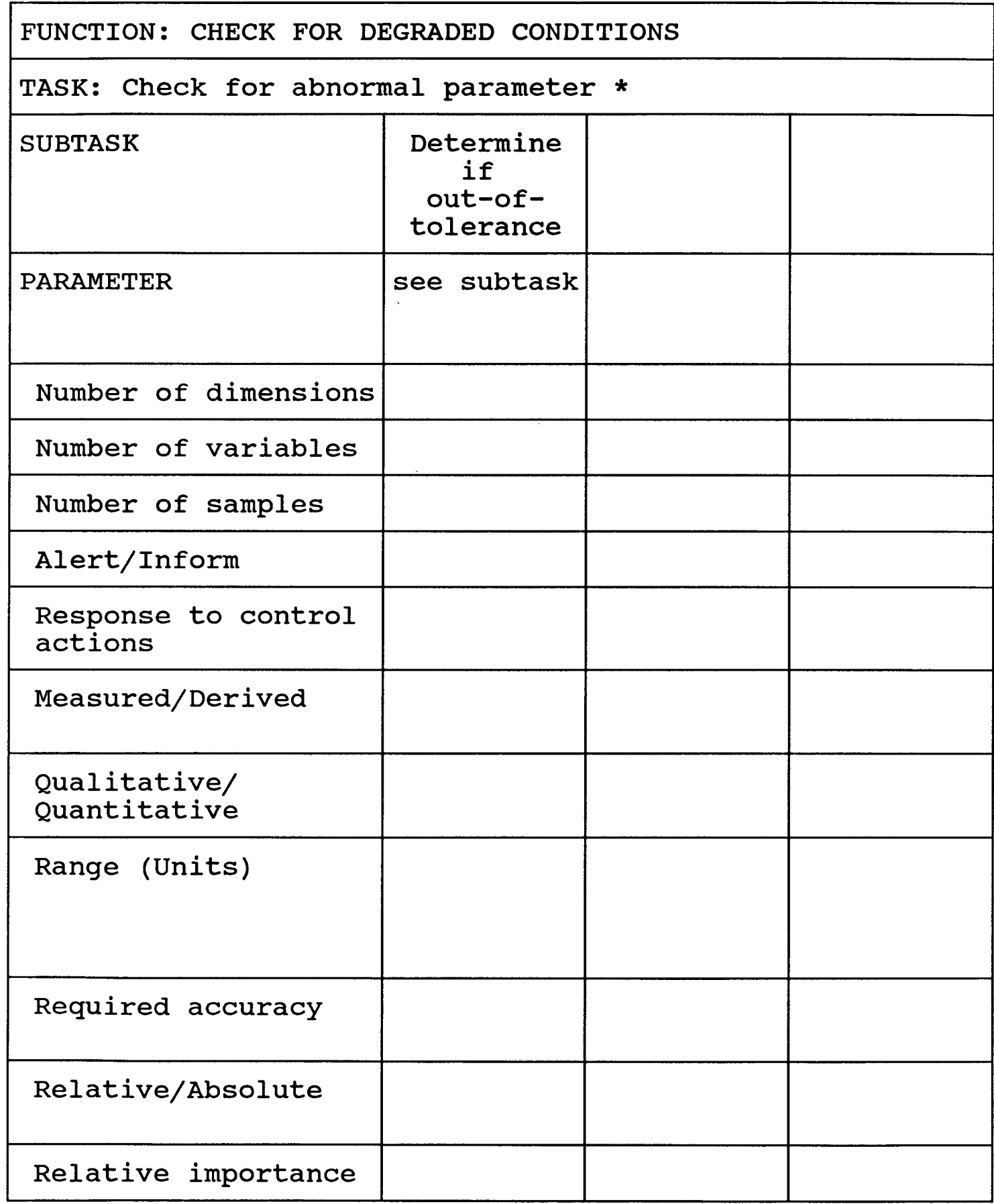

* if the parameter is not out-of-tolerance, then the parameter must be in an abnormal state 


\section{APPENDIX E}

\section{IMPLEMENTATION CONSIDERATIONS}

The primary implementation requirement for the advanced display format (the display designed using the task-oriented approach) was the generation of the estimated value for each of the parameters. In order to provide most of these estimates, a third-order polynomial equation for each parameter was used. The coefficients for these polynomials were obtained from a regression analysis performed on a data set taken from the simulated engine. The estimated values for these parameters were based on the following:

1. Maximum allowable thrust - maximum takeoff EPR adjusted for mach and altitude and limited by the thrust at maximum $\mathrm{N}_{1}$, the thrust at maximum $\mathrm{N}_{2}$, the thrust at maximum EGT.

2. Maximum continuous thrust - maximum continuous EPR adjusted for mach and altitude and limited by the thrust at maximum continuous $\mathrm{N}_{1}$, the thrust at maximum continuous $\mathrm{N}_{2}$, the thrust at maximum continuous EGT.

3. Thrust - control position, mach, altitude.

4. $\mathrm{N}_{1}-\mathrm{EPR}$, mach, and altitude. 
5. $\mathrm{N}_{2}-\mathrm{EPR}$, mach, and altitude.

6. EGT - EPR, mach, and altitude.

7. Fuel flow - EPR, mach, and altitude.

8. Oil pressure - a constant.

9. Oil temperature - a constant.

10. Oil quantity - a constant.

It should be noted that a standard atmospheric model was assumed. That is, altitude had temperature effect included. It should also be noted that two separate submodels were used, one for the engine bleed valve open condition and one for the bleed value closed condition. (Bleed valves are used to facilitate engine acceleration and to prevent high altitude compressor surge by ducting compressor air overboard during low thrust conditions. During normal aircraft takeoff and cruise conditions, the bleed valves are closed.)

The second implementation requirement for the advanced display format involved the calculation of the column height for the column deviation graph. In general, this graph showed the difference between the actual value and the 
estimated value for each parameter, normalized to the full scale value of that parameter. The graph was equally divided into normal, caution, and warning ranges for differences both above and below the estimate. The ranges associated with the differences are as follows:

normal : $-10 \%$ to $10 \%$,

caution : $-15 \%$ to $-10 \%$ and $10 \%$ to $15 \%$

warning : less than $-15 \%$ and greater than $15 \%$

In addition, conventional limitations were merged with the deviations as the parameter approached a limit. For example, the $\mathrm{N}_{1}$ caution limit, which begins at $94 \% \mathrm{~N}_{1}$, was merged with the $\mathrm{N}_{1}$ deviation value beginning at $89 \% \mathrm{~N}_{1}$. The merging was designed so that $\mathrm{N}_{1}$ deviation column would just begin transitioning into the caution area as $\mathrm{N}_{1}$ reaches $94 \%$. 
APPENDIX F

PILOT BRIEFING

162 


\section{PILOT BRIEFING}

\section{Purpose}

The purpose of this evaluation is to compare a modern engine display format, somewhat like the Boeing 757/767, against an advanced display format. This evaluation will use a part-task, real-time simulation. Both takeoff and inflight scenarios will be used. For the takeoff scenarios, the piloting task will be an acceleration, initiated from 0 speed, engine power at idle. The task will terminate at approximately $V_{1}$. The inflight scenarios will require an

increase in engine power from trimmed, level flight, prior to an expedited climb. To reduce the effect of giving excessive emphasis to the engine control and monitoring task, the engine formats will only be visible during the time periods that you would normally view these displays. For the takeoff task, this will be a 4-second period following throttle advance, a 2-second period beginning at 55 knots (for the 60 knot power check), and a 2-second period beginning 5 knots prior to $V_{1}$. For the inflight case, a single 3-second period will be used.

For this test, your only task will be to control and monitor the aircraft engines. For each of the two display formats, you will be given 2 takeoff scenarios and 2 
inflight scenarios. None of the scenarios will be repeated. Measurements will be taken in the form of quantitative (time, control lever position) and qualitative (questionnaire) data.

\section{Training and Initial Subjective Evaluation}

You will be provided approximately 2 hours of training prior to quantitative (recorded performance) data collection. For the initial portion of the training, a familiarization of the TSRV simulator, including the modern engine formats, will be provided. This familiarization will include takeoff and cruise situations using the velocity control wheel steering (VCWS) system. The training scenarios will provide situations similar to those that will be used during the actual test. After you become familiar with the simulated aircraft and aircraft systems, you will be asked to fill out a short questionnaire regarding the engine formats. Following this, familiarization time using the advanced formats will be provided. You will then be asked to fill out a second questionnaire.

During the last portion of the training, the engine displays will be switched on and off in the same manner that will be used during the quantitative data collection part of 
the test.

A summary of the critical engine parameters for the JT8D7 engine is provided on the attached sheet. Prior to the test, you will be required to recall from memory, with $100 \%$ accuracy, all of these parameters. A sample of the test sheet for this requirement is also provided.

\section{Display Formats}

Modern Format: The display elements used in this format should be generally familiar to you. The unique features of this format are as follows:

Operation in a caution region: Any time that you are operating in a caution region, shown by a yellow rangemarking on the display element, the digital readout for that display element will also be displayed in yellow.

Operation in a warning region: Similar to operating in a caution except that the display color is red.

EPR gage : See figure 1.

EPR warning limit: The EPR warning limit, shown by a red 
range-marking on the EPR dial, is a computed takeoff EPR limit (or maximum-continuous EPR if the takeoff and maximum-continuous limits are the same) based on current ambient conditions.

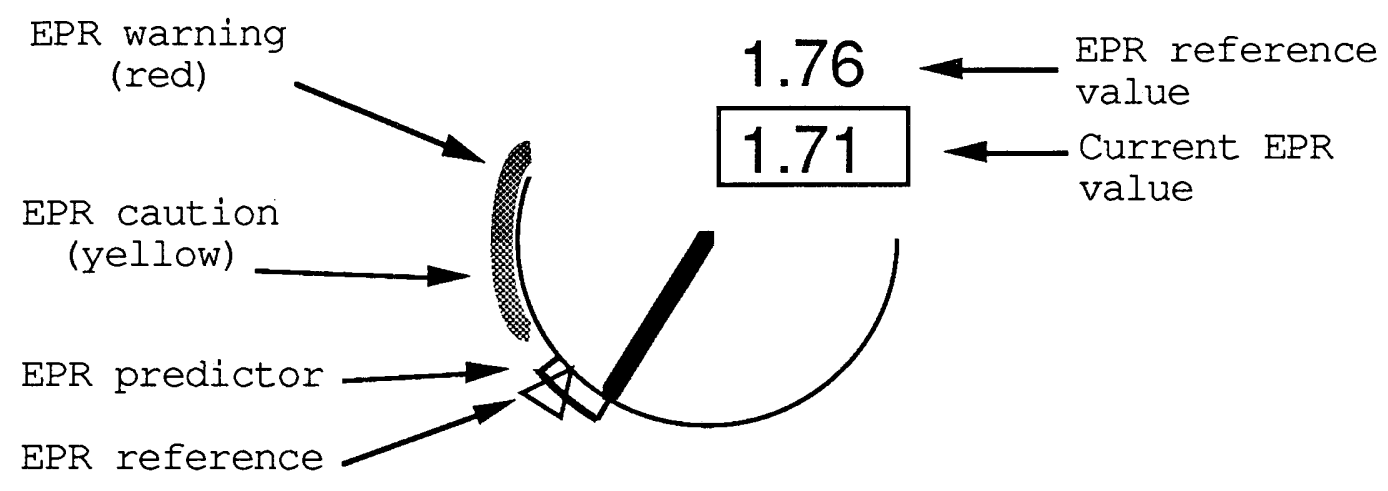

Figure 1. EPR gage.

EPR caution limit: The EPR caution limit, shown by yellow range-marking on the EPR dial, is a computed maximumcontinuous EPR limit based on current ambient conditions. If the takeoff and maximum-continuous limits are the same, no caution limit will be shown.

EPR reference pointer: For the takeoff conditions, an EPR reference pointer will be displayed on the EPR dials. The reference value itself will be digitally presented above the actual EPR value readout.

EPR predictor: The simulated engine fuel control computes a estimate of the EPR value based on current conditions. 
If the estimated and actual EPR values disagree (usually due to spoolup dynamics), an EPR predictor will be displayed on the EPR dial. The predictor will originate at the current EPR value and end at the estimated value.

Advanced Format: The general form for the display elements used in this format are fixed-scales/moving-columns. The display elements themselves may be separated into 2 distinct cases: control and monitoring.

Control: The display elements for control are the thrust indicators (see figure 2), scaled from $-10 \%$ to $+110 \%$, with 100\% defined as the maximum thrust available without exceeding any engine limit. The actual available thrust is shown, in pounds, at the top of each thrust indicator. In addition, the following elements are part of the thrust indicators:

Thrust warning limit: The thrust warning limit, shown by a red range-marking on the thrust scale, always begins at $100 \%$. Under normal operations, no other engine parameter $\left(\mathrm{N}_{1}, \mathrm{~N}_{2}\right.$, or EGT) will be within a warning area unless the current thrust value is in the warning area.

Thrust caution limit: The thrust caution limit, shown by a yellow range-marking on the thrust scale, is based on a 
computed maximum-continuous thrust. Under normal operations, no other engine parameter $\left(\mathrm{N}_{1}, \mathrm{~N}_{2}\right.$, or EGT) will be within a caution area unless the current thrust value is in the caution area.

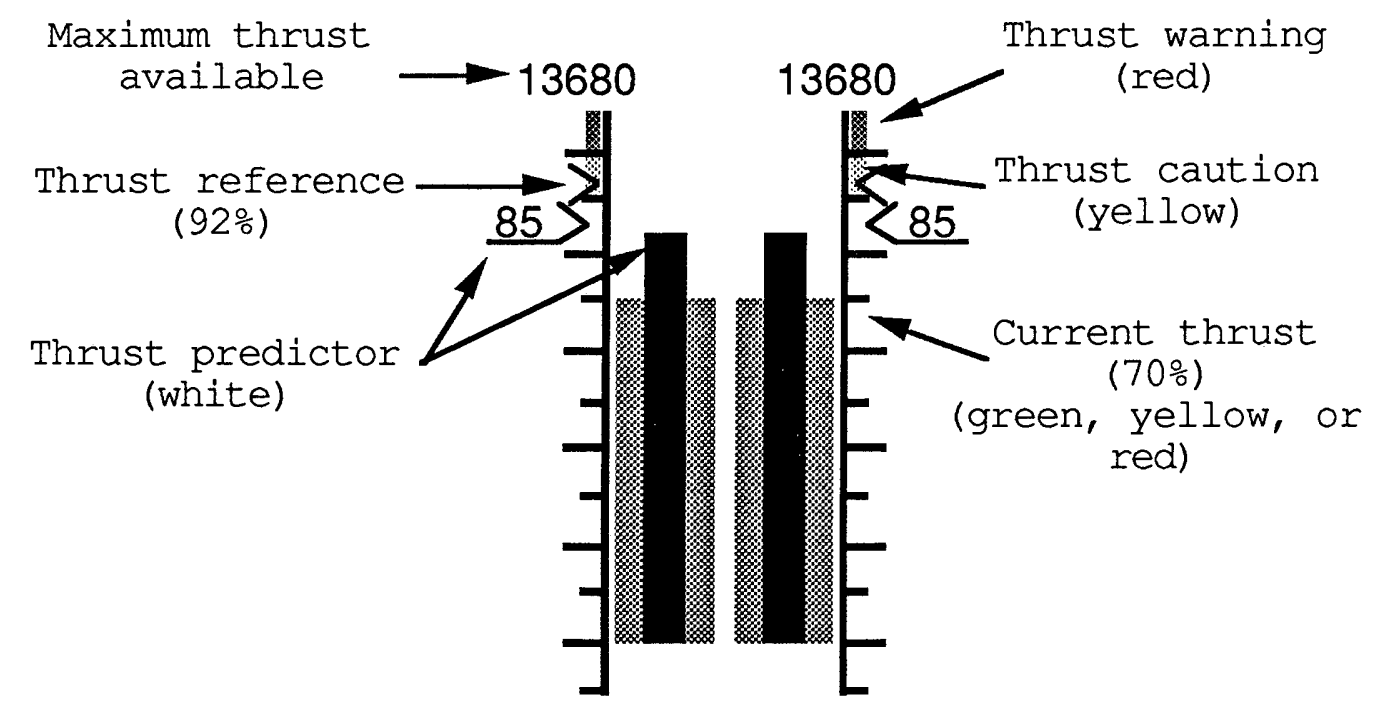

Figure 2. Thrust indicators.

Thrust reference pointer: For the takeoff conditions, an thrust reference pointer will be displayed on each thrust indicator. The reference value itself, in percent of available thrust, will be digitally presented for a 5second period immediately following a change in the reference value.

Thrust predictor: The monitoring system, independent of the engine, computes a estimate of the commanded thrust 
based on current conditions. This estimate is presented both as a predictor column and as a predictor pointer. The predictor pointer includes a digital readout, in percent of available thrust, of the predicted thrust.

Current thrust: The current thrust is displayed as a column on the thrust indicator. The color of the column will reflect the operating condition (green for normal, yellow for caution, and red for warning). Under steadystate situations, the thrust predictor and the current thrust values should be in general agreement.

Monitoring: The major display elements used for monitoring are column-deviation indicators (see figure 3). In general, these indicators will show a difference between the actual value and an estimated value for each engine parameter. The indicators are divided into normal, caution, and warning ranges for differences both above and below the estimate. The ranges associated with the differences are as follows:

$$
\begin{aligned}
& \text { normal : } 0 \text { to } 10 \%, \\
& \text { caution : } 10 \text { to } 15 \% \text {, and } \\
& \text { warning : greater than } 15 \% .
\end{aligned}
$$

In addition, conventional limitations are merged with the deviations as the parameter approaches the limit. For example, the $\mathrm{N}_{1}$ caution limit, which begins at $94 \% \mathrm{~N}_{1}$, is merged with the $N_{1}$ deviation value beginning at $89 \% N_{1}$. The 
merging is designed so that $\mathrm{N}_{1}$ deviation column will just begin transitioning into the caution area as $\mathrm{N}_{1}$ reaches $94 \%$. The deviation columns are the color of the associated range.

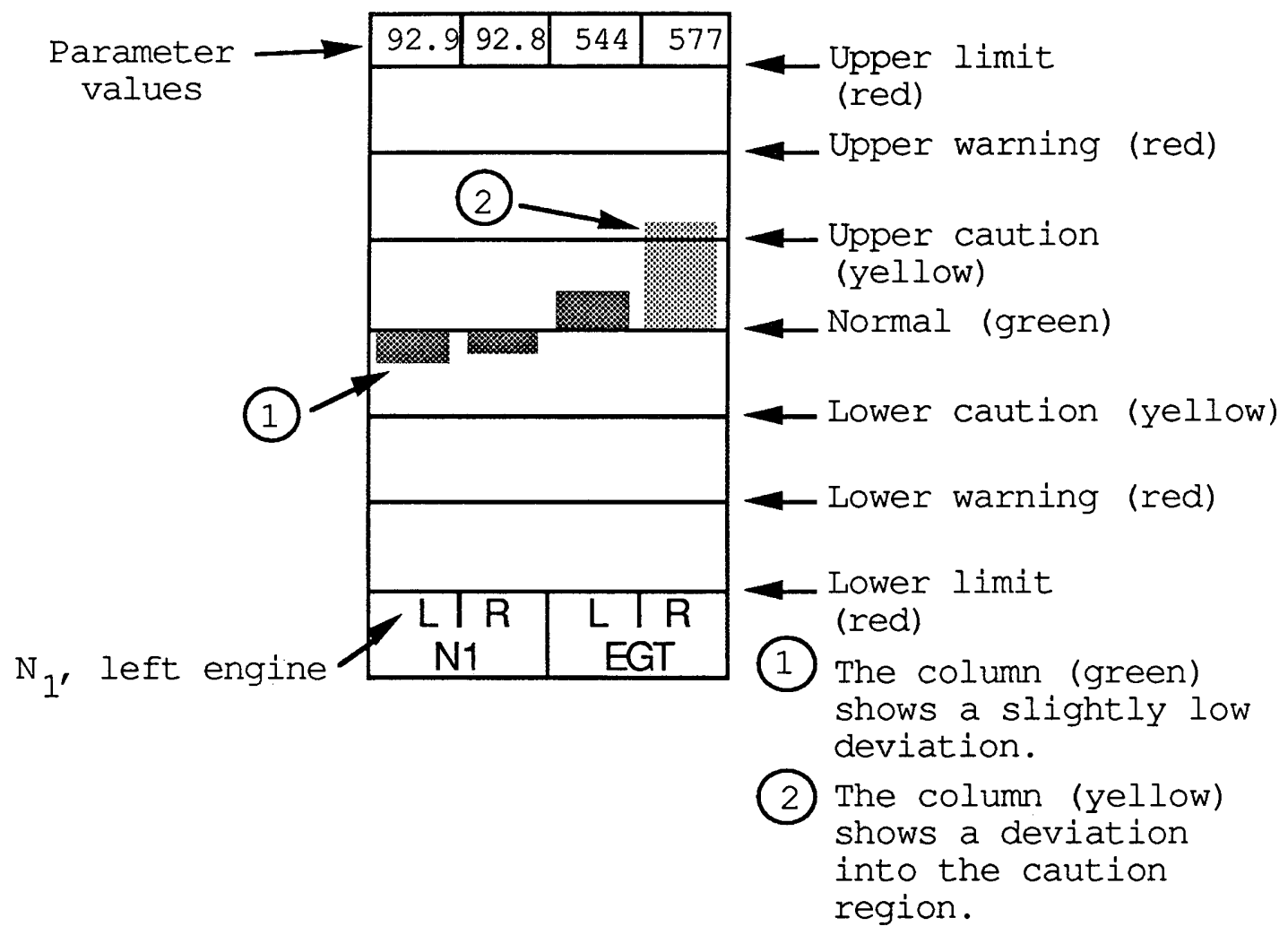

Figure 3. Representative monitoring indicators.

Each column-deviation indicator includes a digital presentation of the actual value. This digital readout will be the same color as the associated column. 


\section{Quantitative-Data Test Sequence}

The quantitative-data part of this test will use both takeoff and inflight scenarios. Your only task will be to control and monitor the aircraft engines. For each of the two display formats, you will be given 2 takeoff scenarios and 2 inflight scenarios. None of the scenarios will be repeated.

For the takeoff task, you will be provided with the appropriate EPR or thrust reference settings and the $V_{1}$ speed. Your task for this situation is to set takeoff power and monitor the engine systems. The data collection will begin at the time you advance the throttles. From the time of throttle advance, you will have 4 seconds to set the takeoff power and monitor the engine systems. The engine displays will blank at the end of this 4-second period. According to the Boeing takeoff checklist, you should adjust takeoff power before 60 knots. To allow you to do this, the engine displays will be turned on at 55 knots for a 2-second period. The displays will again be turned on for a 2-second period beginning 5 knots prior to $V_{1}$ for a final systems check. Performance measures will include control activity and the accuracy in setting takeoff power. If any unusual or abnormal engine response is noted, you should announce "abort takeoff." 
The inflight task will be for you to increase engine power to approximately maximum, as though you were anticipating an expedited climb. For these scenarios, you will have a single 3-second period to both set the engine power and monitor the engine systems.

A general questionnaire will be completed immediately after the quantitative-data test sequence. 
CRITICAL ENGINE PARAMETERS

JT8D-7

EPR and THRUST Limits : EPR and thrust limits are automatically computed and displayed. For takeoff, however, the takeoff performance chart should be consulted for power limits.

$\mathrm{N}_{1}$ Limits :

Normal - 0 to $94 \%$

Caution - 94 to $100.1 \%$

Warning - above $100.1 \%$

EGT Limits :

Normal - below 535 degrees C

Caution - 535 to 570 degrees $C$

Warning - above 570 degrees C

$\mathrm{N}_{2}$ Limits :

Normal - 0 to $94 \%$

Caution - 94 to 100.0 \%

Warning - above $100.0 \%$

Oil Pressure :

Warning - below 35 PSI

Caution - 35 to 40 PSI

Normal - 40 to 55 PSI

Warning - above 55 PSI

Oil Temperature :

Warning - below 40 degrees C

Normal - 40 to 120 degrees C

Caution - 120 to 157 degrees C

Warning - above 157 degrees C

Oil Quantity :

Warning - below $1.0 \mathrm{gal}$

Normal - above $1.0 \mathrm{gal}$ 


\section{APPENDIX G \\ QUIZ OF CRITICAL ENGINE PARAMETERS}

The following quiz will test your knowledge of the critical engine parameters for the JT8D-7 engine. This information would be expected to be committed to memory by any pilot operating an aircraft using these engines. This is a "from memory only" quiz. A score of $100 \%$ accuracy is required to participate as a subject.

1. The NORMAL $\mathrm{N}_{1}$ operating range is _to to t_.

2. The CAUTION $\mathrm{N}_{1}$ operating range is ___ to __

3. The WARNING $\mathrm{N}_{1}$ operating range is anything above $\frac{\%}{2}$

4. The NORMAL $\mathrm{N}_{2}$ operating range is to

5. The CAUTION $\mathrm{N}_{2}$ operating range is to $\%$

6. The WARNING $\mathrm{N}_{2}$ operating range is anything above $\%$

7. The NORMAL EGT operating range is anything below ${ }^{\circ} \mathrm{C}$. 
8. The CAUTION EGT operating range is to to t_ ${ }^{\circ} \mathrm{C}$.

9. The WARNING EGT operating range is anything above ${ }^{\circ} \mathrm{C}$.

10. The NORMAL OIL PRESSURE operating range is to PSI.

11. The CAUTION OIL PRESSURE operating range is to PSI.

12. The WARNING OIL PRESSURE operating range is below or above PSI.

13. The NORMAL OIL TEMPERATURE operating range is to ${ }^{\circ} \mathrm{C}$.

14. The CAUTION OIL TEMPERATURE operating range is to to ${ }^{\circ} \mathrm{C}$.

15. The WARNING OIL TEMPERATURE operating range is below or above ${ }^{\circ} \mathrm{C}$.

16. The NORMAL OIL QUANTITY operating range is anything above GAL. 
17. The WARNING OIL QUANTITY operating range is anything below _ GAL. 


\section{APPENDIX $\mathrm{H}$ \\ PILOT QUESTIONNAIRES}

The questionnaires were administered in the following sequence.

1. Questionnaire $\mathbf{A}$ was administered after the pilot familiarization and qualitative evaluation of the modern format.

2. Questionnaire B was administered after the pilot familiarization and qualitative evaluation of the advanced format.

3. Questionnaire C was administered immediately after Questionnaire B.

4. Questionnaires $\mathrm{C}$ and $\mathrm{D}$ were administered after the quantitative evaluation. 


$$
\text { QUESTIONNAIRE - A }
$$

This is a check-the-block questionnaire. For each question, mark your answer inside the block that best describes your opinion.

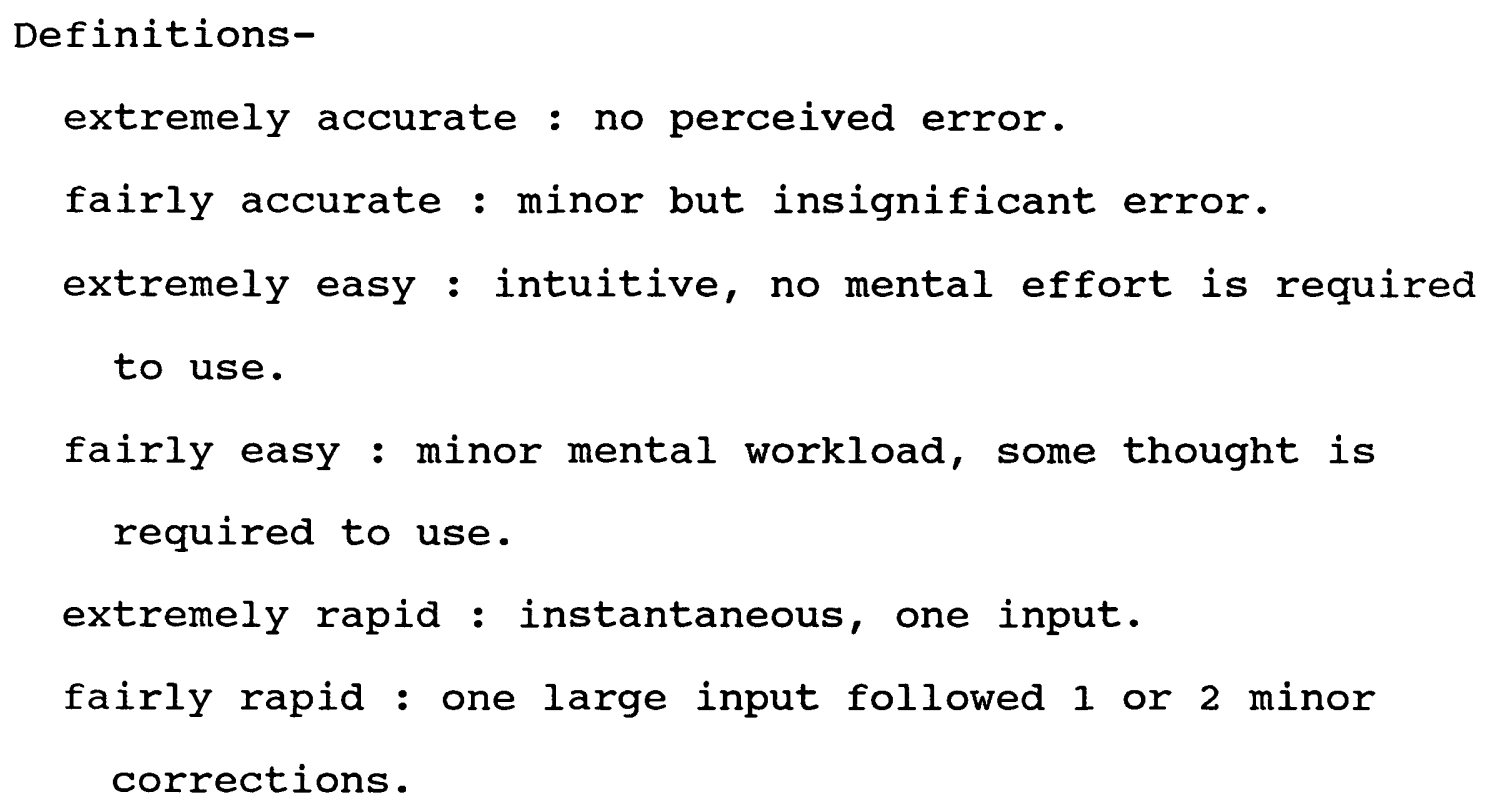

1. Overall, how easy did you find this display format to use?

$\begin{array}{lr}1 & 1 \\ \text { extremely } & \text { fairly } \\ \text { easy } & \text { easy }\end{array}$




\section{QUESTIONNAIRE - A (continued)}

2. How easy did you find the display element for control (EPR) to use?

$\begin{array}{lr}1 & 1 \\ \text { extremely } & \text { fairly } \\ \text { easy } & \text { easy }\end{array}$

3. How rapidly were you able to set engine power?

$\begin{array}{ll}1 & 1 \\ \text { extremely } & \text { fairly } \\ \text { rapid } & \text { rapid }\end{array}$

4. How accurately were you able to set engine power?

$\begin{array}{ll}1 & 1 \\ \text { extremely } & \text { fairly } \\ \text { accurate } & \text { accurate }\end{array}$




\section{QUESTIONNAIRE - A (continued)}

5. How easy did you find the display elements for monitoring (engine health) to use?

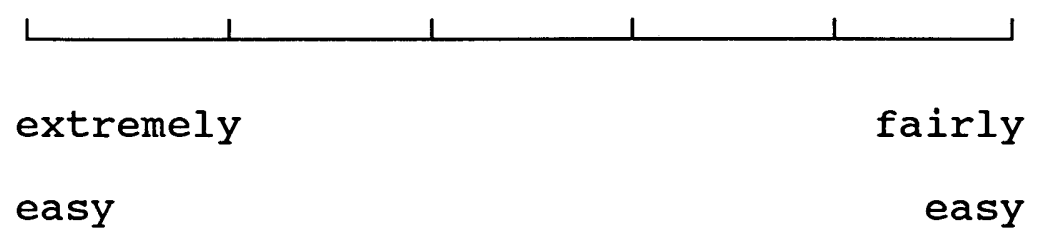

6. How rapidly were you able to detect an out-of-tolerance condition?

$\begin{array}{ll}1 & 1 \\ \text { extremely } & \text { fairly } \\ \text { rapid } & \text { rapid }\end{array}$




$$
\text { QUESTIONNAIRE - B }
$$

This is a check-the-block questionnaire. For each question, mark your answer inside the block that best describes your opinion.

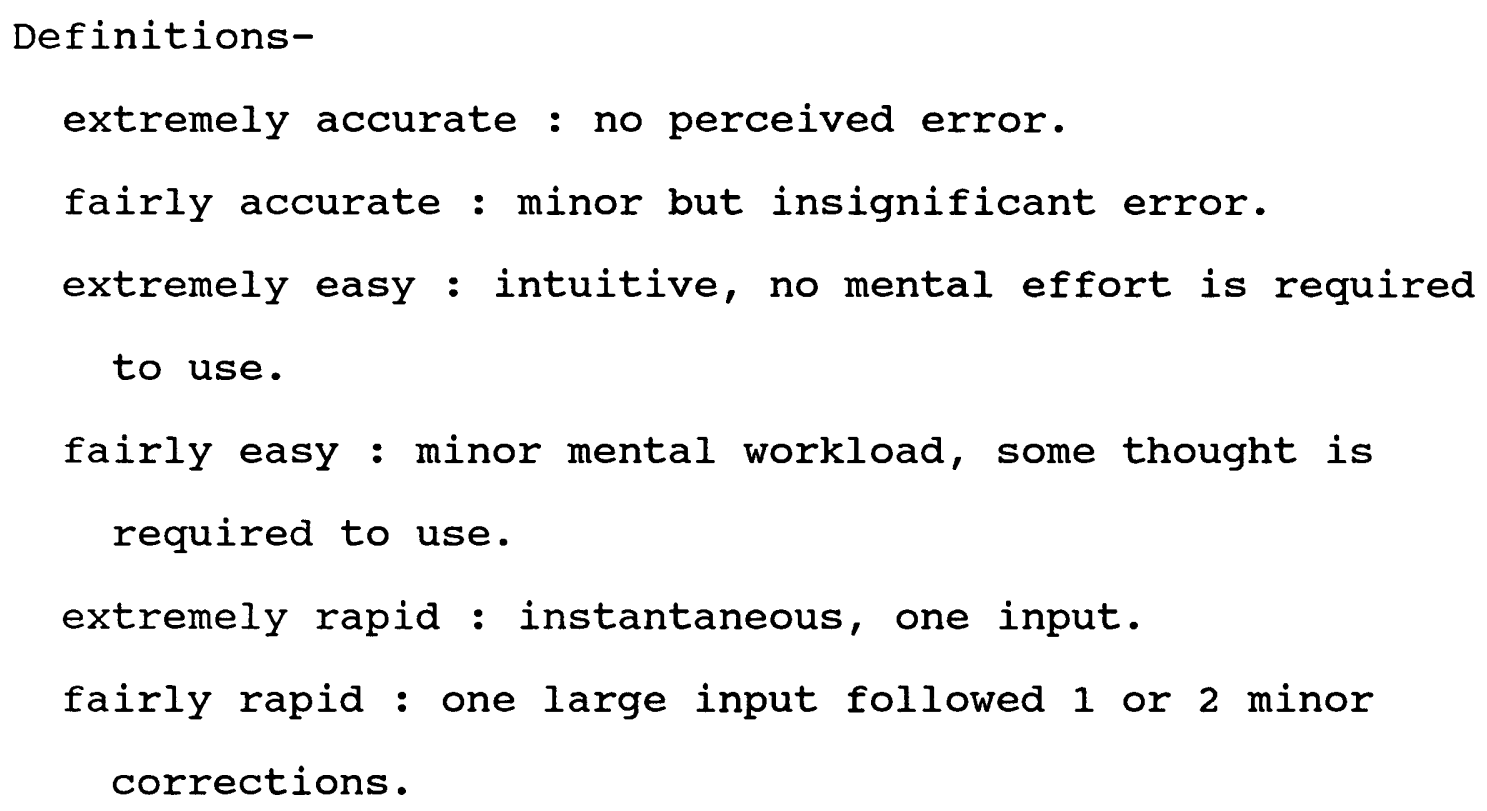

1. Overall, how easy did you find this display format to use?

$\begin{array}{lr}1 & 1 \\ \text { extremely } & \text { fairly } \\ \text { easy } & \text { easy }\end{array}$




\section{QUESTIONNAIRE - B (continued)}

2. How easy did you find the display element for control (thrust) to use?

$\begin{array}{lr}1 & 1 \\ \text { extremely } & \text { fairly } \\ \text { easy } & \text { easy }\end{array}$

3. How rapidly were you able to set engine power?

$\begin{array}{ll}1 & 1 \\ \text { extremely } & \text { fairly } \\ \text { rapid } & \text { rapid }\end{array}$

4. How accurately were you able to set engine power?

$\begin{array}{ll}1 & 1 \\ \text { extremely } & \text { fairly } \\ \text { accurate } & \text { accurate }\end{array}$




$$
\text { QUESTIONNAIRE - B (continued) }
$$

5. How easy did you find the display elements for monitoring (engine health) to use?

$\begin{array}{lr}1 & 1 \\ \text { extremely } & \text { fairly } \\ \text { easy } & \text { easy }\end{array}$

6. How rapidly were you able to detect an out-of-tolerance condition?

$\begin{array}{ll}1 & 1 \\ \text { extremely } & \text { fairly } \\ \text { rapid } & \text { rapid }\end{array}$




$$
\text { QUESTIONNAIRE - C }
$$

This is a check-the-block questionnaire. For each question, mark your answer inside the block that best describes your opinion.

1. Overall, which display format did you find easier to use?

$\begin{array}{lcl} & 1 & 1 \\ \text { modern } & \text { no } & \text { advanced } \\ \text { easier } & \text { difference } & \text { easier }\end{array}$

2. For which display format did you find engine control easier?

\begin{tabular}{|c|c|c|}
\hline modern & no & advanced \\
\hline easier & difference & easier \\
\hline
\end{tabular}




$$
\text { QUESTIONNAIRE - C (continued) }
$$

3. Which display format allowed the faster setting of engine power?

$\begin{array}{lcr} & 1 & 1 \\ \text { modern } & \text { no } & \text { advanced } \\ \text { faster } & \text { difference } & \text { faster }\end{array}$

4. Which display format allowed the more accurate setting of engine power?

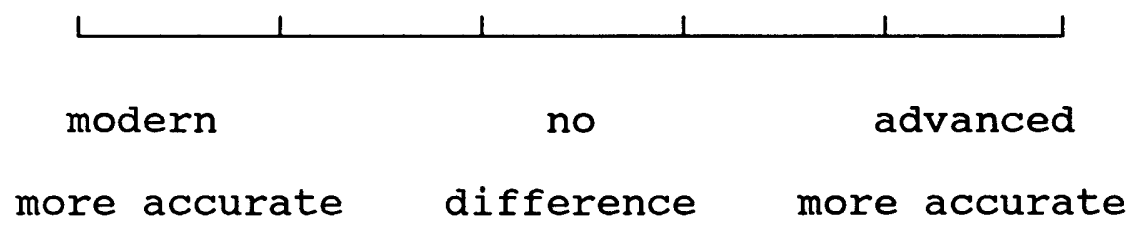

5. For which display format did you find engine monitoring easier?

$\begin{array}{lcll} & 1 & 1 & 1 \\ \text { modern } & \text { no } & \text { advanced } \\ \text { easier } & \text { difference } & \text { easier }\end{array}$




$$
\text { QUESTIONNAIRE - C (continued) }
$$

6. Which display format allowed the faster detection of outof-tolerance conditions?

$\begin{array}{lcr} & \perp & \perp \\ \text { modern } & \text { no } & \text { advanced } \\ \text { faster } & \text { difference } & \text { faster }\end{array}$




$$
\text { QUESTIONNAIRE - D }
$$

Regarding the advanced display only, please provide a short answer to each of the following questions.

1. In general, what did you like or dislike about this format.

2. What did you like or dislike about the thrust display element.

3. What did you like or dislike about the monitoring display elements. 


\section{QUESTIONNAIRE - D (continued)}

4. If you have any additional comments, please include them here. 
Abbott, T.S., Nataupsky, M., and Steinmetz, G.G. 1987. Integration of Altitude and Airspeed Information Into a Primary Flight Display Via Moving-Tape Formats, Evaluation During Random Tracking Task. National Aeronautics and Space Administration, TM 4010 .

Abbott, T.S. and Person, L.H. 1988. Method and System for Monitoring and Displaying Engine Performance Parameters. U.S. Patent application serial no. 270189, November 14, 1988.

Abbott, T.S. and steinmetz, G.G. 1987. Integration of Altitude and Airspeed Information Into a Primary Flight Display Via Moving-Tape Formats. National Aeronautics and Space Administration, TM 89064.

Banks, W.W., Gilmore, W.E., Blackman, H.S., and Gertman, D.I. 1983. Human Engineering Design Considerations for Cathode Ray Tube-Generated Displays. E.G. and G. Idaho, Inc., U.S. Nuclear Regulatory Commission Report NUREG/CR-3003. 
Banks, W.W., Hunter, S.L., and Noviski, O.J. 1985. Human Factors Engineering: Display Development Guidelines. Lawrence Livermore National Laboratory, UCID-20560.

Boeing Commercial Airplane Company 1983. Boeing 757-200 Systems. Boeing Commercial Airplane Company, Renton Division, D6-76549R5.

The Boeing Company 1973. Model 737-100 Operations Manual, Volume 1. The Boeing Company, Boeing Commercial Airplane Group, Renton Washington, D62737-100.

Broderson, D. 1984. Living with EICAS - Operational Experience to Date on the 757 and 767 . Society of Automotive Engineers, SAE Paper 841506 .

Danchak, M.M. 1981. Techniques for Displaying Multivariate Data on Cathode Ray Tubes with Applications to Nuclear Process Control. E.G. \& G. Idaho, Inc., U.S. Nuclear Regulatory Commission Report NUREG/CR-2086.

DeGreene, K.B., ed. 1970. Systems Psychology. Institute of Aerospace Safety and Management, University of Southern California. 
Department of Defense 1987. Human Engineering

Procedures Guide, Military Handbook. DOD-HDBK-763.

Department of Defense 1981. Human Engineering Design Criteria for Military Systems, Equipment and Facilities, Military Standard. MIL-STD-1472C.

Engel, S.E. and Granda, R.E. 1975. Guidelines for Man/Display Interfaces. International Business Machines, IBM Report TR 00.2720.

Frey, P.R., Sides, W.H., Hunt, R.M., and Rouse, W.B. 1984. Computer-Generated Display System Guidelines, Volume 1: Display Design. Electric Power Research Institute, EPRI Report NP-3701.

Gilmore, W.E. 1985. Human Engineering Guidelines for the Evaluation and Assessment of Video Display Units. E.G. \& G. Idaho, Inc., U.S. Nuclear Regulatory Commission Report NUREG/CR-4227.

Gould, J.D. and Lewis, C. 1983. Designing for Usability - Key Principals and What Designers Think. Proceedings CHI 1983, Human Factors in computing Systems, December 12-15, 1983, pp. 50-53. 
Grudin, J., Ehrlich, S.F., and Shriner, R. 1987. Positioning Human Factors in the User Interface Development Chain. Proceedings CHI + GI 1987, Human Factors in Computing systems and Graphics Interface, April 5-9, 1987, pp. 125-131.

Jacob, R.J.K., Egeth, H.E., and Bevan, W. 1976. The Face as a Data Display. Human Factors, vol 18, pp. $189-200$

Jacob, R.J.K. 1978. Facial Representations of Multivariate Data. Naval Research Laboratory, Washington, D.C.

Mahaffey, D.L., Horst, R.L., and Munson, R.C. 1986. Behavioral Comparison of the Efficacy of Bar Graphs and Polar Graphics for Displays of System status. IEEE Conference on Human Factors and Nuclear safety, 1978, IEEE CH2364-8/86/0000-1514, pp. 1514-1519.

Munson, R.C. and Horst, R.L. 1986. Evidence for Global Processing of Complex Visual Displays. Proceedings of the Human Factors Society, 30th Annual Meeting, pp. $776-780$ 
Myers, R.H. 1981. Methods for Presentation and Display of Multivariate Data. National Aeronautics and Space Administration, CR-165788.

National Transportation Safety Board 1982. Aircraft Accident Report. National Transportation Safety Board, NTSB-AAR-82-8 .

Parke, R.B. 1988. New Systems / New Questions. Business \& Commercial Aviation, July 1988, pp. $65-69$.

Reeder, J.P., Schmitz, R.A., and Clark, L.V. 1979. operational Benefits From the Terminal Configured Vehicle. National Aeronautics and Space Administration, TM 80046 .

Ropelewski, R.R 1982. Boeing's New 767 Eases Crew Workload. Aviation Week \& Space Technology, August 23,1982, pp. 41-53.

Smith, S.L. and Aucella, A.F. 1983. Design Guidelines for the User Interface to Computer-Based Information Systems. The Mitre Corp, ESD-TR-83-112, MTR-8857. 
Steinmetz, G.G. 1980. Simulation Development and Evaluation of an Improved Longitudinal VelocityVector Control-Wheel steering Mode and Electronic Display Format. National Aeronautics and Space Administration, TP 1664 .

U.S. Nuclear Regulatory Commission 1981. Human Factors Acceptance Criteria for the Safety Parameter Display System. U.S. Nuclear Regulatory Commission Report NUREG-0835.

Way, T.C., Martin, R.L., Gilmour, J.D., Hornsby, M.E., and Edwards, R.E. 1987. Multi-Crew Pictorial Format Display Evaluation. Flight Dynamics Laboratory, Air Force Wright Aeronautical Laboratories, AFWAL-TR-87-3047. 
VITA

\section{Terence Scott Abbott}

Born in Newport News, Virginia, August 27, 1947. Graduated from Newport News High School in that city, June 1965. Served 3 years with the U.S. Army as a helicopter pilot from 1966 to 1969. Graduated from Old Dominion University in 1975 with a B.S. in Mechanical Engineering. Has been a research engineer with NASA since 1975, conducting research in the conceptual design, development, and evaluation of advanced electronic display formats for aircraft applications. A member of Tau Beta Pi, The Association for Computing Machinery, and the Human Factors Society.

In September 1983, the author was admitted to the College of William and Mary as a graduate student for the Master's program in the Department of Computer Science. The course requirements for this degree have been completed, but not the thesis: Task-Oriented Display Design. 